\title{
$\rrbracket(\mathrm{CM}$
}

${ }_{\text {овм Integrative and Complementary Medicine }}$

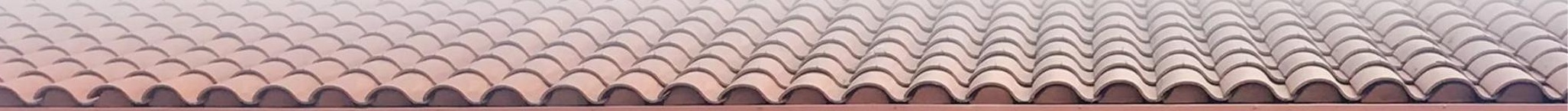

The Robert and Beverly Lewis Family-Cancer Care Center

\section{Cognitive Impairment, Meditative Movement, and Gene Expression in Breast Cancer Survivors}

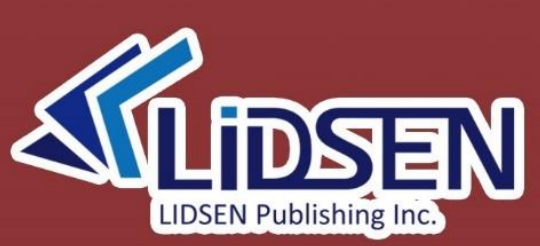


OBM Integrative and

Complementary Medicine

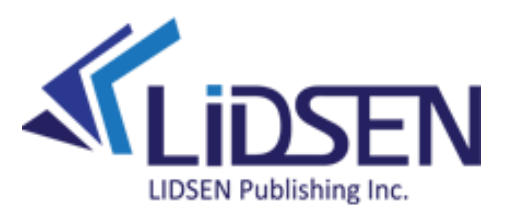

\section{OBM Integrative and \\ Complementary Medicine \\ 2020 Volume 5, Issue 3}

Editor-in-Chief

Professor Gerhard Litsche

Printed Edition Published in OBM Integrative and Complementary Medicine 
Editorial Office

OBM Integrative and Complementary Medicine Editorial Office, 73 Hongkong Middle Road, Qingdao, China

Tel./Fax: +86-532-8979-9572

LIDSEN Publishing Inc.

2000 Auburn Drive, One Chagrin

Highlands, Suite 200, Beachwood, OH 44122, USA

Tel.: +1-216-370-7293

Fax: +1-216-378-7505

http://www.lidsen.com/

This is a reprint of articles from the Issue 3 published online in the open access journal OBM Integrative and Complementary Medicine (ISSN 2573-4393) from July 1 , 2020 to September 30, 2020.

Available at: http://www.lidsen.com/journals/icm/icm-05-03

For citation purposes, cite each article independently as indicated on the article page online and as indicated below:

LastName, A.A, LastName, B.B, LastName, C.C. Article Title. Journal Name Year; Volume(Issue):Article Number; doi.

(C) 2020 by the author. This is an open access article distributed under the conditions of the Creative Commons by Attribution License, which permits unrestricted use, distribution, and reproduction in any medium or format, provided the original work is correctly cited. 


\section{Contents}

\section{Enrico Facco}

Hypnosis for Resilience

Reprinted from: OBM Integrative and Complementary Medicine 2020;5(3):20; doi:10.21926/obm.icm.2002032

Maya Kudo, Misa Hayashi, Peng Tian, Danyang Liu, Lili Wu, Wei Li, Zhaoyang Hong, Yitang Zhao, Toshiaki Nishigaki, Masaaki Nishihara, Kazuo Koike, Tonghua Liu, Ming Gao

YNCRG Inhibited Metabolic Syndrome Through Appetite Suppression and Improved Lipid Metabolism in Metabolic Syndrome Model Rats

Reprinted from: OBM Integrative and Complementary Medicine 2020;5(3):26; doi:10.21926/obm.icm.2002033

Kokila Jeyamurugan, Ratna B Basak

Child Life Specialists in Pediatric Hospital Care

Reprinted from: OBM Integrative and Complementary Medicine 2020;5(3):7; doi:10.21926/obm.icm.2002034

Francisco V. Muñoz, Linda Larkey

Cognitive Impairment, Meditative Movement, and Gene Expression in Breast Cancer Survivors Reprinted from: OBM Integrative and Complementary Medicine 2020;5(3):14; doi:10.21926/obm.icm.2002035

Ramesh Alluri, Hardik Ghelani, Shayal Devi, Vamsi Krishna Inampudi, Srinivas Nammi

Preclinical Investigation of the Acute Effects of Trigonella foenum-graecum Seed Powder on Blood Glucose in Normal and Alloxan-Induced Diabetic Rabbits

Reprinted from: OBM Integrative and Complementary Medicine 2020;5(3):11; doi:10.21926/obm.icm.2002036

Melissa Gaule, Erin Allen, Kathleen Benton

Serious Illness Management: A Fuller Approach to Integrative Palliative Care

Reprinted from: OBM Integrative and Complementary Medicine 2020;5(3):5; doi:10.21926/obm.icm.2002037 79

Mario F. Tecce, Walter Milano, Anna Capasso

Health Benefits of Green Tea in Obesity

Reprinted from: OBM Integrative and Complementary Medicine 2020;5(3):13; doi:10.21926/obm.icm.2002038 84

Giuseppe De Benedittis

Hypnosis: From Neural Mechanisms to Clinical Practice 
Reprinted from: OBM Integrative and Complementary Medicine 2020;5(3):7;

doi:10.21926/obm.icm.2002039 97 
Review

\title{
Hypnosis for Resilience
}

\author{
Enrico Facco 1, 2, 3, *
}

1. Studium Patavinum - Department of Neurosciences, University of Padua, Italy; E-Mail: enrico.facco@unipd.it

2. Science of Consciousness Research Group, Department of General Psychology, University of Padua, Italy

3. Institution F. Granone - Italian Center of Clinical and Experimental Hypnosis (CIICS), Turin (Italy)

* Correspondence: Enrico Facco; E-Mail: enrico.facco@unipd.it

Academic Editor: Giuseppe De Benedittis

Special Issue: $\underline{\text { Hypnosis: from Neural Mechanisms to Clinical Practice }}$

OBM Integrative and Complementary Medicine

2020, volume 5 , issue 3

doi:10.21926/obm.icm.2003032
Received: February 04, 2020

Accepted: April 17, 2020

Published: July 08, 2020

\begin{abstract}
The topic of resilience is of paramount importance. Although the term resilience was coined in the fields of physics and engineering, its use has spread to the fields of social sciences, biology, psychology, and psychiatry, as well as to the industry. Moreover, the term is now endowed with a wide range of meanings. The topic of resilience plays a central role in all critical life events. It is of paramount importance in medicine as well as in psychology and psychotherapy, where it is involved in both psychiatric disorders and physical diseases, particularly when encountering the specter of chronic pain, suffering, disability, and death. The available data indicate the relevance and effectiveness of hypnosis for resilience in numerous clinical conditions, and propose hypnosis as a candidate for a central role in palliative care. Furthermore, resilience is endowed with deep philosophical implications that are not to be neglected during patient management. Indeed, suffering, including the perception of one's doom as well as the real mystery of life and death, relies closely on philosophical, cultural, and ethnic factors. Eastern, as well as pre-Socratic philosophers, based their philosophies on an epistemologically sound, non-dualistic paradigm; they
\end{abstract}

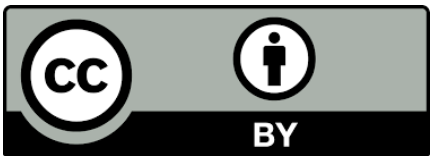

(C) 2020 by the author. This is an open access article distributed under the conditions of the Creative Commons by Attribution License, which permits unrestricted use, distribution, and reproduction in any medium or format, provided the original work is correctly cited. 
profoundly explored the inner-outer world relationship, allowing for so radical a resilience that has no equal in the modern Western culture. Therefore, these philosophies should be re-appraised and properly understood from a metaphilosophical perspective, in order to utilize their wisdom and knowledge in an efficient manner. A few examples of Eastern philosophical concepts drawn from Taoism, Yoga, and Buddhism, as well as those from Heraclitus and Parmenides, which would be potentially useful in patient care, are provided in the present article.

\section{Keywords}

Hypnosis; resilience; philosophy; epistemology; palliative care; Taoism; Buddhism; Yoga

\section{Introduction}

The topic of resilience, owing to its central role in all critical life events, is of paramount importance in the fields of medicine, psychology, and psychotherapy. The term 'resilience' was coined for physics, where it indicated an object able to recoil or spring back into shape after bending. In the context of an individual, resilience refers to the capacity to withstand or rapidly recover from difficult conditions such as those related to family and social relationships, financial stressors, workplace, and health issues.

The term resilience was derived from the Latin word resilire (which means to bounce), and in its broadest sense, it refers to the capacity of a system to adapt to the changes caused by external agents. The term was initially used in the fields of physics and engineering, and then its usage spread to the other fields such as social sciences, biology, psychology, and psychiatry, as well as to the industry, endowing the term with a wide range of meanings, a few of which are summarized as follows $[1,2]$ :

a) The capacity to absorb the deformation elastic energy and subsequently regain the initial shape (in materialss science).

b) Recovering the initial homeostasis following a perturbation or reaching a new state of balance through hallostasis (in biology).

c) A dynamic process of psychological adaptation, including both emotional and intellectual aspects as well as their management, in socio-cultural and environmental interactions.

d) Recovery from perturbation. In psychiatry, when dealing with psychopathic patients with no hope for recovery, resilience is limited to the restoration of the previous condition after it has worsened; for example, recovery from a phase of depression in a patient with severe bipolar disorder. Here, a relevant fact is the time of restoration, where resilience is the counterpart of vulnerability, i.e., it may decrease the proneness rather than preventing the susceptibility to psychopathy.

e) Useful resources for the management of change, i.e., self-transformation and enhanced awareness, which enable one to cope with changing living conditions.

f) Steady change of condition, including the amount of stress required to achieve it.

g) Conditioned resilience, yielded by prolonged treatment - e.g., improvement after the administration of psychiatric drugs, the effects of which may be for a limited duration. On 
the other hand, this could be considered a drug effect rather than actual resilience, unless it also favors a subject's change.

h) Dynamic balance, i.e., the average steady condition compatible with limited disturbances in a relatively steady condition; an example of a dynamic balance between the highs and lows in psychiatry could be borderline personality disorder.

The relevant elements of resilience are: a) threshold and feedback, b) functional redundancy and plasticity, c) management of the adaptation, and d) capacity and awareness. The threshold is defined as the level beyond which the requirement for a change is perceived, while positive or negative feedback may affect the response to critical events, in turn increasing or decreasing it, respectively. Redundancy is largely represented in biological systems and is defined as a property that allows preserving functions following damage. Management of the adaptation may occur through an interactive revision of the hypotheses and feedbacks, rather than simple trials and errors. Furthermore, in the world of business and risk management, resilience may be realized through reactive flexibility, i.e., the capacity to alter one's organization in response to environmental changes, or through proactive robustness, i.e., attempting to prevent crisis or decompensation, or to withstand the change, although possibly accompanied with minor changes or losses [3]. In both psychology and psychiatry, while reactive flexibility allows for second-order changes, the concept of proactive robustness is compatible with first-order changes.

As a matter of the relationship between the individual and the environment - between the inner and outer worlds in their unceasing becoming and transformation - resilience is mainly a cognitive problem, warranting the understanding of the meaning of reality, of what happens in its continuous dynamic change, and of the requirement for updating oneself to adapt to it. Resilience also calls for metacognition to properly understand: a) the meaning, value, and the limits of one's ideas, including the awareness of the mental process es employed to process these ideas; $b$ ) the limitations of the adopted Weltanschauung (view of the world) and Zeitgeist (spirit of times) in which all of us are immersed. In fact, the egocentric perspective of ordinary consciousness is unaware and inclined to naive realism (the belief that senses provide us with a direct awareness of the objects as they really are), where the ego is inclined to perceive the world as constituted of stable, separated objects with an autonomous intrinsic existence. As a consequence, despite being aware of the time stream, the ego is prone to believe that the outer world should remain unchanged and should always fit one's own expectations. This static view also forms the definition of identity, viz. its permanence in a ceaseless one's body and mind transformation, an unsolvable philosophical conundrum [4]. Therefore, any crisis, including the ones occurring in all periods of physiological changes in a lifetime, such as the transition from adolescence to the adult life, and then to aging, the role transitions, disasters, and diseases (with the associated specters of disability and death), becomes a powerful source of distress. This is not a matter of psychotherapy only, and rather, in the context of nature and the meaning of life and its becoming, belongs to philosophy, and, therefore, should be approached as a whole through an integration of both these disciplines.

The whole process of evolution of humankind, including culture, art, science, and technology, is a consequence of the encountered harms and crises. Indeed, fear and distress are powerful stimuli that force one to change, to cope, or to fail, whatever the case may be. Resilience is the virtue of all successful men that have ever lived, including the scientists (one for all, Stephen Hawking) and the artists (e.g., Beethoven, Chopin, Dostoevskij, Mussorgsky, Ravel, van Gogh, Messiaen) who perceived their diseases and disasters as resources, relentlessly continuing on their journey, 
providing humanity with beautiful works. An outstanding example is Olivier Messiaen, who was jailed in 1940 by the Nazis in the concentration camp Stalag VIII-A at Görlitz in Silesia. As he himself narrated, his only concern at the moment of his arrest was to get hold of a booklet regarding orchestral scores, a pencil, and a few music papers. When he underwent the check-up and wore the prison jumpsuit, he was terrified of the risk that his belongings were confiscated the only things, as he stated, that would have assisted him in bearing the hunger and cold that the soldiers themselves would have suffered from. Once there, he came across three other musicians who were playing strings and clarinet, and a malfunctioning piano. In the period of imprisonment, Olivier Messiaen composed the Quatuor pour la Fin $d u$ Temps, a masterpiece of the $20^{\text {th- }}$ century music, mainly while sitting in a latrine (the only quiet spot in the camp). The quartet was played on January 15, 1941, in a building of the camp, before all the prisoners and soldiers. The following month, Olivier was released, as a non-combatant soldier-musician. His religiosity and genius allowed him to transform an awful tragedy into a masterpiece. A common characteristic of all genius people in all the fields of human knowledge is the capacity to relentlessly work for moving on irrespective of the misfortunes, illnesses, and sufferings they may encounter, while the common man remains trapped within his limited horizon and ultimately collapses [5].

\section{Disease, Death, and Resilience}

Culture, the resulting Weltanschauung and Zeitgeist are at the base of the definition and the perceived relevance of all problems, including the terrific concepts of time and death. Indeed, both Weltanschauung and Zeitgeist are characterized by the incapacity of rational thought to be able to grasp their nature and meaning, despite the fact that time is now measured with incredibly high precision. Reflection on its nature has raised unsolvable aporias (logical contradictions) for over two millennia, and even in relativistic and quantum physics, its meaning and reality are under continuing debate [6-8].

It is noteworthy that the Chinese concept of time is considerably different from the Western one, the latter having been introduced in China at the end of $19^{\text {th }}$ century with a neologism. In Taoism, time is conceived as an unceasing renewal, duration, and opportunity - a concept grasped in the West by Bergson's philosophy of time. In Taoism, time - just as anything else - is a manifestation of Tao, which is characterized by the dynamic alternation and reciprocal generation of the two opposite although complementary poles, the Yin and the Yang. Accordingly, in Chinese language, verbs do not have past and future tenses, as the reality and the nature of existence is conceived as a stream, in which everything is transforming in a dynamic, immanent present $[9,10]$. This is also the reason for the absence of opposition between life and death, and as a consequence, the lack of soteriological doctrines, in the Chinese culture. Indeed, this clearly demonstrates that resilience in front of death - a human problem par excellence and the greatest source of anguish among humans - is essentially a matter of philosophy, and the causes for suffering rely closely on the adopted Weltanschauung. Similarly, Buddha was right when he stated that suffering stems from the five skhanda (the components of ordinary consciousness), while Epictetus, a Roman stoic philosopher of the first century A.C., stated that men do not fear things and rather the opinion they have of them [11].

Among all the sources of distress, death represents the greatest one, the mother of all the problems. In the clinical setting, the fear of diseases, pain, suffering, disability, and death is the 
main cause of anxiety disorders and depression. It is noteworthy that dental anxiety and phobia [which may also include symptoms of post-traumatic stress disorder (PTSD)] are significantly correlated to previous bad experiences associated with medicine and/or dentistry [12]. This may also justify the fear associated with all invasive procedures and medical therapies (such as chemotherapy and radiotherapy for cancer). Therefore, a bad doctor-patient relationship might be a cause of severe psychological disorders, turning the caregiver figure into a torturer.

Death has been the unsolved philosophical dilemma for ages, particularly in the West, and at the same time, the most powerful factor supporting both spiritual and material development of humankind. If mankind had been as resilient as not fearing death at all or anything else that could happen, perhaps there would not have been such advancements in science and technology, both of which stem from the will of having power and control on all possible harms [13]. Indeed, such an apparently unattainable level of resilience is that reached by the Taoist great man, as defined by Zhuāngž $[6,7,14-16]$. The Western concept of time, with its rational, mathematical partition (past, present, and future), is the basis for profound anguish of the Western culture, which lies in the belief that everything is doomed to become nothing [17]. The resulting existential dilemma has led to huge religious, philosophical, and scientific developments, as analyzed by the Terror Management Theory and debated in contemporary philosophy between presentism and eternalism [18]. Nevertheless, the life-death problem remains unsolved so far, and the present time, ruled by a materialist monist perspective, is constitutionally unable to properly encounter this problem and accept the mystery associated with it.

According to Emanuele Severino, the Western culture is imbued with nihilism, which stems from the parricide of Parmenides by Plato and Aristotle and is marked by the idea that everything is doomed to become nothing- a questionable, ill-founded concept worth being deeply reappraised $[17,19]$. According to Parmenides, the being

"is, and that it is impossible for anything not to be. The other, namely, that which is not, and that something need not be, that, I tell you, is a completely untrustworthy path. For you cannot know what is not, that is impossible, nor can you utter it; for that can be thought and that can be is the same thing" (Perí Phýseōs, II, III).

In other words, ex nihilo nihil, i.e., from nihil, nothing can arise. Nihilism stems from Plato's conception of the world of ideas, where a concept of nihil may exist. However, it is an abstract positive concept of a negative fact which is self-contradictory, because, by definition, nihil cannot exist. As a consequence, Parmenides' parricide led to incorrectly considering phenomenal appearance for "being" and what disappears for nihil, a view similar to naive realism and disproved by modern physics as well. Indeed, energy cannot be destroyed, can change the form, while the matter is just a concentration of energy (according to the famous Einstein formula, $E=m C^{2} \rightarrow m=$ $\left.E / C^{2}\right)$. Therefore, even matter cannot turn into nothing. Furthermore, in quantum physics, matter is no longer considered the primary manifestation of the world and is rather thought to have manifested as a secondary product from quantum vacuum, rendering the materialist stance based on the classical concept of matter obsolete $[8,20]$. It is noteworthy that the reciprocal transformation between energy (yang) and matter (yin) had already been acutely defined by Taoism over two thousand years ago. In line with Taoism and Parmenides's thought, Hippocrates, the great father of medicine, stated in De Diaeta $(I, 4,9)$ that: 
"Nothing arises from nothing, rather everything changes due to mixture and separation. The men incorrectly think that things arise from the Hades and go back to the Hades, and therefore believe their eyes rather than reason. What is living cannot die, nor is it possible that what is not may begin to be".

In summary, the great wisdom of both Eastern philosophies and the Western pre-Socratic physicoi (philosopher-physicists) and physicians established that life is an inseparable life-death whole, i.e., death is nothing more than a transformation of life and an essential part of it, despite resembling the awful, irreconcilable opposite of this from the illusory, naive, egocentric perspective of ordinary consciousness. In this context, it is worth highlighting that the paradigms of Heraclitus, Parmenides, and Hippocrates were similar to that of Taoism [21], and the best way to translate the original Parmenides' concept of being into Chinese is, indeed, the term Tao [4]. Despite appearing as a metaphysical problem unworthy of attention from modern medical science, it has relevant epistemological implications in the science of consciousness as well as in the definition of the mind-brain-world relationship. The ancient thought also has greater compatibility with quantum physics compared to the classical Western post-Aristotelian thought (for a detailed analysis, see [7]), and the former is of paramount importance in therapy for improving resilience.

In the modern era, which is ruled by positivism and materialism, terminal illness and death have been reduced to a conventional matter of biological mechanisms, their technical management, and the political debate on their bio-ethical implications and resource availability. This inclination is paralleled by the neglect of death in everyday life, which is a defense mechanism that leads to an implicit illusion (or delusion) of immortality coupled to almost obsessive attention to health and physical efficiency. The ostensible obscenity of death and its neglect has been well-defined by Gorer as the pornography of death [22]. Death being an essential part of life rather than its opposite, the tragedy stems from the refusal to acknowledge it, engendered by the deceitful egocentric perspective: as Freud wisely stated paraphrasing a famous Latin motto on the war, si vis vitam para mortem (i.e., if you wish life, set up your death).

One must be aware that the adopted scientific concepts of health, normality, and disease are conventional and statistical in nature; although pragmatically useful, they are weaker than commonly believed and may turn against each other. According to Woodruff et al. [23], the disease may be defined as:

"any condition associated with discomfort, pain, disability, death, or increased liability to these states, regarded by the physicians and the public as properly the responsibility of the medical profession, may be considered a disease".

When considering the fact that we are all going to die one day, health may be paradoxically defined as an asymptomatic illness that would inescapably lead one to death, thereby fulfilling the above-stated definition of disease. The only difference between health and disease is the presence of symptoms and the possibility of diagnosis. Furthermore, suffering and pain may evoke in one, the awareness of one's actual existential condition. According to Le Breton, pain is not a plain symptom of disease, and is rather an incision of the sacred, ripping one from oneself and leading the one to confront one's limitations, the transience of life, and its cost. Pain obliges to metaphysics [24, 25].

If the above discussion is correct, the problems of life, disease, pain, suffering, and death are far from being a simple matter of medical definition from a narrow perspective of a positivist; these problems warrant a psychological and philosophical approach, with philosophy deserving a certain 
important place in both psychotherapy and hypnosis as well as in the patient-doctor relationship.

\section{Hypnosis for Resilience}

Resilience may be regarded as the key player in psychotherapy as well as the remedy for all sources of distress in both medicine and everyday life. This is the reason why the XIII Congress of the European Society of Hypnosis (held in Sorrento, Italy on October 21-25, 2014) was devoted to "Hypnosis and Resilience".

Hypnosis may effectively assist in restructuring patient's problems, an objective that David Spiegel has well-defined as "Trance-formation" [26]. Unlike psychotherapies which rely mainly on the retrospective analysis of the causes of disorders and their rational interpretation (such as psychoanalysis), hypnosis may additionally allow for direct experience in the "here and now" of the patient requirements and what they are seeking for through imagination and plastic monoideism [27-29]. Therefore, hypnosis may behave as a sort of simulator - a tool being increasingly employed in the training of pilots, surgeons, anesthetists, and all the professionals who require developing certain special skills.

Imagination has been understated or even disparaged by the century-old rationalist stance of Western culture. In fact, hypnosis was totally dismissed by the prominent panel of experts convened by King Louis XVI in France as "nothing but heated imagination" [30]. In early $20^{\text {th }}$ century, imagination was incorrectly considered a feature of the less-developed brain of children, primitive people, and inferior races, while conceptual thought was regarded as a privilege of the civilized, Western "superior" man - a sort of collective delusion of self-importance which led to the opprobrious consequences of colonialism and the ideologies of early $20^{\text {th }}$ century. In that positivist climate, Freud himself considered the visual images reported by his patients as related to their neurosis, which had to be replaced with a verbally-mediated rational analysis [31].

However, imagination is a powerful mind faculty that the great artists and scientists are endowed with. For instance, Nikola Tesla reported his incredible eidetic imagery in his autobiography, which allowed him to see with his mind eye all his inventions in complete detail, and even evaluate them prior to constructing them [32]. Albert Einstein, the icon of $20^{\text {th }}$ century science, was a scientist-philosopher who was endowed with a vivid imagination. In an interview to the Sunday Evening Post in October 26, 1929, he stated:

"I'm enough of an artist to draw freely on my imagination. Imagination is more important than knowledge. Knowledge is limited. Imagination encircles the world" [33].

The above-stated facts clearly demonstrate the relevance of imagination for knowledge and the century-old underestimation of imagination by the rationalistic Western culture. In the same years, young Milton Erickson, under complete paralysis following a severe case of polio, invented and taught himself a unique method of rehabilitation, playing mental games with himself, intensely wishing for and imagining playing outside, as well as watching his baby sister who was only learning to walk at that time.

The role and power of imagination have been recognized only recently in neuropsychology. Mental imagery (the "mind eye") is a multifaceted psychological construct that exhibits conceptual and neurobiological overlaps with related cognitive processes, such as attention, memory, and actual perception. Spatial imagery is associated with complex brain activation, including activations 
in the dorsolateral prefrontal cortex, visual cortex, middle frontal gyrus, premotor cortex, and parahippocampal gyrus [34]. Motor imagery facilitates motor performance, by training the associated brain areas and improving the association between process and actions, with the training exerting a long-lasting effect on metacognition [35]. These data also lead to a renewed interest in the potential use of motor imagery in rehabilitation [36-38], confirming the exceptional intuitions of the 17-year-old Milton Erickson one hundred years ago. Hypnosis enhances motor imagery by improving concentration and the connection between sensory information and motor output [39]. This is consistent with the relationship between hypnotic ability and the enhanced functional connectivity between the left dorsolateral prefrontal cortex (belonging to the executive control network) and the salience network (including anterior cingulate cortex, insula, amygdala, and ventral striatum), which allows the somatic, autonomic, and emotional information to be evaluated and integrated [40].

All these data suggest the relevance and effectiveness of hypnosis, with its plastic imagery, in both medical and psychological disorders. The neuropsychological components of the hypnotic simulator - a sort of mental lab - might allow one to virtually perform tasks, process information through a different perspective, and restructure one's problems with higher efficiency with respect to ordinary consciousness and a limited rational interpretation. This may occur without requiring a retrospective analysis of the distressing events of the past and would guide the patient in the present toward the future, updating his/her model of the world. The rational interpretation of past events, despite being undoubtedly useful, may not be sufficient for bringing a change; several patients have reported that it allowed them to understand the origin of their symptoms, although they anyway failed to overcome their limitations and recover.

According to Bandler \& Grinder [41], several patients are self-limiting because of their previous experiences and the resulting model of the world that they have developed, which prevented them from viewing and adopting new options and possibilities. This belongs to the physiology of life; even the oddest behavior, when observed from inside the subject's world, might turn out to be understandable and coherent with the subject's experience and adopted model. If so, an enlargement of patient's model, which would enable him/her to discover new paths and adopt new options and behavior, allows mitigating or even completely resolving the problem, rendering the previous limited behavior unnecessary. The updating and enlargement of the model is an issue of paramount importance in itself for the whole life. Bertrand Russell introduced an outstanding concept of Self enlargement, which encompassed philosophy, science, and psychology [4, 42]:

"All acquisition of knowledge is an enlargement of the Self... This enlargement of Self is not obtained when, considering the Self as it is, one attempts to demonstrate that the world is so similar to this Self that the knowledge of it is possible without any admission of what appears alien... Knowledge is a form of union of the Self and the not-Self; similar to all kinds of union, it is impaired by dominion, and consequently, by any attempt to force the universe into conformity with what one finds in oneself. This view... is untrue... What it refers to as knowledge is not a union with the not-Self, but a set of prejudices, habits, and desires, constructing an impenetrable veil between oneself and the world beyond. The man who has no tincture of philosophy goes through life imprisoned in the prejudices derived from common sense, from the habitual beliefs of his age 
or his nation, and from the convictions which have grown in his mind without the co-operation or consent of deliberate reason".

Therefore, an approach centered on the contemplation of the world beyond one's limited perspective, Weltanschauung and Zeitgeist in the "here and now" may strongly assist in developing resilience. This is not just useful for psychotherapy, rather is also an essential general rule in all the fields of human knowledge, including science, philosophy, and religion.

As far as therapy is concerned, resilience may be regarded as a relevant general component of the treatment, capable of enhancing coping irrespective of the causes of distress. At the same time, resilience removes the risk of possible retraumatization implied in the retrospective analysis of the distressing events.

Bandler and Grinder's model, as well as the psychoanalytic perspective, is compatible with the Solms and Panksepp's neuro-psycho-evolutionary approach, envisioning the evolution from an unconscious life to the first appearance of consciousness up to the development of the highest expression of the Self from a dual-aspect monist perspective [43, 44]. According to Solms and Panksepp's theory, emotions are dependent on the neurodynamics of the innate brain primary circuits yielding an anoetic form of consciousness, the neuro-anatomical base of which belongs to deep brain structures (including the brainstem, hypothalamus, central thalamic nuclei, and limbic circuits). Higher-order, noetic components of consciousness and awareness, as well as the autonoetic, autoreflective ones have their neuro-correlates in more rostral structures, the cerebral hemispheres. The ultimate result of this complex caudo-rostral circuitry is the bidirectional interplay between the anoetic and noetic components, which causes the present experiences to be affected by the past ones and the effects of past experiences to be consequently altered by the autoreflective processes of the present. The latter explains why it is possible to resolve the problems rooted in the past by working in the present to enlarge the patient's model, perspective, and the Self.

The outstanding properties of hypnosis allow it to a relevant tool in palliative care, where it may play a central role in enhancing coping and resilience. Here, resilience is used in its widest sense as the capacity to cope with all the adverse events and all the causes of suffering and pain; for instance, resilience here may also include hypnotic analgesia, which is not in itself a matter of resilience although it may improve resilience by means of enhancing one's ability to control pain. Hypnosis may be used beneficially in all the aspects of palliative care [45-47], including:

1. The management of anxiety, depression, and pain [48-50].

2. The peri-operative period of surgery and invasive procedures, where hypnosis may assist in relieving pre-operative anxiety and concern, improve wellbeing and collaboration, and enhance the stability of cardiorespiratory parameters). It may also improve post-operative wellbeing and wound recovery and may decrease the requirement for the intake of pain killers. It may even be successfully used as the only anesthesia in selected patients [51-54].

3. Physical symptoms, spontaneous or yielded by drug side effects, such as nausea and vomiting, diarrhea, flashes, insomnia, fatigue, and dyspnea [55]. It is noteworthy that most of the afore-stated symptoms could be caused or enhanced as a result of the nocebo effect, i.e., these could be psychosomatic in nature. For instance, a strong nocebo effect was reported in patients belonging to the placebo group in an RCT on cancer-related fatigue (including $79 \%$ insomnia and $38 \%$ nausea) [56]. In this context, hypnosis holds a great potential to assist in relieving the physical symptoms in patients even in severe pathologies 
such as cancer, where the psychosomatic components of suffering have greater relevance than previously believed.

The above-stated indications of hypnosis include a wealth of possible, specific suggestions and metaphors, a detailed description of which is far beyond the scope of the objectives of the present article. All these indications converge on the suggestion that resilience should be regarded as the key player in the whole management, which extends from the first diagnosis of chronic progressive disease all the way up to its terminal state. Hypnosis may assist in better confrontation overall and improve coping and resilience; this would be achieved through ego strengthening, mindfulness, usage of metaphors that assist in mitigating disturbing ideas, negative emotions, and any other causes of worry, and including the philosophical implications discussed above.

\section{Relevant Clues from Eastern Philosophies}

The above-discussed philosophical implications should not be regarded as abstract speculations. Rather, they are concrete, pragmatic reflections to be considered in clinical practice when dealing with distress, suffering, disease, and death. The modern medicine, with its governing mechanist-reductionist approach, has cured diseases rather than the patients, neglecting all the relevant subjective factors as if the mind would have no role to play in both health and disease, a fact that has huge epistemological implications [7, 21, 57]. Indeed, its paradigm is metaphysical in nature, stemming from the mathematical apriorism of Galileo and the original sin of Galilean Sciences, i.e., the compromise with the Church and Inquisition (which claim an exclusive competence on the soul), the genius of Descartes promoted through its radical dualism. Therefore, the novel sciences were epistemologically ill-founded as these were a consequence of political friction, which caused their field of interest to be forcibly limited to the Cartesian res extensa, and in medicine, to the earthen body machine. As a consequence, the observer was removed from the observed facts in the illusion of the neutrality of the former, and maintained so, until the revolution started in the $20^{\text {th }}$ century by quantum physics. Owing to its neglect of the consciousness and subjectivity, the positivist-materialist perspective governing medical science has been constitutionally unsuitable for properly understanding and managing the subjective phenomena, including pain and suffering.

Unlike the modern Western culture, Eastern philosophies have developed a profound knowledge regarding the inner world and its relationship with the external reality using a nondualistic perspective. It is noteworthy that according to the etymology of the term Yoga, a word that stems from the Sanskrit term yujir (binding together or joining), it indicates the reunion of mind and body, I and the non-I (i.e., mind-body-world), a state in which all the ostensibly opposite and incompatible phenomena are dissolved in an inseparable whole. Taoism and pre-Socratic philosophers, as well as Hippocrates, held the coniunctio oppositorum, i.e., convergence and reciprocal generation of the opposites. Over 2,000 years ago, Buddhism had already recognized and deeply analyzed the illusory stance of the Ego, the existence of the unconscious, the limitations of conceptual thought, the relevance of empathy and compassion, and the path of liberation from all the attachments and sorrows [14]. Together, all these belief systems established the path to wisdom and enlightenment, enabling one to live well, die well, and remain in a state of unshakable resilience, rather than seeking power from an egocentric utilitarian perspective. Therefore, according to the previously adopted approach to defining the Self [4], resilience may be 
better understood from a metaphilosophical perspective, by moving beyond the limited ethnocentric modern Western perspective and the positivist inclination to consider its concepts and findings as universal.

The discussion on metaphilosophical criteria and their application in the analysis of Eastern culture is far beyond the limited scope of an article (for further details, see [9, 58-62]). Therefore, the present article would just outline a few clues drawn from Buddhism and Taoism, in order to better understand their relevance in regard to resilience. The relevance of Eastern philosophy is also closely associated with the huge historical, procedural, and neuropsychological links between hypnosis and meditation [14, 16, 63-65], which have recently led to the introduction of what is referred to as mindful hypnosis $[66,67]$. Indeed, mindfulness meditation, which should be regarded as the best technique of Western meditation, is basically an adaptation of Vipassana meditation, while Śamatha meditation (meditation of the dwelling calm) is associated with hypnotic absorption and neutral hypnosis. Similar to hypnosis, dhāranā (the induction of yoga meditation) is based on focused attention and deep relaxation, while dhyāna (the meditative state) could be translated as meditative absorption and contemplation, which may engender a flow of images. Similarly, Buddhist meditation involves a detached observation of one's states and mental objects, and letting them go.

Eastern philosophers, unlike the Western ones, have unvaryingly merged theoretical philosophy and practical philosophy as a whole, devoting themselves to self-knowledge and the path for emancipation, i.e., liberation from all the attachments and conditioning, up to the level of wisdom, saintliness, and enlightenment. All the Eastern philosophies included meditation as an essential practice for reaching a complete metacognitive awareness and to get rid of $M \bar{a} y \bar{a}-$ the mask of illusion of the ordinary consciousness (i.e., the flawed naive realism and what Kant referred to as the unavoidable natural illusion $[4,57,68])$. Moreover, meditation, which allows for the subject's empowerment, may also serve as a healing technique.

As stated above, hypnosis has strong links to Eastern meditation [14, 16, 63-65]. In fact, the first mesmerists were deeply interested in the Eastern philosophies and healing practices, which they considered similar to their own discipline and claimed that Mesmer had only provided a scientific interpretation for these. In the early $19^{\text {th }}$ century, The Zoist, a journal on mesmerism, published several articles on Indian practices; hypnosis was also compared to Taoist practices and Yoga meditation (also referred to as hibernation), and was considered as an ecstatic or Mesmeric condition $[16,65]$. Neutral hypnosis may also favor intense experiences similar to those achieved with meditation and the ones associated with mystic and near-death experiences, such as "having no thoughts, being one with everything, increased meaningfulness, letting things happen, and merging with pure light or energy", among others [69-71].

Buddhism originated as a consequence of a pragmatic observation of reality, i.e., the universal presence of pain and suffering in the world. As Siddharta Gautama stated:

"Birth is pain, aging is pain; illness is pain; death is pain; attaching to what is displeasing is pain; separating from what is dear is pain; not obtaining what is wished for is pain. In brief, the five skhanda [the clusters of consciousness; author's note], which are the basis of the attachment to existence, are pain» (Samyutta Nikāya, 56, 11).

This apparently pessimistic cosmic view of pain is the starting point of the path to the most radical liberation from suffering, according to the Four Noble Truths (Majjhima Nikaya 26, 
Ariyapariyesana Sutta: The Noble Search). Therefore, both the stepping stone and the endpoint of Buddhism are akin to the essence of medicine and psychology, rendering Siddhartha Gautama the greatest psychotherapist in the history of humankind. The surprisingly modern viewpoint of Siddhartha Gautama recognized that the origin of suffering lies in the ordinary consciousness and ego. In brief, the path to liberation from suffering warrants overcoming the narrow limits and flaws along the path toward wisdom, a fact which also engenders the most radical resilience.

It is similar to Taoism. As Lăozĭ stated, "the sage men are self-aware and not self-absorbed; selfrespect is not self-importance" [72]. Zhuāngzĭ defined the problem as follows:

"The perfect man has no self (Chapter 1)... Do not let your outward stance affect your inner self, nor allow your inner self to be drawn out (Chapter 4)... One who seeks fame and thereby loses his real self is no gentleman (Chapter 6)... The mean or petty person is willing to risk his very body for gain. The scholar risks his own self for fame... All of these different types, with differing claims to fame, have damaged their innate nature and risked their lives in the same way (Chapter 8)... Everyone in the world appears to be concerned only with his own self. This implies the whole world is full of anxiety (Chapter 14)" [4, 15].

The above-stated trait d'union between meditation and hypnosis allows certain valuable Eastern concepts to be exploitable in hypnotherapy; they include certain concepts from preSocratic philosophers, which share the non-dualistic paradigm of Taoism, based on the coniunctio oppositorum. Therefore, it would be worth outlining a few of these concepts prior to concluding the present article, which may assist in contributing to hypnotic suggestions and metaphors and/or could be included in the philosophical reflection outside the formal hypnotic sessions.

\subsection{Taoism \& Pre-Socratic Philosophy}

As stated earlier, the concept of Tao has an equivalent in the Parmenides' concept of being, while the Yin-Yang polarity appears tantamount to the Parmenides' light and dark night [4], as stated in the Perì Phýseos (VIII, 51-6):

"Henceforth, learn the opinions of mortals, listening to the deceptive ordering of my words. Mortals have settled in their minds, to speak of two forms, one of which they should have left out, and that is where they deviate from the truth. They have assigned an opposite to each, marked distinct from one another".

If the separation of the opposites is deceitful, the belief based on this separateness is a source of suffering, which leads one to anxiety in an endless attempt to escape from what is rejected or feared. Heraclitus, who properly described the dynamic course of events (also similar to the YinYang), wisely demonstrated how deceitful the ontological separation of the opposites is:

"Opposition unites. From what draws apart, emerges the most beautiful harmony. All the things occur by means of strife (DK 22B9)... Men do not know how something that is at variance agrees with itself. It is an attunement of opposite tensions, similar to that of the bow and the lyre (DK 22B52)... It is the same thing in us that is quick and dead, awake and asleep, young and old; the formerare shifted and become the latter, and the latter in turn are shifted and become the former (DK 22B89)... For god, all things are fair and good and just men suppose that certain things are unjust, while the others are just (DK 
22B103)... The disease makes health sweet and good; hunger, satiety; toil, rest (DK 22B112)".

When one completely understands that the opposites are not different, irreconcilable entities and rather just the complementary attributes of an inseparable deeper unit, the apparent bad part may be integrated in the whole along with the good one, and may be better accepted, despite remaining unpleasant; its intrinsic dynamics also emphasize its transience, both representing essential steps toward resilience. Indeed, nothing could be perceived and known without its opposite, not even pleasure without pain and good without evil. This was the initial condition of young Siddhartha Gautama, a crowned prince kept in the dark regarding the distressing events of life (disease, aging, and death), who began waking up when he realized the universal presence of pain in the world, and ultimately established the Buddhist way of liberation from it.

A further useful clue for resilience is provided by an ancient Chinese saying- "If you have a problem and there is a solution, what are you worried about? If you have a problem and there is no solution, what are you worried about?" The detached equanimity of the great Taoist man and his apparently unattainable resilience has been correctly defined by Zhuāngzĭ as follows [73, 74]:

"The titles and honors of this world are of no interest to him, nor is he concerned at the disgrace of punishments. He knows that there is no distinction between right and wrong, or between great and little. I have heard it been said that 'the Tao man earns no reputation, perfect Virtue is not followed, the great man is self-less'. In perfection, this is the path he follows... The perfect man is a pure spirit... He does not feel the heat of burning deserts or the cold of the vast waters. He is not frightened by the lightning which is capable of splitting open mountains, or by the storm capable of whipping up the seas... Neither death nor life concerns him; how could gain and loss disturb him? (Chapter 16)".

This absolute resilience also includes a non-spilt view of life and death in line with both Hippocrates and Heraclitus thoughts:

"Life follows death and death is the forerunner of life. Who can know their ways? Human life begins with the original breath; when it comes together, there is life, and when it is dispersed, there is death. As death and life are together in all this, which one of them should be termed as bad? All the forms of life are one, yet we regard some as beautiful, as they are spiritual and wonderful; others we count as ugly, as they are diseased and rotting. But the diseased and the rotting could become spiritual and wonderful, and the spiritual and the wonderful could become diseased and rotting. It is said that 'all that is under Heaven is one breath'. The sages always comprehend such unity (Chapter 22)".

These sentences, the wisdom of which is unquestionable, illustrate the mystery of life and death in a blissful manner, including their inseparability, and ultimately, the ontological inexistence of death, which is just a part of the dynamic process of life transformation. Death remains a tragedy for the ego; getting rid of the narrow, illusory perspective of the ego and contemplating the whole world as a ceaseless transformation of the "breath" (the Greek psyché, blow, energy), allows to view death to be not as bad as it appears from an egocentric, nihilistic, materialist perspective. 


\subsection{Patañjali's Yoga-Sūtra}

Nirodha and the internal witness are the two key concepts of Patañjali's Yoga-sūtra, and the former allows disclosing the latter [75]. The term nirodha indicates an insight into the pure consciousness, which is void of any content (lying beyond perception, concepts, and any category of the mind). The ordinary consciousness is inclined to self-identification with mental objects (the inputs received from the outer and inner worlds) crossing one's mind, leading one to assume these and the related experiences as parts of oneself. The truth, however, is that the mind is their master and host; in itself, it is the pure awareness of the agent, the witness who observes phenomena and may choose to remain detached and untroubled.

Metaphorically (and this may be a hypnotic approach to assist the patient in understanding it), the flow of ordinary consciousness could be compared to an exposed film, where the images are the flow of experience, while nirodha could be recognized as that unexposed subtle stripe between subsequent images (their support), of which one is usually unaware [16]. Therefore, nirodha is a meaningful step toward metacognition, which allows reaching a higher level of awareness and stability in encountering life's experiences. The internal witness is the detached neutral subject consisting of pure awareness, which enables one to control the activity of the ordinary consciousness, and recognize the nature of the mental objects and subsequently let them flow away without being conditioned by them; this was stated clearly by Patañjali in the following words:

"1.3. Yoga is the control (nirodha) of the modifications of the wave-vortex of mind activity (cittavrtti).

1.4. Then, the Seer abides in Itself, resting in its own True Nature, which is referred to as Self realization (tada drashtuh svarupe avasthanam).

4.5 While the activities of the emergent mind fields may be diverse, the one mind is the director of the many (pravritti bhede prayojakam chittam ekam anekesam)."

This wise analysis of the human mind by Patañjali is outstandingly profound and in perfect agreement with the concept of enlargement and complete realization of the Self [4].

\subsection{Buddhism}

Buddhism aims for a radical liberation from pain and suffering (dukkha), and the two key concepts of anicca and śūnyatā (the impermanence and the vacuity of reality, respectively) form its core. According to Buddhism, the world is not constituted of independent, separated "things" endowed with an intrinsic autonomous existence, and are rather interrelated transient events, the phenomenal appearance of which is the consequence of a co-creation of reality (unattainable in itself) and the human way of perceiving and coding it. Furthermore, Buddhism does not admit the existence of an Ego as a reified substance. Rather, the ego is conceived as a functional aggregate at the superficial layer of the empirical mind directed toward the outer world.

Buddhism, with its view of the world as constituted of interrelated events being in perfect agreement with quantum physics, is epistemologically sound and surprisingly modern [7, 20]. The relationship between the mind and the world described in Buddhism is consistent with the Pooper and Eccles' theory of the three worlds, a modified version of which is held by the author of the 
present article [7, 57, 76]. Furthermore, the nature of dukkha described in Buddhism is consistent with the present definition of pain in medicine, viz. a matter of experience rather than a plain epiphenomenon of stimulation of pain pathways in the nervous system [77-79]. This is equivalent to saying "no experience, no pain", a fact implying that pain could be well-managed by altering the experience. This definition is compatible with the observed outstanding analgesic effects of hypnosis, and exposes the self-contradictory overriding attitude of conventional medicine to rely just on drugs, which stems from its materialist-reductionist stance. A relevant aspect in the psychological management of suffering and pain (besides the hypnotic suggestions which are aimed at directly increasing the pain threshold [80]) is detachment from all the sources of sorrow by adopting a neutral, non-judgmental disposition. As emphasized by Siddhartha himself, suffering is closely related to the mismatch between what happens and what was expected:

"Birth is pain; aging is pain; illness is pain; death is pain; attaching to what is displeasing is pain; separating from what is dear is pain; not obtaining what is wished for is pain. In brief, the five skhanda [the clusters of consciousness], which are the basis for attachment to existence, are pain» (Samyutta Nikāya, 56.11).

Certainly, accepting does not necessarily imply approving or adopting a passive fatalist behavior. Rather, according to the Chinese saying stated earlier, acceptance allows for better coping with the life events, moving on to resolve problems when possible, and coming to terms with what is inescapable.

The proper approach to be followed is described well by the motto-“One must never mourn a paradise lost, rather live well even in hell". Paradise and hell are neither physical nor metaphysical places; they are just conditions of the mind. This is why, at first glance, the Indian concepts of samsāra (the world of becoming and suffering) and nirvāna (extinguishment) may appear as the irreconcilable opposites to the Western reader, similar to the concept of heaven and hell, which is rather not true. The Western reader may become disappointed upon discovering that samsāra is nirvāna and nirvāna is samsara, the two different perspectives of human consciousness. Samsāra is the common inclination to focus on what is going awry, on what has been lost, thereby perceiving and depicting the outer world as hell. Nirvāna, being a non-judgmental stance, is to perceive everything (both good and bad things) without focusing on what has been lost, allowing for a fresh open-minded starting point that assists in discovering that good things are inseparably intermingled with the displeasing ones. For instance, the same beautiful sunset may be inspiring to an open mind that is ready to contemplate it, while it would be not be perceived as or deemed irrelevant by a worried mind that is focused on its own ordeal. Therefore, as Buddha stated, the source of suffering is in the ego and the ordinary consciousness, which have a narrow perspective.

The philosophical issues discussed above may appear odd or irrelevant to the modern view ruled by the clear-cut rationality of positive sciences. However, these philosophies are the expression of the several-thousand-year old thoughts of the great sage men, which should be reappraised and properly understood. Indeed, these thoughts belong to what Karl Jaspers referred to as the axial period (around 500 B.C., in the spiritual process extending from 800 B.C. to 200 B.C.) [81]:

"The most extraordinary events are concentrated in this period. Confucius and Lao-Tse were living in China, and all the schools of Chinese philosophy came into being... India produced the Upanishads and the Buddha, and similar to China, ran the whole gamut of philosophical possibilities down to sceptiscism, materialism, 
sophism, and nihilism in Iran, Zarathustra taught a challenging view of the world, as a struggle between good and evil; in Palestine, the prophets made their appearance... Greece witnessed the appearance of Homer, and of the philosophers Parmenides, Heraclitus, and Plato... Everything implied by these names developed during these few centuries, almost simultaneously in China, India, and the west, without any one of these regions knowing the others. What is new about this age is that man became conscious of the Being as a whole, of himself and his limitations. He experiences the terror of the world and his own powerlessness. He asks radical questions. Face to face with the void, he strived for liberation and redemption. By consciously recognizing his limits, he set for himself his highest goals. He experienced absoluteness in the depths of selfhood and in the lucidity of transcendence... Consciousness became, once again, conscious of itself; thinking became its own object... Spiritual conflicts arose... The most contradictory possibilities were essayed. Discussions... and the division of the spiritual realm into opposites... created unrest and movement, to the extent of spiritual chaos. As a result of this process, hitherto unconsciously accepted ideas, customs, and conditions were subjected to examination, were questioned, and liquidated. Everything was swept into the vortex."

In this inevitable process of reappraisal of the ancient thought, one must refrain from inadvertently adopting the ordinary ethnocentric, chronocentric, and egocentric Western perspective, which is conditioned by the axioms and theories adopted in the present Zeitgeist and the related traps of logic. In this context, it is worth emphasizing that science must not be confused with a narrow, acritical adoption of a given paradigm and set of [undemonstrated] axioms, the nature of which is metaphysical in nature - a fact which led Husserl to define the objectivism of positive sciences as a transcendental naivety worth of reappraisal [82]. Indeed, any rational discipline is based on undemonstrated axioms, and despite being valuable, remains dóxa (relative knowledge, opinion); Aristotle himself warned of the necessity of constantly wondering regarding the truthfulness of such axioms (Metaphysics 1005b, 1-5).

\section{Author Contribution}

The author is responsible for the entire process of writing up, revising, and approving the final version of this manuscript.

\section{Competing Interests}

The author has declared that no competing interests exist.

\section{References}

1. Angeler DG, Allen CR. Quantifying resilience. J Appl Ecol. 2016; 53: 617-624.

2. Angeler DG, Allen CR, Persson ML. Resilience concepts in psychiatry demonstrated with bipolar disorder. Int J Bipolar Disord. 2018; 6: 1-8.

3. Wieland A, Wallenburg CM. The Influence of relational competencies on supply chain resilience: A relational view. Int J Phys Distrib Logist Manag. 2013; 43: 300-320. 
4. Facco E, Al khafaji BE, Tressoldi P. In search of the true self. J Theor Philos Psychol. 2019; 39: 157-180.

5. Facco E. Esperienze di premorte. Scienza e coscienza ai confini tra fisica e metafisica. Lungavilla (PV): Edizioni Altravista; 2010. pp. 146-152

6. Taroni P. Filosofie del tempo. Il concetto di tempo nella storia del pensiero occidentale. Milano: Mimesis; 2012. pp. 397-398.

7. Facco E, Fracas F. L'enigma della coscienza. Milano: Mondadori; 2018. pp. 1

8. Fracas F. II mondo secondo la fisica quantistica. Segrate (Mlano): Sperling \& Kupfer; 2017.

9. Cabella M. Idee dell'umano tra Cina e Occidente. Genova, Italy: ECIG - Università; 2017.

10. Jullien F. II tmepo. Elementi di filosofia del vivere. Roma, Italy: Luca Sossella Ed.; 2002.

11. Epictetus, Torode S. The manual: A philospher's guide to life. UK: CreateSpace Independent Publishing Platform; 2017.

12. Facco E, Gumirato E, Humphris G, Stellini E, Bacci C, Sivolella S, et al. Modified dental anxiety scale: Validation of the Italian version. Minerva Stomatol. 2015; 64: 295-307.

13. Severino E. Legge e Caso. MIlano: Adelphi; 1980.

14. Facco E. Meditazione e Ipnosi tra neuroscienze, filosofia e pregiudizio. Lungavilla, PV, Italy: Altravista; 2014.

15. Zhuangzi. Zhuangzi. Indianapolis, US: Hackett Classics; 2009.

16. Facco E. Meditation and hypnosis: Two sides of the same coin? Int J Clin Exp Hypn. 2017; 65: 169-188.

17. Severino E. The essence of nihilism. Brooklin, NY: Verso; 2016.

18. Testoni I, Bisceglie D, Ronconi L, Pergher V, Facco E. Ambivalent trust and ontological representations of death as latent factors of religiosity. Cogent Psychol. 2018; 5: 1429349.

19. Severino E. Essenza del nichilismo. Mllano: Adelphi; 1982.

20. Wilczek F. The lightness of being: Mass, ether, and the unification of forces. New York, NY; 2010.

21. Facco E, Tagliagambe S. Ritornare a Ippocrate. In: Riflessioni sulla medicina di oggi. Milano, Italy: Mondadori; 2020.

22. Gorer G. The pornography of death. In: Death curr. Perspect., Palo Alto (CA): Mayfield; 1976, p. 71-76.

23. Woodruff RA, Goodwin DW, Guze SB. Psychiatric diagnosis. New York: Oxford University Press; 1974.

24. Le Breton D. Antropologia del dolore. Sesto San Giovanni, MI: Meltemi; 2007.

25. Le Breton D. Esperienze del dolore: Tra distruzione e rinascita. Torino: Raffaello Cortina Editore; 2010.

26. Spiegel D. Tranceformations: Hypnosis in brain and body. Depress Anxiety. 2013; 30: 342-352.

27. Granone F. Trattato di ipnosi. Torino: UTET; 1989.

28. Casiglia E. Trattato di ipnosi e altre modificazioni di coscienza. Padova, Italy: CLEUP; 2015.

29. Casiglia E, Finatti F, Tikhonoff V, Stabile M, Mitolo M, Gasparotti F, et al. Granone's plastic monoideism demonstrated by functional magnetic resonance imaging (fMRI). Psychology. 2019; 10: 434-448.

30. Spiegel D. Mesmer minus magic: Hypnosis and modern medicine. Int J Clin Exp Hypn. 2002; 50: 397-406. 
31. Thomas NJT. Supplement to mental imagery. European responses: Jaensch, Freud, and Gestalt psychology. 2010. Available from: Http://PlatoStanfordEdu/Entries/MentalImagery/European-ResponsesHtml

32. Tesla N. My Inventions: The autobiography of Nikola Tesla. Radford, USA: Wilder Publications; 2014.

33. Isaacson W. Einstein's god. In: Einstein, his life and universe. New York: Simon \& Schuster; 2007.

34. Sack AT, Schuhmann T. Hemispheric differences within the fronto-parietal network dynamics underlying spatial imagery. Front Psychol. 2012; 3: 214.

35. Rademaker RL, Pearson J. Training visual imagery: Improvements of metacognition, but not imagery strength. Front Psychol. 2012; 3: 24-33.

36. Wondrusch C, Schuster-Amft C. A standardized motor imagery introduction program (MIIP) for neuro-rehabilitation: Development and evaluation. Front Hum Neurosci. 2013; 7: 477.

37. Steenbergen B, Jongbloed-Pereboom M, Spruijt S, Gordon AM. Impaired motor planning and motor imagery in children with unilateral spastic cerebral palsy: Challenges for the future of pediatric rehabilitation. Dev Med Child Neurol. 2013; 55: 43-46.

38. Hoyek N, Di RF, Collet C, Hoyek F, Guillot A. The therapeutic role of motor imagery on the functional rehabilitation of a stage II shoulder impingement syndrome. Disabil Rehabil. 2014; 36: 1113-1119.

39. Muller K, Bacht K, Schramm S, Seitz RJ. The facilitating effect of clinical hypnosis on motor imagery: An fMRI study. Behav Brain Res. 2012; 231: 164-169.

40. Hoeft F, Gabrieli JD, Whitfield-Gabrieli S, Haas BW, Bammer R, Menon V, et al. Functional brain basis of hypnotizability. Arch Gen Psychiatry. 2012; 69: 1064-1072.

41. Bandler R, Grindler J. The strucutre of magic. Palo Alto: Science and Behavior Books; 1975.

42. Russell B. The value of phylosiphy. In: Problems of philosophy. Oxford, UK: Oxford University Press; 1912.

43. Panksepp J. Affective consciousness: Core emotional feelings in animals and humans. Conscious Cogn. 2005; 14: 30-80.

44. Solms M, Panksepp J. The "Id" knows more than the "Ego" admits: Neuropsychoanalytic and primal consciousness perspectives on the interface between affective and cognitive neuroscience. Brain Sci. 2012; 2: 147-175.

45. Facco E, Casiglia E, Zanette G, Testoni I. On the way of liberation from suffering and pain: Role of hypnosis in palliative care. Ann Palliat Med. 2018; 7: 63-74.

46. Elkins G, Fisher W, Johnson A, Sliwinski J. Clinical hypnosis for the palliative care of cancer patients. Oncology. 2012; 26: 26-30.

47. Marcus J, Elkins G, Mott F. A model of hypnotic intervention for palliative care. Adv Mind Body Med. 2003; 19: 24-27.

48. Thompson T, Terhune DB, Oram C, Sharangparni J, Rouf R, Solmi M, et al. The effectiveness of hypnosis for pain relief: A systematic review and meta-analysis of 85 controlled experimental trials. Neurosci Biobehav Rev. 2019; 99: 298-310.

49. Alladin A. Cognitive hypnotherapy for psychological management of depression in palliative care. Ann Palliat Med. 2018; 7: 112-124.

50. Alladin A. Cognitive hypnotherapy for accessing and healing emotional injuries for anxiety disorders. Am J Clin Hypn. 2016; 59: 24-46. 
51. Facco E. Hypnosis and anesthesia: Back to the future. Minerva Anestesiol. 2016; 82: 13431356.

52. Tefikow S, Barth J, Maichrowitz S, Beelmann A, Strauss B, Rosendahl J. Efficacy of hypnosis in adults undergoing surgery or medical procedures: A meta-analysis of randomized controlled trials. Clin Psychol Rev. 2013; 33: 623-636.

53. Facco E, Pasquali S, Zanette G, Casiglia E. Hypnosis as sole anaesthesia for skin tumour removal in a patient with multiple chemical sensitivity. Anaesthesia. 2013; 68: 961-965.

54. Potie A, Roelants F, Pospiech A, Momeni M, Watremez C. Hypnosis in the perioperative management of breast cancer surgery: Clinical benefits and potential implications. Anesthesiol Res Pract. 2016; 2016: 2942416.

55. Carlson LE, Toivonen K, Flynn M, Deleemans J, Piedalue KA, Tolsdorf E, et al. The role of hypnosis in cancer care. Curr Oncol Rep. 2018; 20: 93.

56. de la Cruz M, Hui D, Parsons HA, Bruera E. Placebo and nocebo effects in randomized doubleblind clinical trials of agents for the therapy for fatigue in patients with advanced cancer. Cancer. 2010; 116: 766-774.

57. Facco E, Lucangeli D, Tressoldi P. On the science of consciousness: Epistemological reflections and clinical implications. Explor J Sci Heal. 2017; 13: 163-180.

58. Pasqualotto G. East \& West. Venice, Italy: Marsilio Editori; 2008.

59. Jullien F. De l'etre au vivre. Lexique eurochinoise de la pensée. Paris, France: Gallimard; 2015.

60. Lazerowitz M. A note on metaphylosophy. Metaphilosophy. 1970; 1: 91.

61. Overgaard S, Gilbert P, Burwood S. An introduction to metaphilosophy. Cambridge University Press; 2013.

62. Weber R. "How to compare?" - on the methodological state of comparative philosophy. Philos Compass. 2013; 8: 593-603.

63. De Benedittis G. Neural mechanisms of hypnosis and meditation. J Physiol Paris. 2015; 109 : 152-164.

64. Holroyd J. The science of meditation and the state of hypnosis. AmJ Clin Hypn. 2003; 46: 109128.

65. Schmit DT. The mesmerists inquire about "oriental mind powers": West meets East in the search for the universal trance. J Hist Behav Sci. 2010; 46: 1-26.

66. Alladin A. Mindfulness-based hypnosis: Blending science, beliefs, and wisdoms to catalyze healing. Am J Clin Hypn. 2014; 56: 285-302.

67. Elkins G, Olendzkj N. MIndful hypnotherapy: The basics for clinical practice. New York, NY, US: Springer; 2019.

68. Kant E. Critique of pure reason. Cambridge, UK: CAmbridge University Press (1998); 1781.

69. Cardeña E, Jönsson P, Terhune DB, Marcusson-Clavertz D. The neurophenomenology of neutral hypnosis. Cortex. 2013; 49: 375-385.

70. Facco E, Casiglia E, Al Khafaji BE, Finatti F, Duma GM, Mento G, et al. The neurophenomenology of out-of-body experiences induced by hypnotic suggestions. Int J Clin Exp Hypn 2019; 67: 39-68.

71. Cardena E. The phenomenology of deep hypnosis: Quiescent and physically active. Int J Clin Exp Hypn. 2005; 53: 37-59.

72. Tzu L. Tao Te Ching. London, UK: Penguin Books Ltd.; 2009.

73. Palmer M. The book of Chuang Tzu. London: Penguin Books; 2006. 
74. Zhuāngzi (CHuang-Tzu). No Title. Milano: Adelphi; 1983.

75. Patanjali. The Yoga Sutras of Patanjali. NewYork, NY: North Point Press; 2009.

76. Popper KR, Eccles JC. The self and his brain. Berlin: Springer-Verlag; 1977.

77. Merskey H. The taxonomy of pain. Med Clin North Am. 2007; 91: 13-20.

78. Merskey H. Logic, truth and language in concepts of pain. Qual Life Res. 1994; 3: S69-S76.

79. Merskey H. Pain terms: A list with definitions and notes on usage. Recommended by the IASP subcommittee on taxonomy. Pain. 1979; 6: 249.

80. Facco E. Hypnosis as anesthesia for invasive procedures. In: Hypnosis for acute and procedural pain management: Favorite methods of master clinicians. Seattle, US: Denny Creek Press; 2019.

81. Jaspers K. The axial period. In: The origin and goal of history. Abingdon, Oxfordshire, UK: Routedge Revivals; 2011.

82. Husserl E. The crisis of european sciences and transcendental phenomenology: An introduction to phenomenological philosophy. Evanstone: Northwestern University Press; 1970.

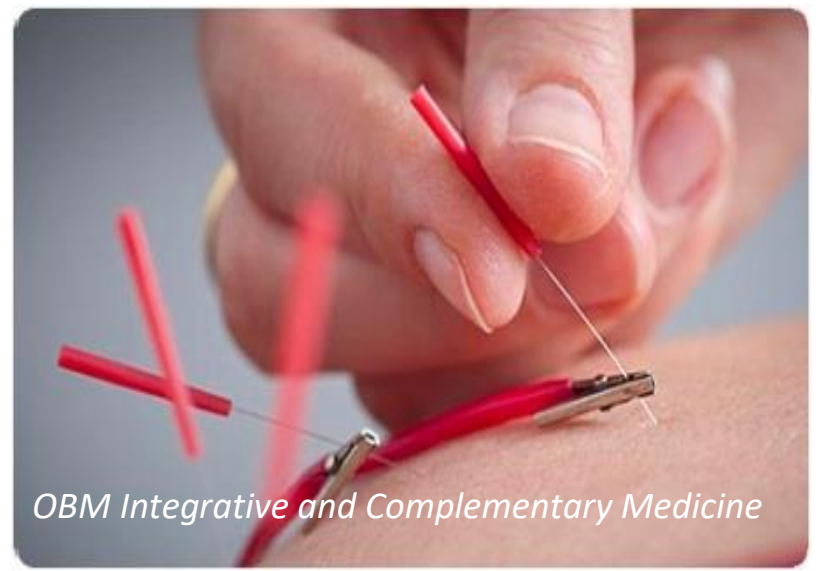

Enjoy OBM Integrative and Complementary Medicine by:

1. Submitting a manuscript

2. Joining in volunteer reviewer bank

3. Joining Editorial Board

4. Guest editing a special issue

For more details, please visit: http://www.lidsen.com/journals/icm 
Research Article

\section{YNCRG Inhibited Metabolic Syndrome Through Appetite Suppression and Improved Lipid Metabolism in Metabolic Syndrome Model Rats}

Maya Kudo ${ }^{1}$, Misa Hayashi ${ }^{1}$, Peng Tian ${ }^{3}$, Danyang Liu ${ }^{4}$, Lili $\mathrm{Wu}^{3}$, Wei $\mathrm{Li}^{4}$, Zhaoyang Hong ${ }^{5}$, Yitang Zhao ${ }^{5}$, Toshiaki Nishigaki ${ }^{6}$, Masaaki Nishihara ${ }^{7}$, Kazuo Koike ${ }^{4}$, Tonghua Liu ${ }^{3}$, Ming Gao ${ }^{1,2}$, *

1. School of Pharmaceutical Science, Mukogawa Women's University, 11-68 Koshien Kyuban-cho, Nishinomiya, Hyogo 663-8179, Japan; E-Mails: 1422006@mwu.jp; hayasi27@mukogawa-u.ac.jp; gaoming@mukogawa-u.ac.jp

2. Institute for Biosciences, Mukogawa Women's University, 11-68 Koshien Kyuban-cho, Nishinomiya, Hyogo 663-8179, Japan

3. Key Laboratory of Health Cultivation of the Ministry of Education, Beijing University of Chinese Medicine, 11 North 3rd-ring East Road, 100029 Chaoyang District, Beijing, China; E-Mails: delladepp@yeah.net; gingnido_566@163.com; thliu@vip.163.com

4. Faculty of Pharmaceutical Sciences, Toho University, 2-2-1 Miyama, Funabashi, Chiba 274-8510, Japan; E-Mails: 3020008r@st.toho-u.jp; liwei@phar.toho-u.ac.jp; koike@phar.toho-u.ac.jp

5. Hundred herbs source science and technology group Co., Ltd, 101100 Room 204-1-143, Rigria House, Cuiping Tongzhou District, Beijing, China; E-Mails: yitong@hongrun-group.com; hongchaoyang@hongrun-group.com

6. M\&K Laboratories Co., Ltd, 1286-18 Azusagawayamato, Matsumoto, Nagano 390-1701, Japan; E-Mails:mk-info@thisismk.co.jp

7. Protein Chemical Co., LTD, 1-1-7 Uchisaiwai-cho, Chiyoda-ku, Tokyo 100-0011, Japan; E-Mails: nishihara@prochemi.co.jp

* Correspondence: Ming Gao; E-Mail: gaoming@mukogawa-u.ac.jp

Academic Editor: Rafat A. Siddiqui

Special Issue: Managing Obesity through Nutraceuticals

OBM Integrative and Complementary Medicine

2020 , volume 5 , issue 3

doi:10.21926/obm.icm.2003033
Received: April 13, 2020

Accepted: June 30, 2020

Published: July 09, 2020

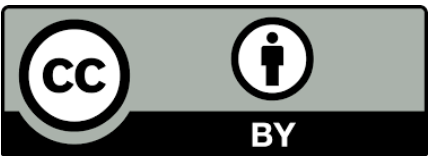

(C) 2020 by the author. This is an open access article distributed under the conditions of the Creative Commons by Attribution License, which permits unrestricted use, distribution, and reproduction in any medium or format, provided the original work is correctly cited. 


\begin{abstract}
Increased body fat mass can lead to lifestyle diseases such as hypertension, diabetes, and hyperlipidemia. Metabolic syndrome is a cluster of conditions that increases the onset of multiple diseases, such as cardiovascular diseases, stroke, and type 2 diabetes, which are closely related to lipid metabolism; therefore, new prevention approaches and treatments are needed. Our study investigated the effects and mechanism of YNCRG on anti-obesity in metabolic syndrome model SHR.Cg-Lepr ${ }^{\mathrm{cP}} / \mathrm{NDmcr}$ (SHRCP) rats. Eight-week-old male SHRCP rats were administered YNCRG or water by gavage for eight weeks and sacrificed. The tissues were immediately dissected for future experiments. We also used WKY rats as a rodent model. YNCRG induced reductions in food intake, body weight, and body fat mass in SHRCP rats. We also analyzed the mechanism of food intake regulation in the hypothalamus. Expression of POMC was significantly increased in the YNCRG group. However, JAK2 showed no change between the two groups. Phosphorylation levels of Akt (Ser473) and FoxO1 were significantly increased in the YNCRG group. Moreover, mTOR was significantly phosphorylated by YNCRG treatment. These results suggest that YNCRG can induce appetite suppression through the mTOR-Akt-FoxO1-POMC signaling pathway. YNCRG also induced a reduction in body fat mass. In adipose tissue, phosphorylation of AMPK was significantly increased in the YNCRG group. Also, LKB1 and PKA (upstream factors of AMPK), and ACC and HSL (downstream factors of AMPK) were significantly phosphorylated with the YNCRG treatment. Our results indicate that YNCRG can treat MetS by decreasing body fat mass of SHRCP rats through appetite suppression and improvement of lipid metabolism.
\end{abstract}

\title{
Keywords
}

YNCRG; metabolic syndrome; body fatty mass; appetite suppression; lipid metabolic pathway

\section{Introduction}

An increasing trend toward Western dietary patterns in Japan is considered to be a risk factor for obesity and insulin resistance, which are central to the development of the metabolic syndrome (MetS) [1, 2]. MetS is caused by an imbalance between energy intake and energy expenditure [3] and results in hypertension, high blood glucose, and diabetes. It is also a risk factor for arteriosclerosis. MetS is caused by overeating, stress, lack of exercise, and weight gain. Although drugs are administered when symptoms appear, there is concern that long-term drug use may adversely affect the human body. Therefore, the development of herbal medicine is desirable.

The molecular mechanism of MetS is still under investigation, with the involvement of multiple complicated signaling pathways. Recently, proopiomelanocortin (POMC), a food intake regulator protein, has been shown to affect appetite suppression. Two signaling pathways regulate POMCleptin signaling and insulin signaling. Binding of leptin to its specific receptor activates Janus kinase 2 (JAK2) and the signal transducer and activator of transcription 3 (STAT3) [4] and stimulates POMC expression in the hypothalamus. Insulin signaling begins with the binding of insulin to the 
insulin receptor (IR), resulting in phosphorylation of insulin receptor substrate 1 (IRS1) and protein kinase B (Akt). Akt is stimulated, and phosphorylation activity increases, leading to phosphorylation of Forkhead box $\mathrm{O} 1$ (FoxO1) by Akt $[5,6]$. Finally, phosphorylated FoxO1 increases the expression of POMC, causing appetite suppression.

Adipose tissue plays a major role in energy homeostasis, lipid metabolism, and insulin action [7]. AMP-activated protein kinase (AMPK) is a crucial cellular energy sensor [8]. Calciumcalmodulin/dependent protein kinase (CaMKK) and liver kinase B1 (LKB1) are the two major enzymes that catalyze AMPK phosphorylation [9, 10]. Furthermore, they can modulate the expression of downstream target genes involved in lipogenesis and lipolysis such as acetyl-CoA carboxylase (ACC), fatty acid synthase (FAS) and hormone-sensitive lipase (HSL) $[11,12]$. AMPK is considered a potential target in the treatment of metabolic disorders.

For centuries, traditional herbal medicines have played an important role in maintaining good health. Generally, herbal medicines have been considered for the treatment of diseases with multiple conditions such as MetS. In this study, a formulation named YNCRG was selected to evaluate the anti-obesity and anti-MetS activities. The formulation contained Tochu leave extract as the main ingredient. The other ingredients were Red koji rice (Monascus purpureus), Noni (Morinda citrifolia), L-Citrulline (L-Cit), and gamma-aminobutyric acid (GABA). Previous studies have reported that Tochu can ameliorate MetS. In this study, we developed a new mixture of five natural resources named YNCRG, which has Tochu as the major ingredient. YNCRG has been shown to improve lipid metabolism, treat hypertension, and suppress appetite.

Tochu (Eucommia ulmoides Oliv.), belonging to the family of Eucommiaceae, has a long history of use in traditional Chinese medicine. Tochu leaves have been paid more attention due to its antiMetS activities, such as hypolipidemic [13], antibacterial [14], hepatoprotective [15], and antihypertensive [16] effects. Red koji rice, an edible fungus, has been widely used to produce wines and other fermented foods, particularly in Asia $[17,18]$. In a recent study, Red koji rice showed an anti-obesity effect in high-fat diet obese rats [19]. Noni is a traditional medicinal plant [20] with a long history of use as a food in tropical regions [21]. Noni has been reported to have a broad range of therapeutic effects and effective remedy for cold, influenza, diabetes, hypertension, cancer, and other illnesses [22, 23]. L-Citrulline (L-Cit) is a free amino acid found in cucurbits such as watermelon [24]. In our previous report, L-Cit was shown to have an anti-obesity effect due to appetite suppression [25]. GABA is one of the natural amino acids found in plants, animals, and humans. In particular, GABA ${ }_{B}$ receptors regulate POMC expression [26].

SHR.Cg-Lepr ${ }^{\mathrm{cP}} / \mathrm{NDmcr}$ (SHRCP) rats spontaneously develop moderately elevated blood glucose with hyperphagia, insulin resistance, obesity, dyslipidemia, and hypertension, traits that resemble those of human pre-diabetes and MetS $[27,28]$. This study investigated the mechanism of action and possible synergistic effects of YNCRG on MetS in terms of appetite suppression and lipid metabolic pathways in SHRCP rats.

\section{Materials and Methods}

All procedures were carried out in accordance with the guiding principles for the care and use of animals in the field of physiological sciences established by the Physiological Society of Japan. The study was approved by the Ethics Committee of Laboratory Animals at Mukogawa Women's University (grant number: P-06-2018-01-A; date of approval: November 27, 2018). 


\subsection{Preparation of YNCRG}

YNCRG contains Eucommia ulmoides (Tochu leaves was supplied by Maruzen Pharmaceuticals Co., Ltd, Hiroshima, Japan, Lot number: 01101047), Monascus purpureus (Red koji rice was supplied by Kobayashi Pharmaceutical Co., Ltd, Osaka, Japan, Lot number: 320-180801), Morinda citrifolia (Noni was supplied by Earth Ship Co., Ltd, Osaka, Japan, Lot number: 40004), L-Citrulline (L-Cit was supplied by Protein Chemical Co., LTD, Tokyo, Japan, Lot number: 75A05CT) and gamma-aminobutyric acid (GABA, which was supplied by Coach Boueki Co., Ltd, Osaka, Japan, Lot number: 20180104), in a proportion of 4:2:2:1:1.

Dosage: We determined the dose of YNCRG based on a human weighting $50 \mathrm{~kg}$ taking $9 \mathrm{~g}$ YNCRG daily. We used 15 times this amount in SHRCP rats and decided on an experimental period for which the effect of YNCRG on metabolic syndrome would be the strongest.

\subsection{Experimental Animals}

SHRCP rats and the Wister Kyoto (WKY) rats (Japan SLC, Inc., Shizuoka, Japan) were 6-week-old males. All rats were kept at $22-24{ }^{\circ} \mathrm{C}$ under artificial lighting with a $12 \mathrm{~h} /$ daylight and dark cycle. Rats were fed CE-2 (normal chow, CLEA Japan, Inc. Japan) for two weeks to stabilize their metabolic condition. Rats were then randomly assigned to three groups ( $n=9,8,8$ in each group): a control group (normal water); a YNCRG group (water with $3.6 \mathrm{~g} / \mathrm{kg}$ body weight/day YNCRG); and a WKY group (normal water). We administered water or YNCRG to SHRCP rats by gavage, measured body weight every day, and recorded food and water intake once a week. Blood pressure was measured once every two months, 24-h-urine was collected once a month, and an oral glucose tolerance test (OGTT) was performed after an 8-week treatment period.

All rats were sacrificed after the 8-week treatment period after $24 \mathrm{~h}$ of fasting. Rats were anesthetized with isoflurane and all efforts were made to minimize suffering. Blood samples were collected from the abdominal aorta using injection needles and sera were centrifuged, frozen, and stored at $-20{ }^{\circ} \mathrm{C}$ until later analyses. The tissues (liver, kidneys, heart, fat, aortic, adrenal gland, pancreases, brain) were immediately dissected and cleaned to measure organs and tissue weights, and organs and tissues were promptly frozen in liquid nitrogen and stored at $-80{ }^{\circ} \mathrm{C}$ for western blotting and real-time PCR analysis.

All procedures were carried out in accordance with the guiding principles for the care and use of animals in the field of physiological sciences established by the Physiological Society of Japan. The study was approved by the Ethics Committee of Laboratory Animals at Mukogawa Women's University (permit Number: P-06-2018-01-A).

\subsection{Biochemical Analysis of Serum and Urine}

Non-fasting blood glucose (NFBG) was measured using a self-testing glucose kit at the end of the 8-week treatment period. Serum total cholesterol (TC), triglycerides (TG), aspartate aminotransferase (AST), and alanine aminotransferase (ALT) were measured enzymatically using an assay kit (Wako, Japan). We asked a vendor to measure serum albumin (ALB), blood urea nitrogen (BUN), creatinine (Cre), uric acid (UA), urine-total protein (TP), urine-urine nitrogen (UN) and urine-Cre. 


\subsection{Blood Pressure and Heart Rate Measurements}

Systolic blood pressure (SBP), diastolic blood pressure (DBP), and heart rate were measured using a sphygmomanometer (UR-1000, Ueda Co., Chiba) with the tail-cuff method once every two weeks.

\subsection{OGTT}

Blood was sampled via the tail vein after 12-18 $\mathrm{h}$ of fasting. Fasting blood glucose (FBG) was quantified using the glucose oxidase method at $0,30,60,90,120 \mathrm{~min}$ after glucose $(1 \mathrm{~g} / \mathrm{kg})$ loading in the OGTT. The area under the curve (AUC) was then calculated from the serum glucose content [29].

\subsection{Assessment of Body Composition}

Body composition was analyzed by bioelectrical impedance analysis (BIA) (ImpediVET, ImprdiMed Ltd., Brisbane, Australia) as previously described [30].

\subsection{Primary and Secondary Antibodies}

Western blotting was performed with the following commercially available antibodies: antirabbit Akt, anti-rabbit phosphor-Akt (Ser473) anti-rabbit phosphor-Akt (Thr308), anti-rabbit FoxO1, anti-rabbit phosphor-FoxO1, anti-rabbit phosphor-IRS1 (Ser1101), anti-rabbit phosphormammalian target of rapamycin (mTOR) (Ser2448), anti-rabbit phosphor-S6 kinase (S6K) (Ser240/244), anti-rabbit phosphor-janus activating kinase 2 (JAK2) (Ser1007/1008), anti-rabbit AMPK, anti-rabbit phosphor-AMPK, anti-rabbit phosphor-CaMKK, anti-rabbit phosphor-LKB1, antirabbit phosphor-protein kinase $A$ (PKA), anti-rabbit ACC, anti-rabbit phosphor-ACC, anti-rabbit HSL, anti-rabbit phosphor-HSL, anti-rabbit CCAAT/enhancer-binding protein (C/EBP) $\alpha$, anti-rabbit C/EBP $\beta$, anti-rabbit peroxisome proliferator-activated receptor $\gamma$ (PPAR $\gamma$ ), anti-rabbit IgG and antimouse IgG from Cell Signaling Technology (Beverly, MA, USA); anti-rabbit POMC, anti-goat agoutirelated protein (Agrp), anti-rabbit phospho-IRS1 (Tyr465), anti-rabbit IRS1 and ant-goat IgG from Santa Cruz Biotechnology; and anti-mouse $\beta$-Actin from Sigma (St. Louis, MO, USA).

\subsection{Protein Extraction Experiments}

Hypothalamus and fat tissues were homogenized in ice-cold homogenization buffer containing $50 \mathrm{mM}$ Tris- $\mathrm{HCl}$ (pH 7.4), $100 \mathrm{mM} \mathrm{NaCl}, 1 \%$ Nonident P-40, 0.25\% Na deoxycholate, $0.1 \%$ SDS, 1 mM EDTA, $50 \mathrm{mM} \mathrm{NaF}, 2 \mathrm{mM} \mathrm{Na}_{3} \mathrm{VO}_{4}, 30 \mathrm{mM}$ Na pyrophosphate, $2 \mathrm{mM}$ PMSF, $1 \mathrm{mM}$ benzanidine, $0.02 \mathrm{~g} / \mathrm{mL}$ trypsin inhibitor, $0.02 \mathrm{~g} / \mathrm{mL}$ leupeptin, and $0.02 \mathrm{~g} / \mathrm{mL}$ aprotinin. After placing in an ice bath for $30 \mathrm{~min}$, the samples were centrifuged at 12,000 rpm for $10 \mathrm{~min}$. The supernatants were isolated to obtain protein samples. Proteins were extracted by boiling the tissue samples in 0.5 $\mathrm{mM}$ Tris- $\mathrm{HCl}$ ( $\mathrm{pH} 6.8$ ), glycerol, 10\% SDS, 0.1\% bromophenol blue, and 2-mercaptethanol [25]. 


\subsection{Western Blot Analysis}

Proteins (10-20 $\mathrm{\mu g} /$ Lane) were electrophoresed using 10-12.5\% SDS-PAGE gel at $100 \mathrm{~V}$ for $90-$ $120 \mathrm{~min}$. We used the same gel and a separate gel for western blot analysis to assess experimental progress. After fractionating, proteins were transferred onto a polyvinylidene difluoride (PVDF) membrane (Amersham Life Science Inc. Buckinghamshire) at $100 \mathrm{~mA}$ for 1-2 $\mathrm{h}$. The membranes were blocked with Blocking One or Blocking One-P (Nacalai Tesque, Japan) for $30 \mathrm{~min}$. After appropriate blocking, the membranes were incubated overnight with the primary antibody in antibody solution 1 (Toyobo, Japan). They were then washed with TTBS containing $1 \mathrm{M} \mathrm{Tris-HCl}(\mathrm{pH}$ 7.5), $\mathrm{NaCl}$, and 20\% Tween 20 and finally incubated for $1 \mathrm{~h}$ with a 1:5000-2000 dilution of antirabbit, goat and mouse IgG-horseradish peroxidase. Detection was achieved using a Chemi-Lumi One Super (Nacalai Tesque, Japan). $\beta$-Actin was used as an internal control. Protein band densities were analyzed using Image J software from the National Institutes of Health [25].

\subsection{RNA Extraction and Real-Time PCR}

otal RNA was isolated using Sepasol (R)-RNA I Super G (Nacalai Tesque, Japan) from liver tissue and quantified using spectrophotometry at $260 \mathrm{~nm}, 280 \mathrm{~nm}$, and $320 \mathrm{~nm}$. RNA was reversetranscribed into cDNA using ReverTra Ace ${ }^{\circledR}$ qPCR RT Master Mix with a gDNA remover (TOYOBO, Japan) according to the manufacturer's protocol and used for the amplification of target genes in real-time PCR with THUNDERBIRD SYBR qPCR Mix (TOYOBO, Japan). The specific primers were obtained from Thermo Fisher Scientific (Waltham, MA, USA). The PCR amplification was performed in Thermal Cycler Dice (Takara Bio Inc. Japan) as follows: 1 cycle at $95^{\circ} \mathrm{C}$ for $30 \mathrm{~s}$, and 40 cycles at $95^{\circ} \mathrm{C}$ for $5 \mathrm{~s}$ and $60^{\circ} \mathrm{C}$ for $30 \mathrm{~s}$. The fold differences in mRNA expression levels were analyzed using the 2- ${ }^{\triangle \Delta C T}$ method. Relative mRNA expression levels were calculated as the ratio of each transcript relative to the housekeeping gene, glyceraldehyde-3-phosphate dehydrogenase (GAPDH). The primer sequences are listed in Table 1 [29].

Table 1 Specific primer sequences.

\begin{tabular}{lll}
\hline Genes & Forward & Reverse \\
\hline GAPDH & AGAACATCATCCCTGCATCCA & CCGTTCAGCTCTGGGATGAC \\
Sirt1 & TGAAGCTGTTCGTGGAGATATTTTT & CATGATGGCAAGTGGCTCAT \\
FAS & GGCATCATTGGGCACTCCTT & GCTGCAAGCACAGCCTCTCT \\
\hline
\end{tabular}

\subsection{LC-MS Analysis}

LC-ESI-MS analysis was carried out using an LCMS-8040 triple quadrupole LC/MS/MS mass spectrometer (Shimadzu Co., Ltd., Kyoto, Japan) with a YMC-Triart C18 column $(3.0 \mu \mathrm{m}, 150 \times 20$ $\mathrm{mm}$ I.D.). The flow rate was $0.2 \mathrm{~mL} / \mathrm{min}$, and the column temperature was maintained at $35^{\circ} \mathrm{C}$. The mobile phase was composed of $A\left(0.1 \%\right.$ formic acid in $\left.\mathrm{H}_{2} \mathrm{O}\right)$ and $B(0.1 \%$ formic acid in acetonitrile) with a gradient as follows: $10 \%$ B in $0-3 \mathrm{~min}, 10-50 \%$ B in $3-10 \mathrm{~min}, 50-90 \%$ B in $10-$ $40 \mathrm{~min}, 100 \% \mathrm{~B}$ in $40-50 \mathrm{~min}$. The mass spectrometer was operated in both positive- and negative ion modes with the full scan mode in the range of $100-1600 \mathrm{~m} / \mathrm{z}$. The optimized instrument 
settings were as follows: interface voltage, $4.5 \mathrm{kV}$ in the positive-ion mode, and $-3.5 \mathrm{kV}$ in the negative ion mode; collision voltage, $15 \mathrm{~V}$; dry gas, $15 \mathrm{~L} / \mathrm{min}$, and dry temperature $350^{\circ} \mathrm{C}$.

YNCRG $(0.5 \mathrm{~g})$ was ultrasonically extracted with $\mathrm{MeOH}(20 \mathrm{~mL})$ at room temperature for $1 \mathrm{~h}$. The extracted solutions $(1 \mathrm{~mL})$ were purified using a Sep-Pak C18 plus short cartridge and diluted to $10 \mathrm{~mL}$. The solutions were filtered through a $0.45 \mu \mathrm{m}$ syringe filter. A volume of $2 \mu \mathrm{L}$ was injected for LC-ESI-MS analysis [31].

\subsection{Statistical Analysis}

Data are expressed as the mean \pm S.E.M. Statistical analyses of the data were performed using Student's t-test between the control group and the YNCRG group. A $p$-value of less than 0.05 was considered significant.

\section{Results}

\subsection{Effects of YNCRG on Body Weight, Food Intake, Organ and Tissue Weights, and Body Fat Mass in SHRCP and WKY Rats}

First, we examined the effects of YNCRG on body weight and food intake. When rats were treated daily with YNCRG or water for eight weeks, body weight, body weight gain and food intake were significantly lower in the YNCRG group compared with the control group (Fig. 1A, B, C). After sacrificing the rats, we measured organ and tissue weights and body fat mass. There were no significant differences in organ and tissue weights between the two groups (Table 2). However, body fat mass was significantly decreased in the YNCRG group (Fig. 1D).

Table 2 Effect of YNCRG on organ and tissue weights in SHRCP and WKY rats.

\begin{tabular}{|c|c|c|c|}
\hline & Control & YNCRG & WKY \\
\hline Liver (mg/g (B.W.)) & $42.6 \pm 1.38$ & $38.0 \pm 2.68$ & $26.1 \pm 0.31$ \\
\hline Kidneys (mg/g (B.W.)) & $2.89 \pm 0.16$ & $2.91 \pm 0.18$ & $3.57 \pm 0.41$ \\
\hline $\begin{array}{l}\text { Adrenal gland (mg/g } \\
(\text { B.W.)) }\end{array}$ & $0.07 \pm 0.009$ & $0.08 \pm 0.004$ & $0.10 \pm 0.009$ \\
\hline Heart (mg/g (B.W.)) & $3.03 \pm 0.15$ & $2.86 \pm 0.07$ & $3.01 \pm 0.05$ \\
\hline $\begin{array}{l}\text { Epididymal fat (mg/g } \\
\text { (B.W.)) }\end{array}$ & $20.1 \pm 0.73$ & $19.0 \pm 1.05$ & $15.9 \pm 0.54$ \\
\hline Brain (mg/g (B.W.)) & $2.83 \pm 0.04$ & $3.23 \pm 0.18 * *$ & $4.22 \pm 0.04$ \\
\hline
\end{tabular}




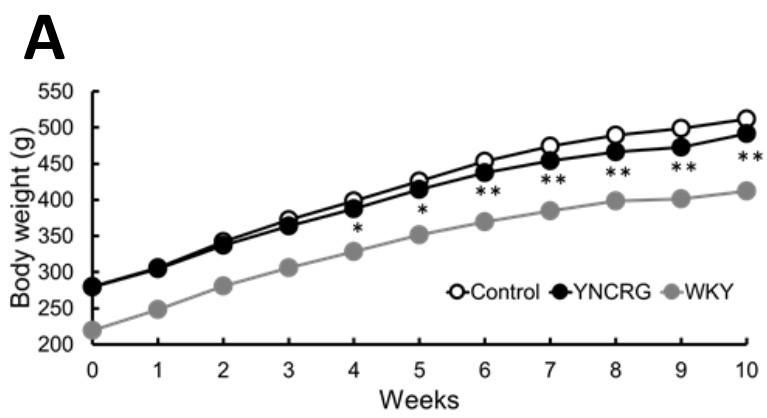

B

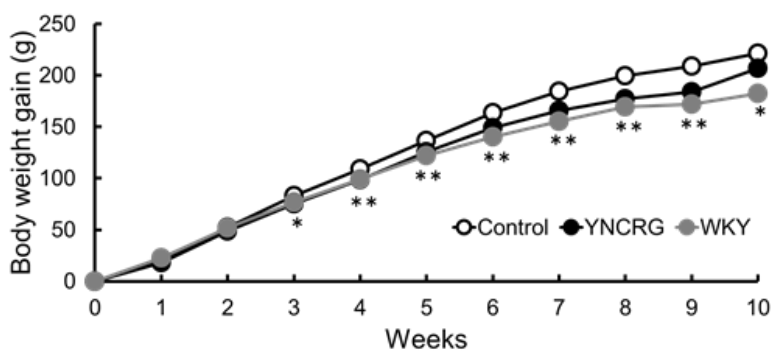

C

D
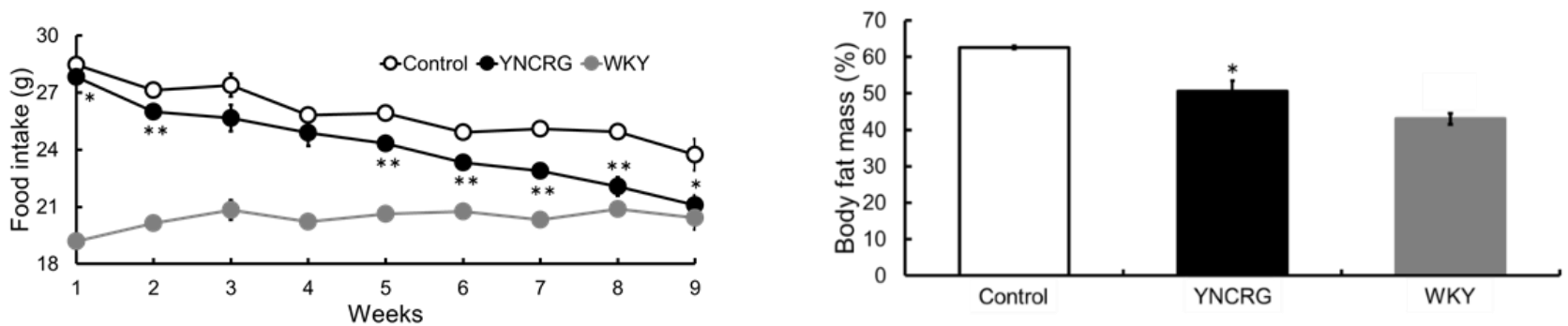

Figure 1 Effect of YNCRG on body weight, food intake, and organ and tissue weights in SHRCP and WKY rats.

Eight-week-old male SHRCP and WKY rats were treated daily with YNCRG or water for eight weeks. Bodyweight (A), body weight gain (B), food intake (C), and body fat mass (D). Data are expressed as the mean \pm S.E.M.; $n=9,8,8$ in control, YNCRG, and WKY groups, respectively, ${ }^{*} \mathrm{P}<0.05,{ }^{*} \mathrm{P}<0.01$ vs. control group.

\subsection{Effects of YNCRG on Metabolic Parameter Levels in Serum in SHRCP and WKY Rats}

Next, we investigated various metabolic parameters in the serum in SHRCP and WKY rats. Serum TC tended to decrease after 8-week YNCRG treatment, but TG levels were unchanged between the two groups. After eight weeks of administration with YNCRG, the AST and ALT levels, which indicate liver function, were decreased in the YNCRG group suggesting that YNCRG does not have negative effects on the liver. Also, the non-fasting blood glucose level was significantly decreased in the YNCRG group. Further, we measured serum ALB, BUN, Cre, and UA, which are kidney damage markers. Their levels were not affected in the YNCRG group (Table 3).

Table 3 Effect of YNCRG on various serum blood parameters in SHRCP and WKY rats.

\begin{tabular}{llll}
\hline & Control & YNCRG & WKY \\
& & & \\
\hline TC $(\mathrm{mg} / \mathrm{dL})$ & $70.6 \pm 8.88$ & $67.0 \pm 10.2^{\#}$ & $54.5 \pm 10.7$ \\
$\mathrm{TG}(\mathrm{mg} / \mathrm{dL})$ & $612.1 \pm 40.3$ & $496.7 \pm 52.7$ & $21.0 \pm 4.47$ \\
AST $(\mathrm{IU} / \mathrm{L})$ & $140.4 \pm 24.1$ & $70.3 \pm 22.4^{*}$ & $85.3 \pm 21.0$ \\
ALT (IU/L) & $47.7 \pm 6.4$ & $35.1 \pm 10.4$ & $4.0 \pm 3.7$ \\
NFBG (mg/dL) & $143.1 \pm 12.0$ & $108.1 \pm 8.40^{*}$ & $96.1 \pm 3.41$ \\
\hline
\end{tabular}




\begin{tabular}{llll}
\hline ALB $(\mathrm{g} / \mathrm{dL})$ & $5.05 \pm 0.20$ & $6.88 \pm 0.01$ & $4.59 \pm 0.22$ \\
$\mathrm{BUN}(\mathrm{mg} / \mathrm{dL})$ & $27.2 \pm 0.87$ & $29.8 \pm 2.01$ & $24.3 \pm 1.86$ \\
$\mathrm{Cre}(\mathrm{mg} / \mathrm{dL})$ & $0.28 \pm 0.02$ & $0.33 \pm 0.03$ & $0.46 \pm 0.01$ \\
$\mathrm{UA}(\mathrm{mg} / \mathrm{dL})$ & $2.49 \pm 0.34$ & $2.66 \pm 0.42$ & $1.56 \pm 0.20$
\end{tabular}

Eight-week-old male SHRCP and WKY rats were treated daily with YNCRG or water for eight weeks. Data are expressed as the mean \pm S.E.M.; $n=9,8,8$ in control, YNCRG, and WKY groups, respectively, ${ }^{*} \mathrm{P}<0.05,{ }^{*} \mathrm{P}<0.01$ vs. control group.

\subsection{Effects of YNCRG on Metabolic Parameter Levels in Urine in SHRCP and WKY Rats}

First, we measured the $24 \mathrm{~h}$ urine level after treatment for 4 and 8 weeks. The urine volume at eight weeks was significantly lower in the YNCRG group. However, urine TP, UN, and Cre were unchanged between the two groups (Table 4).

Table 4 Effects of YNCRG on urine level, urine TP, UN, and Cre in SHRCP and WKY rats.

\begin{tabular}{lllll}
\hline & Weeks & Control & YNCRG & WKY \\
& 4 & $27.3 \pm 1.76$ & $23.6 \pm 2.17$ & $14.9 \pm 1.25$ \\
Urine level (mL) & 8 & $26.4 \pm 1.25$ & $20.4 \pm 1.65^{*}$ & $16.4 \pm 0.46$ \\
& 4 & $24.4 \pm 3.57$ & $19.2 \pm 1.47$ & $15.7 \pm 1.92$ \\
& & $42.0 \pm 5.90$ & $46.0 \pm 5.51$ & $9.04 \pm 0.84$ \\
Total protein (mg) & 8 & $567.3 \pm 27.9$ & $535.4 \pm 55.5$ & $327.9 \pm 36.2$ \\
& 4 & $385.5 \pm 13.4$ & $394.4 \pm 30.3$ & $187.5 \pm 20.1$ \\
Urine nitrogen & 8 & $8.26 \pm 0.47$ & $7.03 \pm 0.52$ & $8.46 \pm 0.79$ \\
(mg) & 4 & $6.28 \pm 0.39$ & $6.50 \pm 0.50$ & $7.01 \pm 0.48$ \\
& 8 & & &
\end{tabular}

Eight-week-old male SHRCP and WKY rats were treated daily with YNCRG or water for eight weeks. Data are expressed as the mean \pm S.E.M.; $n=9,8,8$ in control, YNCRG, and WKY groups, respectively, ${ }^{*} \mathrm{P}<0.05,{ }^{* *} \mathrm{P}<0.01$ vs. control group.

\subsection{Effects of YNCRG on SBP, DBP, and Heart Rate in Urine in SHRCP and WKY Rats}

SBP and DBP were significantly decreased in the YNCRG group compared with those in the control group. However, heart rate did not change between the two groups (Fig. 2A, B, C). 


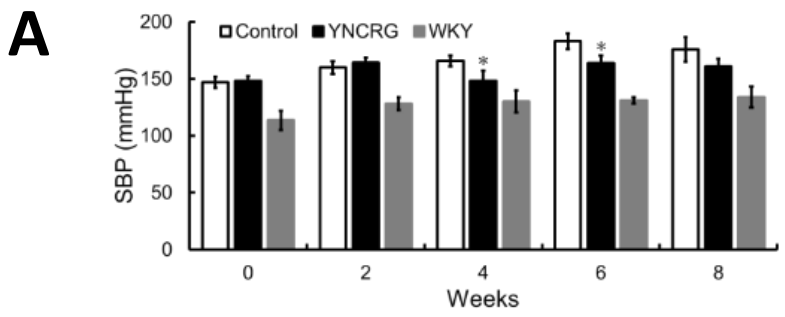

B
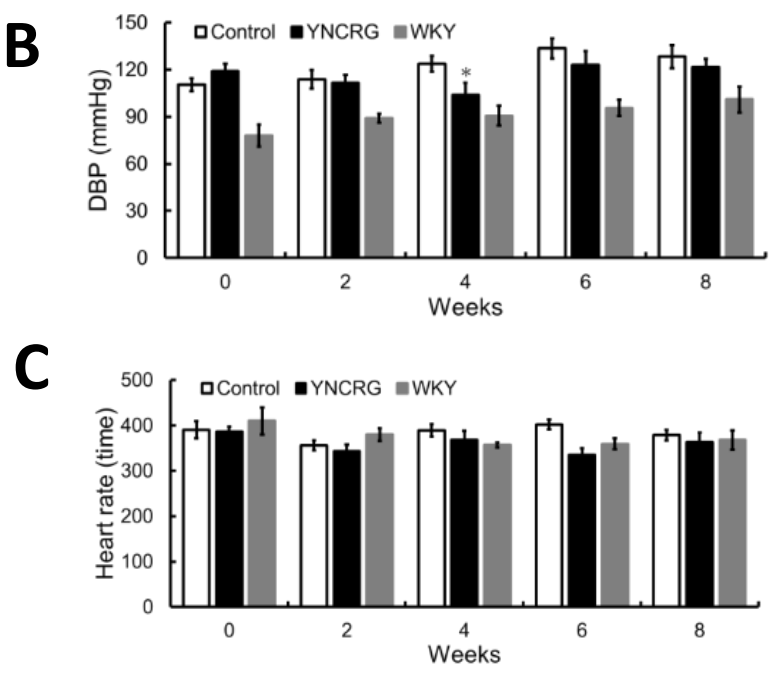

Figure 2 Effect of YNCRG on SBP, DBP and heart rate in SHRCP and WKY rats.

Eight-week-old male SHRCP and WKY rats were treated daily with YNCRG or water for eight weeks. SBP (A), DBP (B) and heart rate (C). Data are expressed as the mean \pm S.E.M.; $n=9,8,8$ in control, YNCRG and WKY groups, respectively, ${ }^{*} \mathrm{P}<0.05$ vs. control group.

\subsection{Effects of YNCRG on Glucose Tolerance in SHRCP and WKY Rats}

The OGTT showed that YNCRG inhibited blood glucose increase in a time-dependent manner and improved glucose metabolism (Fig. 3A, B).

A

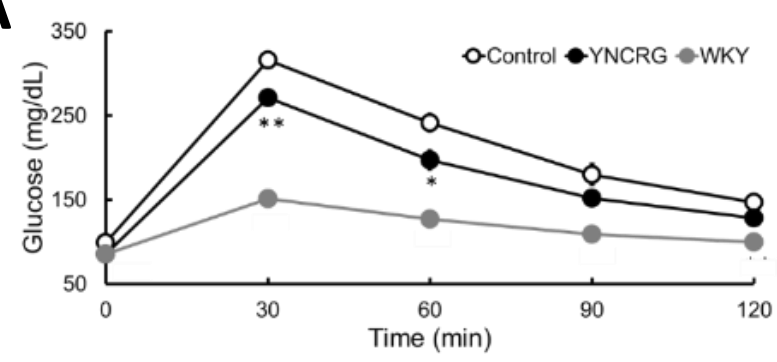

B

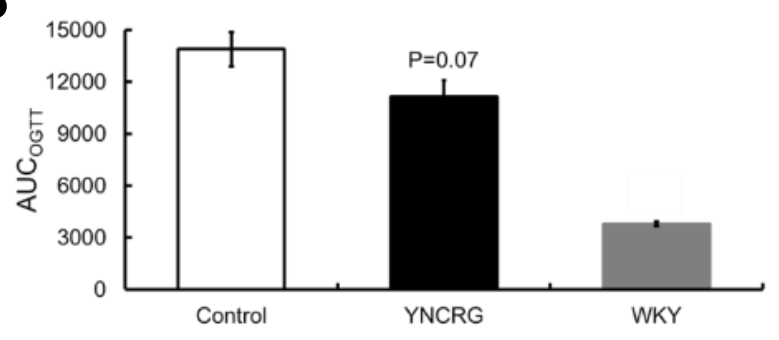

Figure 3 Effect of YNCRG on glucose tolerance in SHRCP and WKY rats.

Eight-week-old male SHRCP and WKY rats were treated daily with YNCRG or water for eight weeks. Blood glucose (A) and AUC (B). Data are expressed as the mean \pm S.E.M.; $n$ $=9,8,8$ in control, YNCRG and WKY groups, respectively, ${ }^{*} P<0.05, * * P<0.01$ vs. control group. 


\subsection{Effects of YNCRG on Food Intake Regulation Factors and Leptin Signaling in the Hypothalamus of SHRCP and WKY Rats}

As YNCRG affected food intake in SHRCP rats, we examined hypothalamic factors involved in food intake regulation. We measured the expression of Agrp, a peptide that promotes appetite, using Western blot analysis. The expression of Agrp was not affected by the YNCRG treatment (Fig. $4 A)$. On the other hand, expression of POMC, which suppresses appetite, was significantly higher in the YNCRG group than that in the control group, suggesting that YNCRG affects appetite suppression due to increased POMC expression (Fig. 4B). Two signaling pathways regulate POMC expression in the hypothalamus: leptin signaling and insulin signaling. First, to examine the effects of YNCRG on leptin signaling in the hypothalamus of SHRCP rats, we calculated the JAK2 phosphorylation ratio. The JAK2 phosphorylation ratio was not significantly different between the two groups, suggesting that leptin signaling was not stimulated by the YNCRG treatment (Fig. 4C).

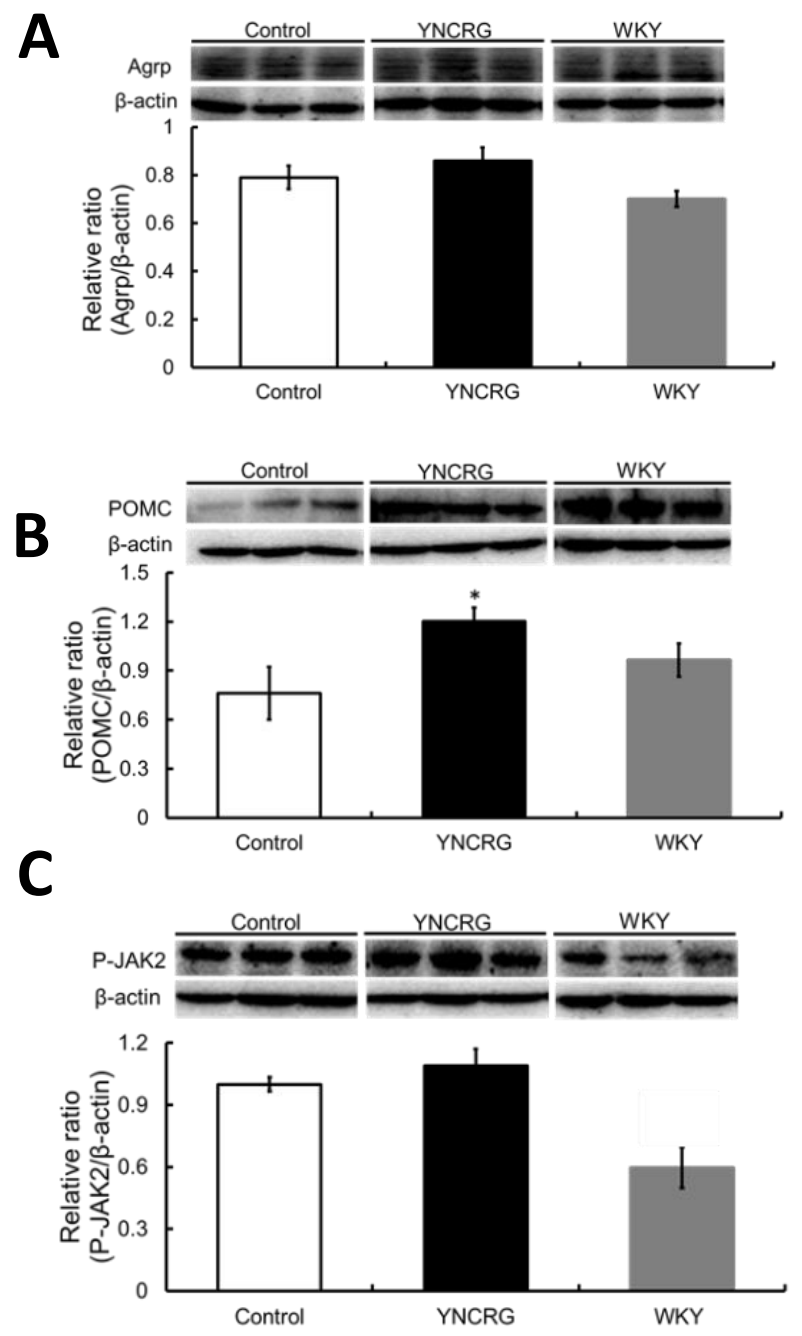

Figure 4 Effect of YNCRG on food intake regulation factors and leptin signaling in SHRCP and WKY rats.

Eight-week-old male SHRCP and WKY rats were treated daily with YNCRG or water for eight weeks. Agrp (A), POMC (B) and JAK2 (C). Data are expressed as the mean \pm S.E.M.; $n=9,8,8$ in control, YNCRG and WKY groups, respectively, ${ }^{*} \mathrm{P}<0.05$ vs. control 
group.

\subsection{Effects of YNCRG on insulin signaling in the hypothalamus of SHRCP and WKY rats}

As YNCRG was not involved in leptin signaling, we examined the effects of YNCRG on insulin signaling, which regulates POMC expression as well as leptin signaling, in SHRCP rats. We measured phosphorylated Akt expression as it is a central enzyme in insulin signaling. Akt (Ser473) phosphorylation significantly increased in the YNCRG group compared with the control group (Fig. $5 A$ ). On the other hand, the expression of phosphorylated Akt ( $\mathrm{Thr} 308$ ) did not change in the two groups (Fig. 5B). Also, FoxO1, a downstream factor of Akt, was significantly phosphorylated in the YNCRG group (Fig. 5C). However, the expression of phosphorylated IRS1 (Ser1101, Tyr465) expressions was not significantly different between the two groups (Fig. 5D, E), suggesting that Akt did not phosphorylate via IRS1 signaling; therefore, we hypothesized that another pathway was stimulated by Akt. We measured phosphorylated mTOR expression as another target of Akt phosphorylation signaling. Expression of phosphorylated mTOR was significantly higher in the YNCRG group than in the control group (Fig. 5F), suggesting that YNCRG enhanced Akt phosphorylation by stimulating mTOR. However, S6K phosphorylation did not change with YNCRG treatment in SHRCP rats (Fig. 5G).
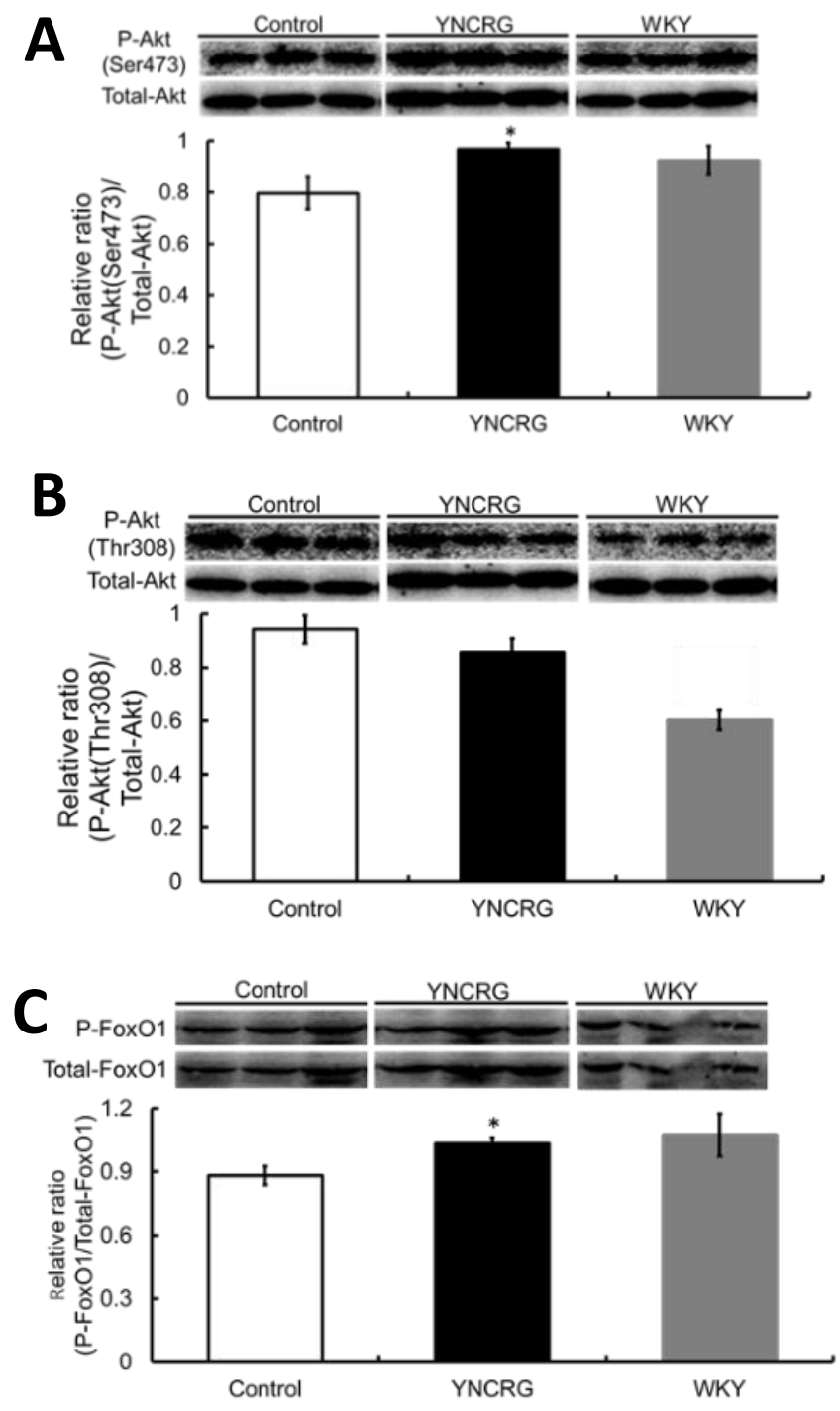

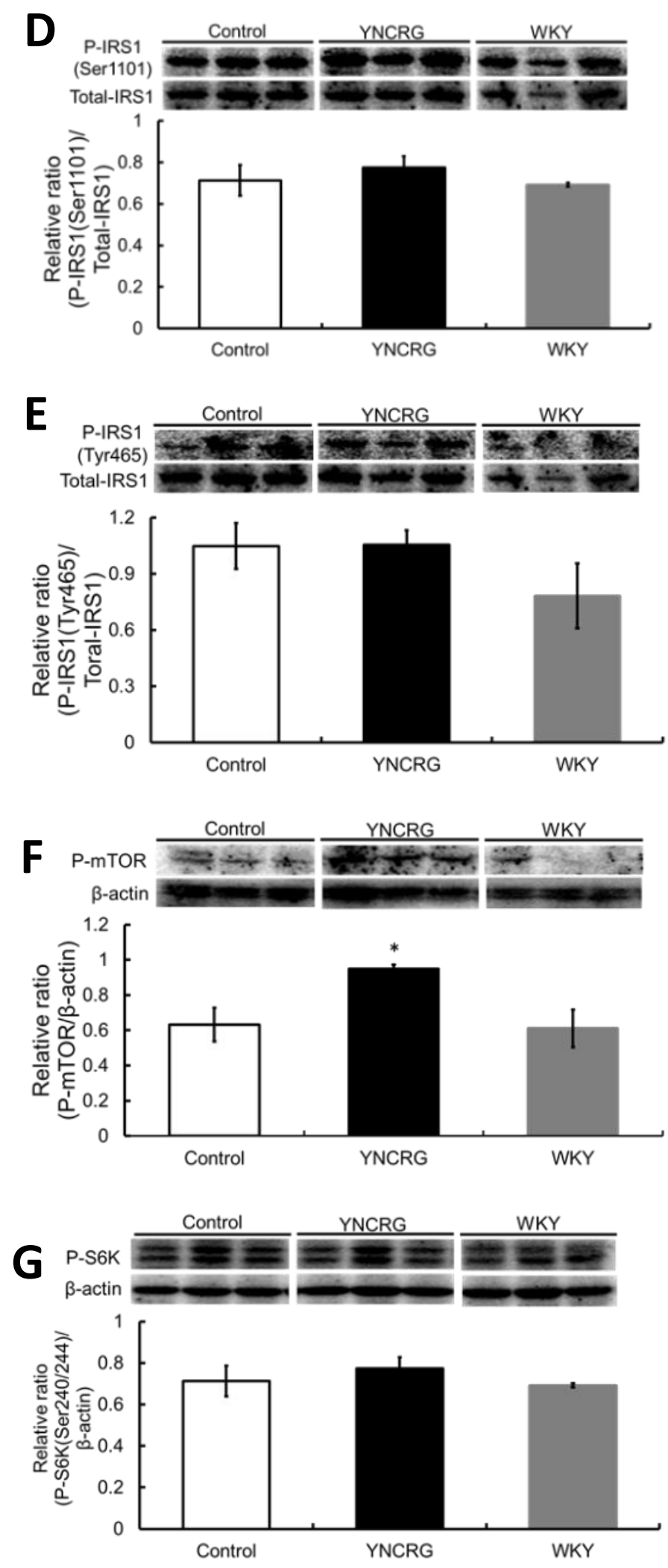

Figure 5 Effect of YNCRG on insulin signaling in the hypothalamus in SHRCP and WKY rats.

Eight-week-old male SHRCP and WKY rats were treated daily with YNCRG or water for eight weeks. Akt (Ser473, Thr308), FoxO1, IRS1 (Ser1101, Tyr465), mTOR and S6K (A-G). Data are expressed as the mean \pm S.E.M.; $n=9,8,8$ in control, YNCRG and WKY groups, respectively, $* \mathrm{P}<0.05$ vs. control group. 


\subsection{Effects of YNCRG on the Expression of Lipid Metabolism-Related Proteins and Genes in the Epididymal Fat in SHRCP and WKY Rats}

As YNCRG affected body weight and body fat mass in SHRCP rats, we examined phosphorylation of the AMPK level, which is the main enzyme in the lipid metabolic pathway, using epididymal fat. AMPK phosphorylation of epididymal fat was significantly increased in the YNCRG group (Fig. 6A). Next, we measured phosphorylated LKB1 and PKA as they are upstream factors of AMPK. LKB1 and PKA phosphorylation significantly increased in the YNCRG group compared with that in the control group (Fig. 6B, C). However, phosphorylated CaMKK, Akt (Ser473), and the mRNA levels of Sirt1 were not significantly different between the two groups (Fig. 6D, E, F).

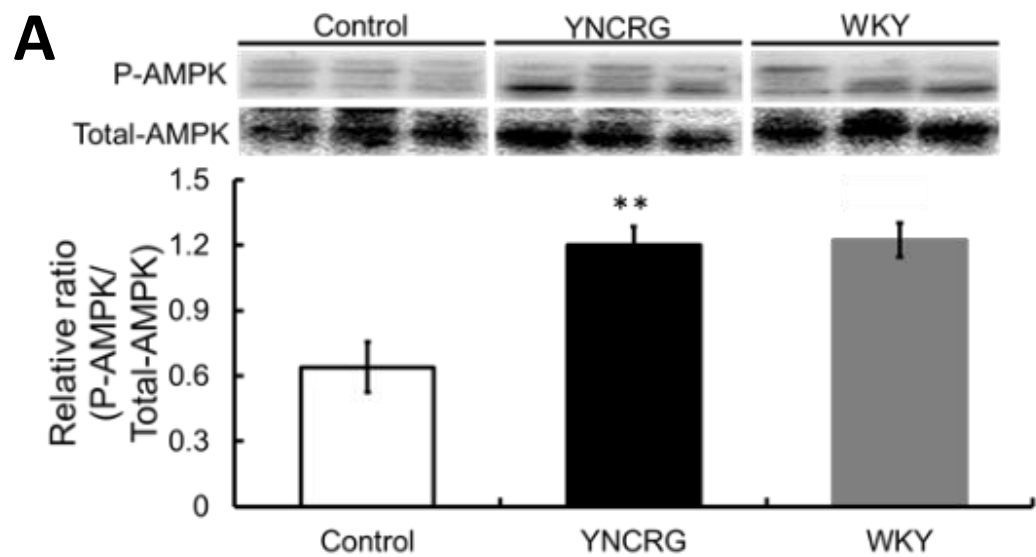

B
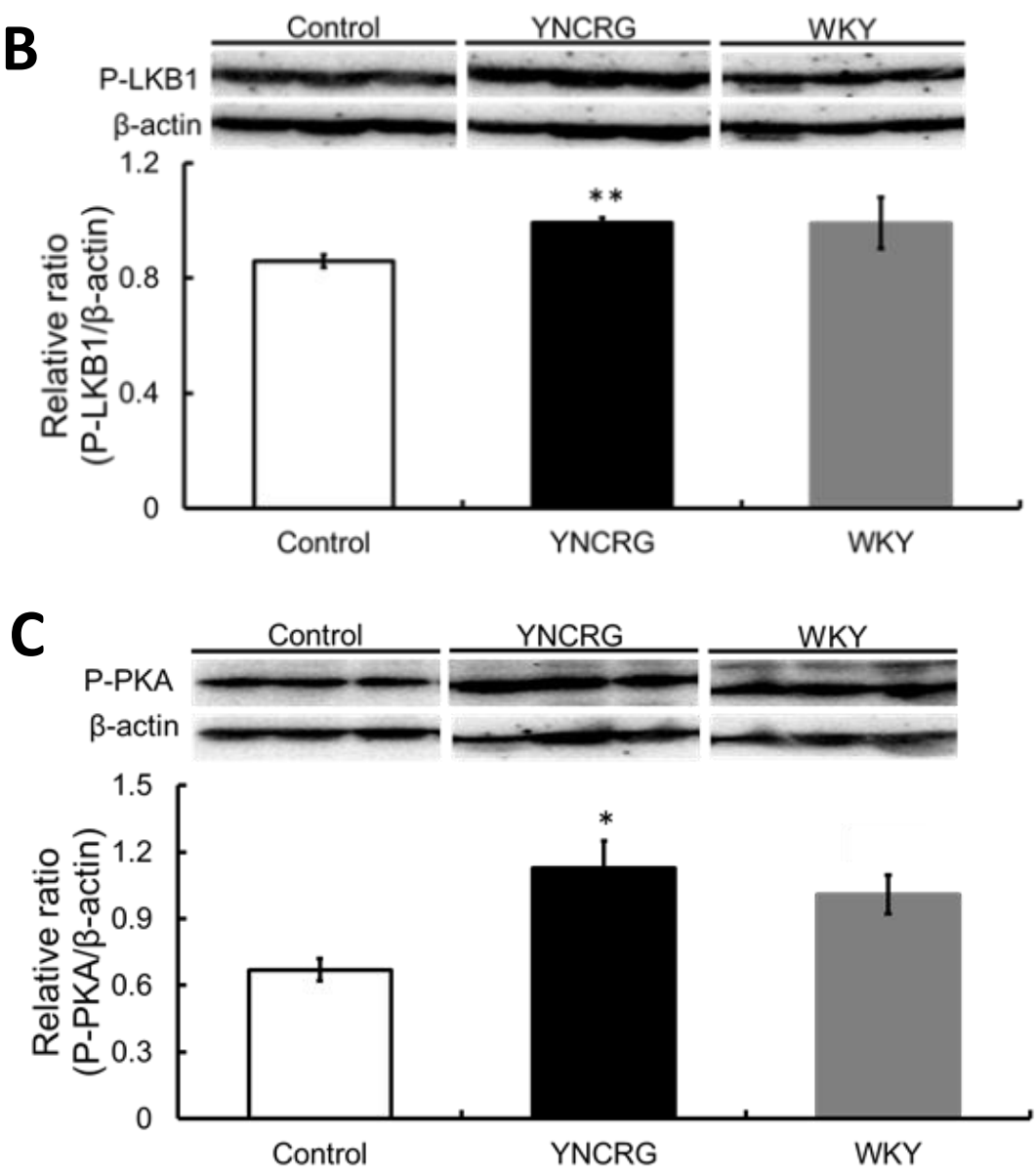


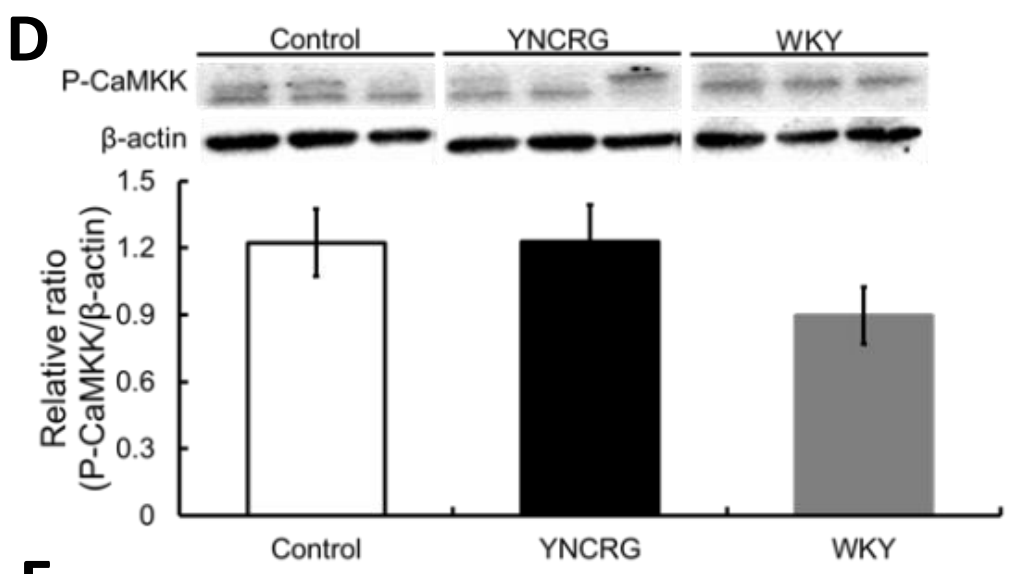

E
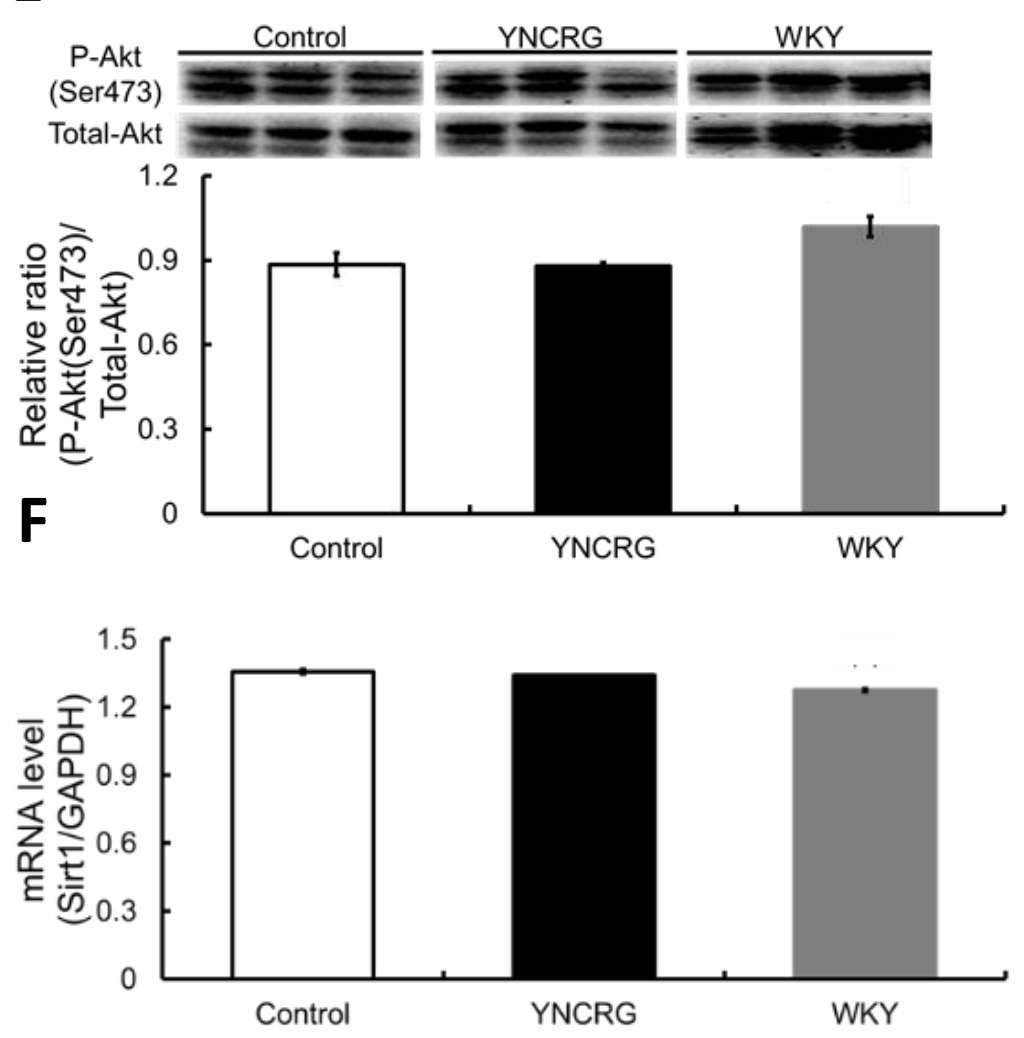

Figure 6 Effect of YNCRG on the expression of lipid metabolism-related proteins and genes in the epididymal fat in SHRCP and WKY rats.

Eight-week-old male SHRCP and WKY rats were treated daily with YNCRG or water for eight weeks. AMPK, LKB1, PKA, CaMKK, Akt (Ser473) and Sirt1 (A-F). Data are expressed as the mean \pm S.E.M.; $n=9,8,8$ in control, YNCRG and WKY groups, respectively, ${ }^{*} \mathrm{P}<0.05,{ }^{*} * \mathrm{P}<0.01$ vs. control group.

\subsection{Effects of YNCRG on the Expression of AMPK Downstream Factors of Lipid Metabolism- Related Proteins and Genes in the Epididymal Fat in SHRCP and WKY Rats}

We also investigated downstream factors of AMPK, i.e., ACC, FAS, HSL, C/EBP $\alpha, C / E B P \beta$ and PPAR $\gamma$. The mRNA level of FAS and protein levels of C/EBP $\alpha, C / E B P \beta$, and PPAR $\gamma$ did not change in the two groups (Fig. 7A, B, C, D). However, the phosphorylation levels of ACC and HSL were significantly increased in the YNCRG group (Fig. 7E, F). 
A

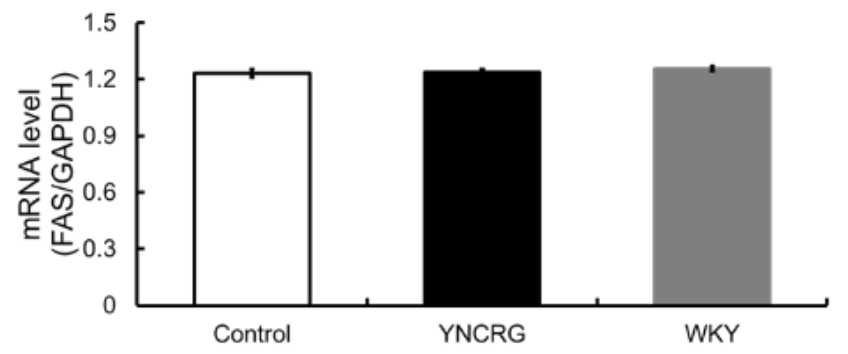

B

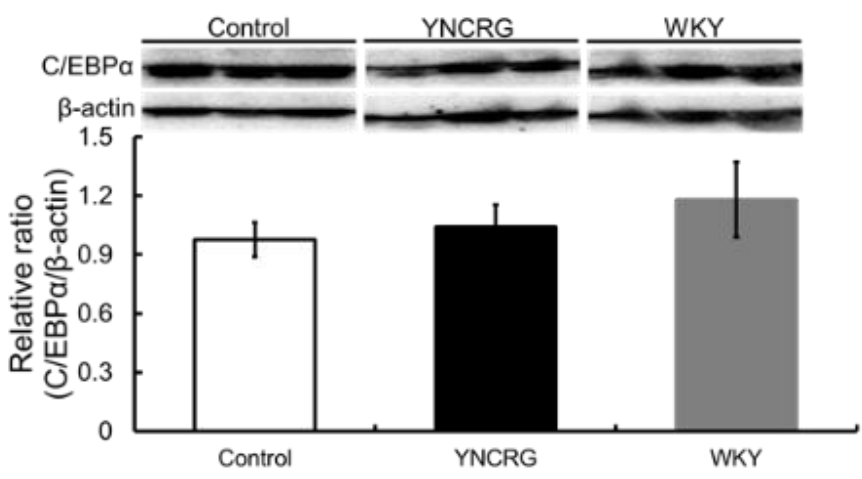

C

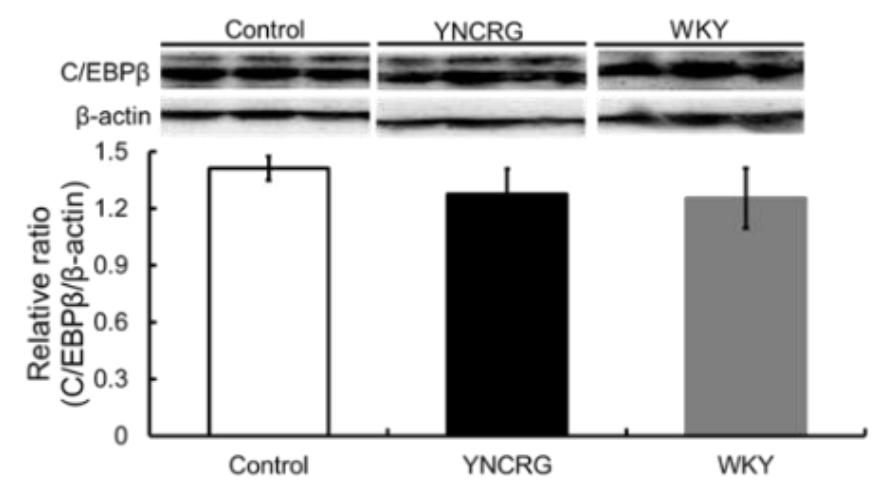

D

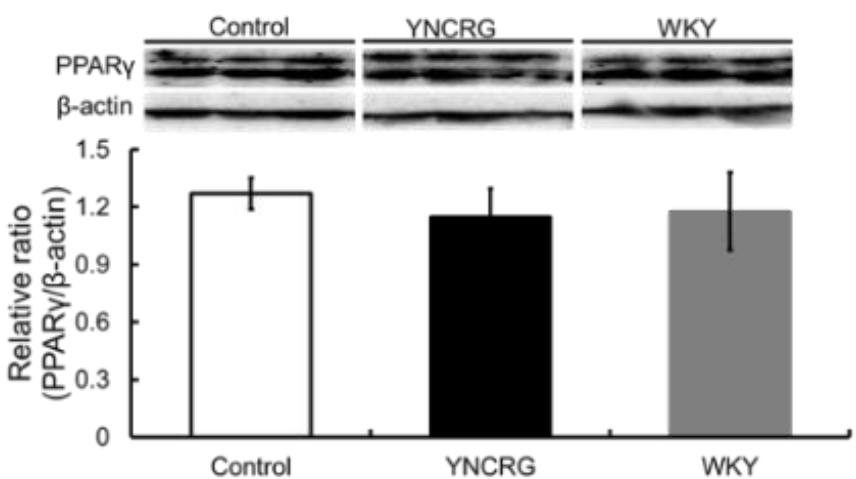

E

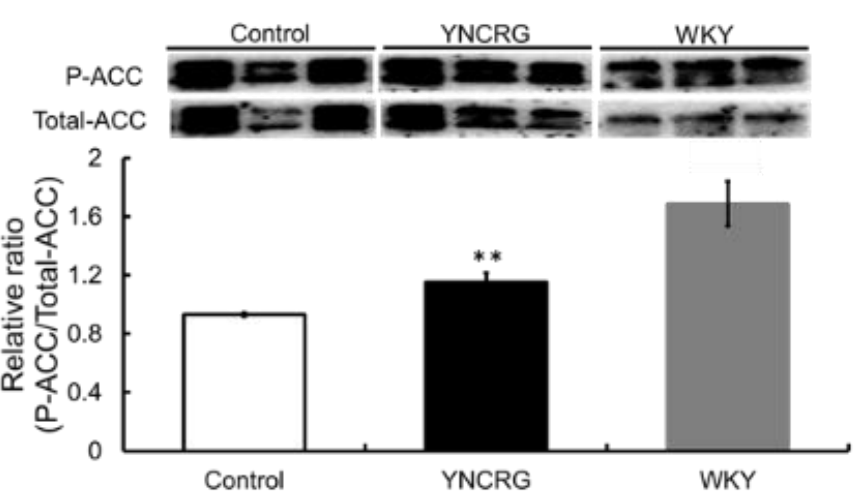




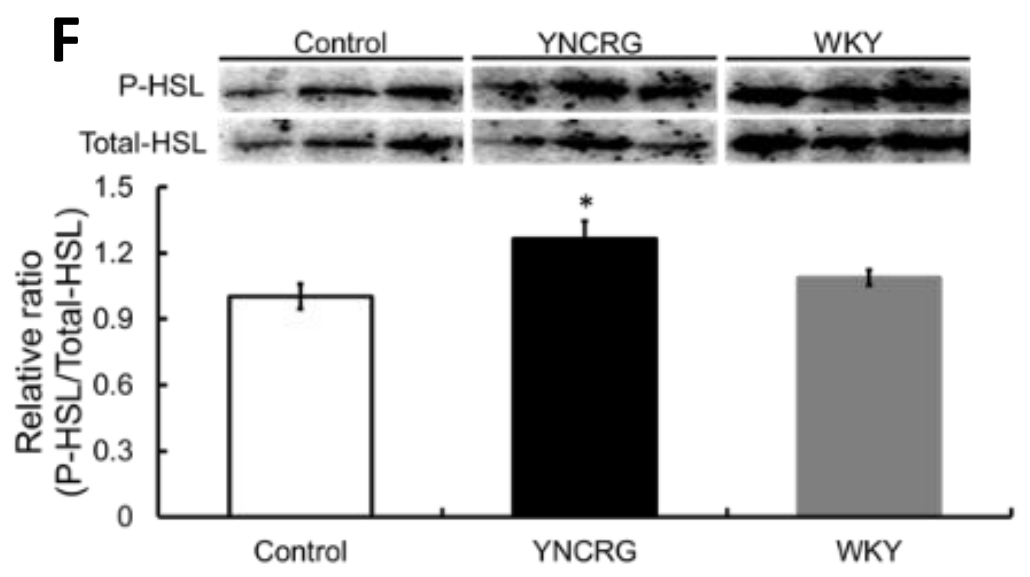

Figure 7 Effects of YNCRG on the expression of AMPK downstream factors of lipid metabolism-related proteins and genes in the epididymal fat in SHRCP and WKY rats.

Eight-week-old male SHRCP and WKY rats were treated daily with YNCRG or water for eight weeks. FAS, C/EBP $\alpha, C / E B P \beta, P P A R \gamma, A C C$ and HSL (A-F). Data are expressed as the mean \pm S.E.M.; $n=9,8,8$ in control, YNCRG, and WKY groups, respectively, ${ }^{*} \mathrm{P}<0.05,{ }^{*} \mathrm{P}<0.01$ vs. control group.

\subsection{Identification of Main Constituents in YNCRG by LC-ESI-MS Analysis}

The chemical constituents in YNCRG were analyzed using LC-ESI method. The total ion chromatogram (TIC) of the sample solution in positive ion mode is shown in Figure 8 . Based on the interpretation of the MS fragmentation patterns and also a comparison of those with available standard compounds, seven peaks were tentatively identified in the LC-MS chromatogram (Fig. 9). Peak 1 (chlorogenic acid), peak 5 (scandoside methyl ester), and peak $6((+)$-pinoresinol) were considered originally from Tochu leaves or Noni, and peak 2 (genistin acetate) was from red koji rice, while peaks 3 (mangiferin), peak 4 (dehydroconiferyl alcohol) and peak 7 (6ahydroxyadoxoside) were considered as constituents from Noni.

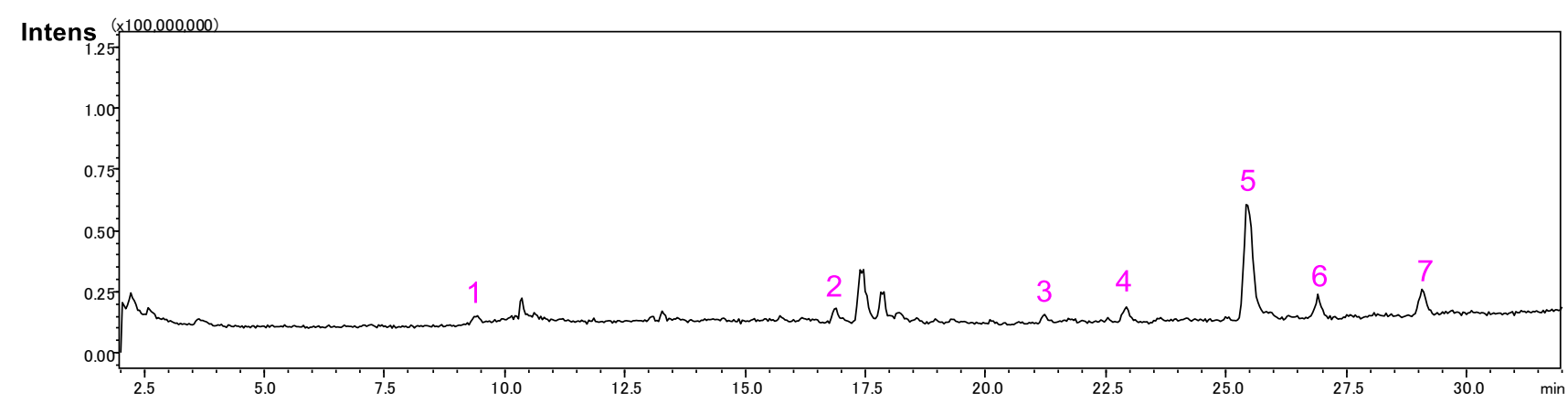

Figure 8 Total ion chromatogram of YNCRG by LC-ESI-MS in positive ion mode. Note. Two peaks at $17.5 \mathrm{~min}$ were from the background and not identified. 

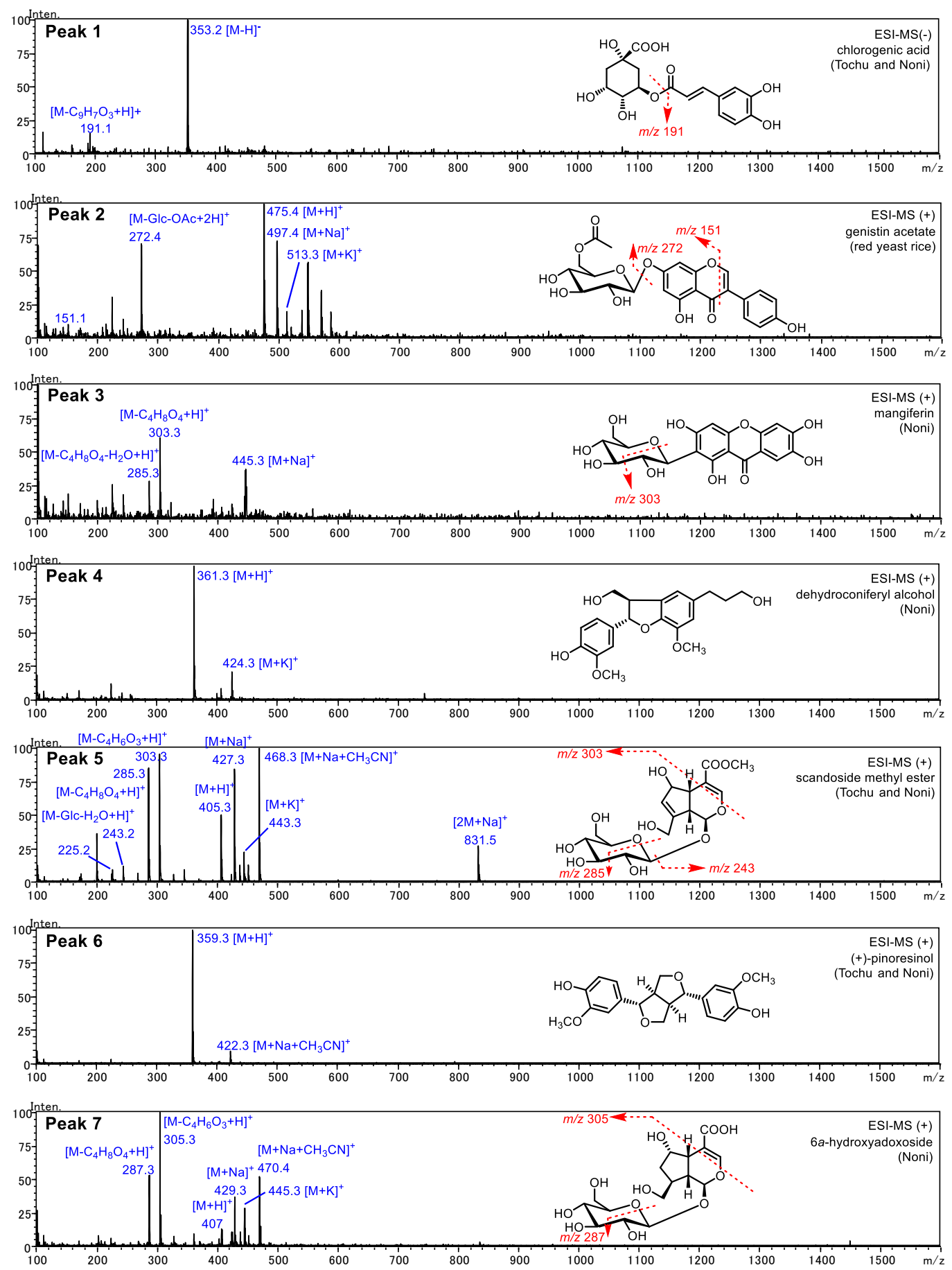

Figure 9 LC-ESI-MS spectra and proposed fragmentation pathways of peak 1-7. (-) ESI-MS spectrum of peak 1 and (+) ESI-MS spectra of peaks 2-7.

\section{Discussion}

The main result of this study was that YNCRG inhibited body weight gain by the reduction in body fat mass via appetite suppression and an improvement in the lipid metabolic pathway in SHRCP rats. The underlying mechanisms were identified as increased expression of POMC in the hypothalamus, inhibition of lipogenesis, and promotion of lipolysis in the adipose tissue. 
Two signaling pathways, leptin signaling, and insulin signaling, regulate POMC expression. Leptin is a key regulator of feeding and long-term energy homeostasis that acts on discrete neuronal pathways to reduce food intake and body fat content [32]. One mechanism involved in leptin regulation of cellular function is the activation of JAK2 and STAT3 signaling [33, 34], and this appears to play a major role in the energy homeostasis mechanism. In this study, we showed that YNCRG does not phosphorylate JAK2, which is involved in leptin signaling. These results suggest that the change in POMC neuronal expression is not related to leptin signaling in YNCRG treatment.

Akt is the central enzyme in insulin signaling, and Akt activity is regulated by various factors such as IR-IRS1 signaling and mTOR signaling. We clarified that YNCRG increased the ratio of phosphorylated Akt (Ser473) in the hypothalamus of SHRCP rats. YNCRG did not affect the ratio of IRS1 phosphorylation, so we examined Akt-mTOR signaling as another possible pathway. mTOR, a phosphorylation target of Akt, was stimulated and showed increased expression of amino acids [35]. mTOR is the catalytic subunit of the mTORC1 and mTORC2 complexes. If mTORC2 phosphorylation increases, Akt phosphorylation, and FoxO1 phosphorylation also increase, and this, in turn, increases POMC expression. On the other hand, mTORC1 activity causes a negative feedback loop in the insulin signaling pathway. Activation of mTORC1 leads to the phosphorylation of downstream S6K, which participates in several processes, including protein synthesis and proliferation $[15,36]$. Further, increased activity of the mTOR-S6K signaling pathway leads to serine phosphorylation of IRS1, creating a negative feedback loop in insulin signaling that attenuates insulin sensitivity $[37,38]$. In our study, we considered that YNCRG stimulated mTORC2 phosphorylation because phosphorylation of factors involved in signaling through mTORC1, such as S6K and IRS1, did not change in the two groups. We concluded that YNCRG induced appetite suppression by activation of the mTORC2-Akt FoxO1-POMC signaling pathway in the hypothalamus of SHRCP rats (Fig. 10).

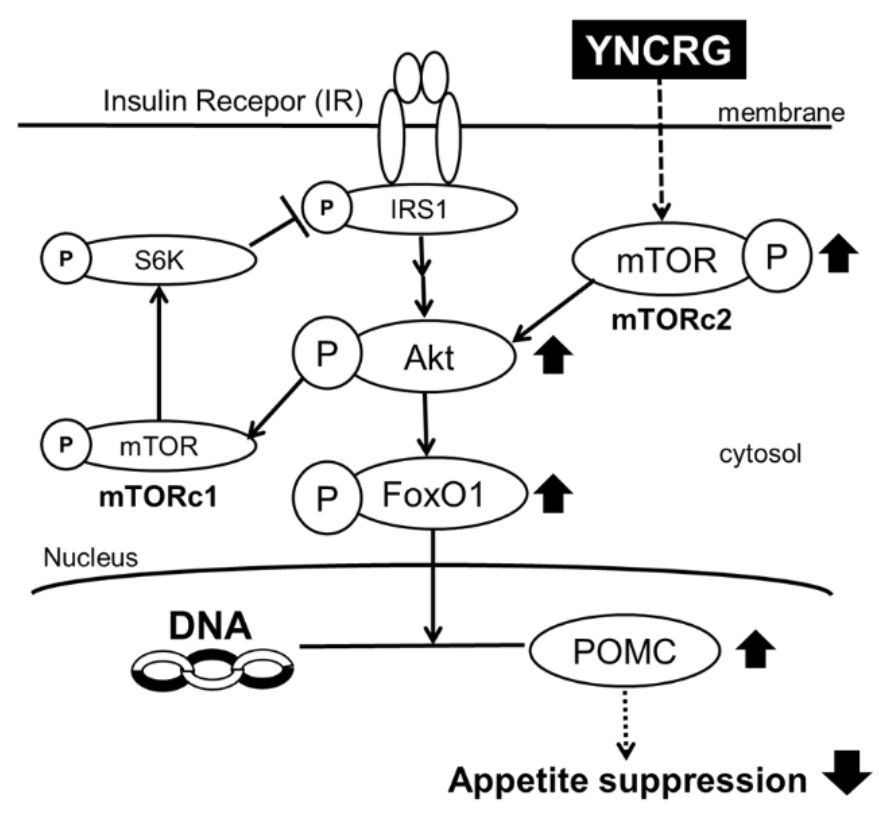

Figure 10 Signaling of appetite suppression in the hypothalamus of the YNCRG-treated rats. 
YNCRG treatment for eight weeks also led to body fat mass reduction. To understand the mechanism of this reduction, we investigated the expression levels of lipid metabolism-related proteins and genes in adipose tissue of SHRCP and WKY rats. LKB1/AMPK signaling is known to be involved in lipid metabolism [39]. In this study, AMPK, the main enzyme in the lipid metabolic pathway, and LKB1 were significantly phosphorylated in the YNCRG group. Moreover, PKA, an upstream factor of LKB1, was affected by YNCRG treatment, suggesting that YNCRG can promote lipid metabolism through the PKA-LKB1-AMPK pathway. A previous study reported that AMPK is also activated by an upstream factor, CaMKK [40]. The activation of AMPK in the YNCRG group did not affect the phosphorylation of CaMKK, indicating that activation of AMPK by YNCRG was not dependent on CaMKK. YNCRG also affected the lipogenesis-related protein ACC and lipolysis protein HSL but did not upregulate the level of $C / E B P \alpha, C / E B P \beta$, or PPAR $\gamma$. These results indicate that YNCRG inhibited ACC and promoted HSL expression, suggesting that YNCRG is involved in both lipogenesis inhibition and lipolysis promotion. We suggest that YNCRG may reduce body fat mass by activation of lipid metabolism, inhibition of lipogenesis, and promotion of lipolysis via AMPK activation in adipose tissue (Fig. 11).

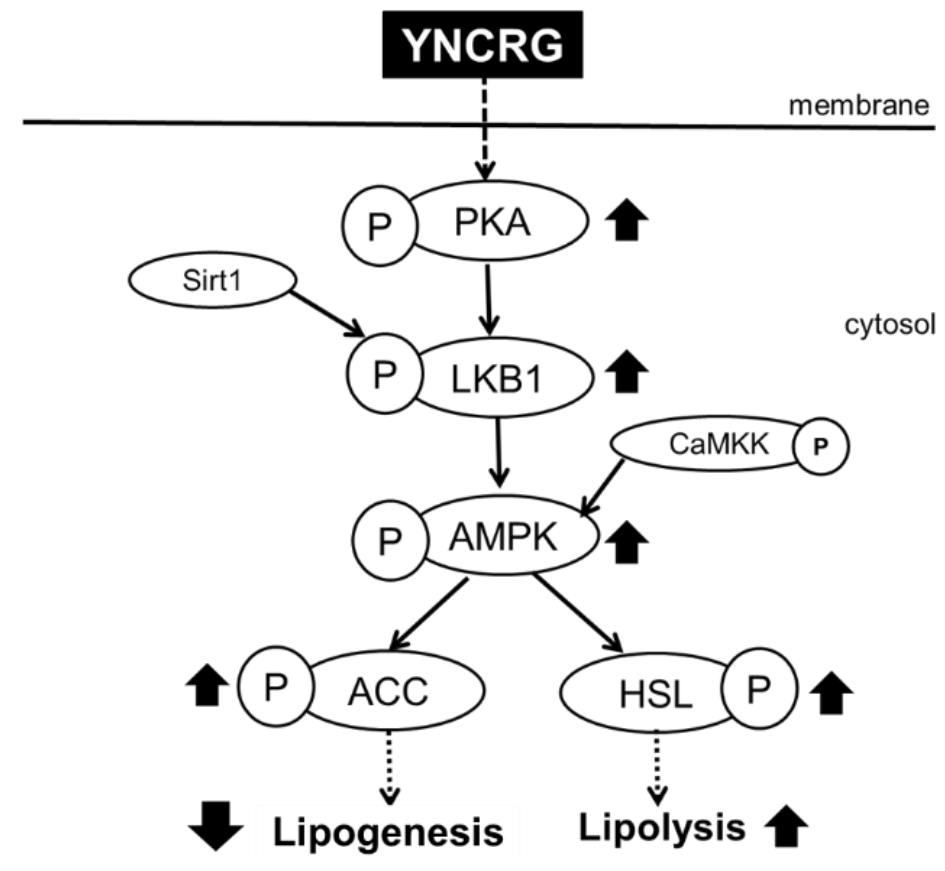

Figure 11 Signaling of fat mass reduction in the adipose tissue of YNCRG-treated rats.

YNCRG inhibited body weight gain. The mechanisms involved are appetite suppression in the hypothalamus and reduction in body fat mass due to improvement in the lipid metabolic pathway caused by lipogenesis inhibition and lipolysis promotion in adipose tissue in SHRCP rats.

YNCRG contains five extracts and chemical compounds from herbal plants. Previously, we reported that L-Cit reduced obesity via appetite suppression using high-fat diet-fed Sprague Dawley (SD) rats [11]. Furthermore, the regulation of POMC expression through GABA is essential for proper energy balance [12]. YNCRG contains L-Cit and GABA, both of which are thought to be involved in body weight gain reduction effect via appetite suppression. Regarding other compounds, Eucommia ulmoides has demonstrated anti-hypertensive, anti-hyperlipidemic, 
and anti-obesity effects [41-45] and Monascus purpureus also showed an anti-obesity effect via the inhibition of differentiation and lipogenesis in high-fat diet-fed obese rats [6].

Also, some studies have demonstrated that the principal bioactive compounds from Morinda citrifolia have potential beneficial effects in obesity and obesity-related metabolic dysfunction [46]. It is suggested that components Eucommia ulmoides, Monascus purpureus, and Morinda citrifolia may be involved in a bodyweight gain suppressive effect due to body fat mass reduction via an improvement in the lipid metabolic pathway.

However, there are many unknown mechanisms regarding the detailed interactions of YNCRG, i.e., a mixture of five components, so we plan to investigate the detailed mechanism in future studies.

\section{Conclusions}

We elucidated the mechanism of action and possible synergistic effects of YNCRG on MetS through amelioration of appetite suppression and lipid metabolism in SHRCP rats.

In our study, AST and ALT levels, which indicate liver function, were not affected. Besides, YNCRG had no negative effect on bowel movements or activities. Moreover, we observed the dissected stomach and intestines, and could not find any abnormal features. Therefore, we consider that the YNCRG dose used in our study has no toxicity or side effects.

Further studies are planned. YNCRG may become a new treatment option for MetS, especially due to its inhibition of body weight gain due to body fat mass reduction via appetite suppression and improvement in the lipid metabolic pathway. It can be used in clinical practice in the future.

\section{Abbreviations}

MetS: metabolic syndrome

POMC: proopiomelanocortin

JAK2: janus kinase 2

STAT3: signal transducer and activator of transcription 3

IR: insulin receptor

IRS1: insulin receptor substrate 1

Akt: protein kinase $B$

FoxO1: forkhead box 01

AMPK: AMP-activated protein kinase

CaMKK: Calcium-calmodulin/dependent protein kinase

LKB1: liver kinase B1

PPAR $\gamma$ : peroxisome proliferator-activated receptor $\gamma$

C/EBP: CCAAT/enhancer-binding protein

SREBP-1c: sterol regulatory element binding protein $1 \mathrm{c}$

ACC: acetyl-CoA carboxylase

FAS: fatty acid synthase

Sirt1: Sirtuin 1

HSL: hormone-sensitive lipase

SHRCP: SHR.Cg-Lepr ${ }^{\mathrm{cP}} / \mathrm{NDmcr}$

L-Cit: L-Citrulline 
GABA: gamma-aminobutyric acid WKY: Wister Kyoto OGTT: oral glucose tolerance test NFBG: non-fasting blood glucose TC: total cholesterol

TG: triglyceride

AST: aspartate aminotransferase

ALT: alanine aminotransferase

ALB: albumin

BUN: blood urea nitrogen

Cre: creatinine

UA: uric acid

TP: total protein

UN: urine nitrogen

SBP: Systolic blood pressure

DBP: diastolic blood pressure

FBG: fasting blood glucose

AUC: area under the curve

BIA: bioelectrical impedance analysis

PVDF: polyvinylidene difluoride

mTOR: mammalian target of rapamycin

S6K: S6 kinase

PKA: protein kinase $A$

Agrp: agouti related protein

GAPDH: glyceraldehyde-3-phosphate dehydrogenase

Sirt1: sirtuin1

SD: Sprague Dawley

\section{Acknowledgments}

Not applicable.

\section{Author Contributions}

Author contributions are as follows: study design, MK, MH, TL and MG; experiments, MK, MH, PT, DL and LW; data analysis, MK; providing the five plant materials, $L W, Z H, Y Z, T N$ and $M N$; and writing of the manuscript, MK, TL and MG.

\section{Funding}

Not applicable.

\section{Competing Interests}

The authors have declared that no competing interests exist. 


\section{References}

1. Wang $T$, Kusudo $T$, Takeuchi $T$, Yamashita $Y$, Kontani $Y$, Okamatsu $Y$, et al. Evodiamine inhibits insulin-stimulated mTOR-S6K activation and IRS1 serine phosphorylation in adipocytes and improves glucose tolerance in obese/diabetic mice. PLoS One. 2013; 8: e83264.

2. Kopelman PG. Obesity as a medical problem. Nature. 2000; 404: 635-643.

3. Susanti VY, Sasaki T, Yokota - Hashimoto H, Matsui S, Lee YS, Kikuchi O, et al. Sirt1 rescues the obesity induced by insulin-resistant constitutively-nuclear FoxO1 in POMC neurons of male mice. Obesity. 2014; 22: 2115-2119.

4. Park HK, Ahima RS. Leptin signaling. Prime Rep. 2014; 6: 73.

5. White MF. IRS proteins and the common path to diabetes. Am J Physiol Endocrinol Matab. 2002; 283: E413-E422.

6. Zoncu R, Efeyan A, Sabatini DM. mTOR: From growth signal integration to cancer, diabetes and ageing. Nat Rev Mol Cell Biol. 2011; 12: 21-35.

7. Kim JE, Chen J. Regulation of peroxisome proliferation-activated receptor-activity by mammalian target of rapamycin and amino acid in adipogenesis. Diabetes. 2004; 53: 27482756.

8. Liu H, Wang J, Liu M, Zhao H, Yaqoob S, Zheng M, et al. Antiobesity effects of ginsenoside Rg1 on 3T3-L1 preadipocytes and high fat diet-induced obese mice mediated by AMPK. Nutrients. 2018; 10: 830.

9. Kou R, Sartoretto J, Michel T. Regulation of Rac1 by simvastatin in endothelial cells: Differential roles of AMP-activated protein kinase and calmodulin-dependent kinase kinasebeta. J Biol Chem. 2009; 284: 14734-14743.

10. Hardie DG. The AMP-activated protein kinase pathway-new players upstream and downstream. J Cell Sci. 2004; 117: 5479-5487.

11. Mota de Sa P, Richard AJ, Hang H, Stephens JM. Transcriptional regulation of adipogenesis. Compr Physiol. 2017; 7: 635-674.

12. Smith $U$, Kahn BB. Adipose tissue regulates insulin sensitivity: Role of adipogenesis, de novo lipogenesis and novel lipids. J Intern Med. 2016; 280: 465-475.

13. Fujikawa T, Hirata $T$, Wada A, Kawamura N, Yamaguchi $Y$, Fujimura $K$, et al. Chronic administration of Eucommia leaf stimulates metabolic function of rats across several organs. Br J Nutr. 2010; 104: 1868-1877.

14. Zheng J, Liu D, Zhao SQ, Su J, Yan QP, Chen L, et al. Enzymatic extraction and antibacterial activity of aucubin from Eucommia ulmoides leaves. J Chinese Med Mater. 2012; 35: 304-306.

15. Hung MY, Fu TYC, Shih PH, Lee CP, Yen GC. Du-Zhong (Eucommia ulmoides Oliv.) leaves inhibits CCl4-induced hepatic damage in rats. Food Chem Toxicol. 2006; 44: 1424-1431.

16. Luo LF, Wu WH, Zhou YJ, Yan J, Yang GP, Ouyang DS. Antihypertensive effect of Eucommia ulmoides Oliv. Extracts in spontaneously hypertensive rats. J Ethnopharmacol. 2010; 129: 238-243.

17. Ma J, Li Y, Ye Q, Li J, Hua Y, Ju D, et al. Constituents of red yeast rice, a traditional Chinese food and medicine. J Agric Food Chem. 2000; 48: 5220-5225.

18. Yu HC, Hsu JL, Chang Cl, Tan FJ. Antioxidant properties of porcine liver proteins hydrolyzed using Monascus purpureus. Food Sci Biotechnol. 2017; 26: 1217-1225. 
19. Lee CL, Wen JY, Hsu YW, Pan TM. Monascus-fermented yellow pigments monascin and ankaflavin showed anti-obesity effect via the suppression of differentiation and lipogenesis in obese rats fed a high-fat diet. J Agric Food Chem. 2013; 61: 1493-1500.

20. Whistler WA. Traditional and herbal medicine in the Cook Islands. J Ethnopharmacol. 1985; 13: $239-280$

21. Wang MY, West BJ, Jensen CJ, Nowicki D, Su C, Palu AK, et al. Morinda citrifolia (Noni): A literature review and recent advances in Noni research. Acta Pharmacol Sin. 2002; 23: 11271141

22. Singh YN, Ikahihifo T, Panuve M, Slatter C. Folk medicine in Tonga. A study of the use of herbal medicines for obstetric and gynaecological conditions and disorders. J Ethnopharmacol. 1984; 12: 305-329

23. Solomon IN. Tahitian Noni Juice: The tropical fruit with 101 medical uses. Salt Lake City: Woodland Publishing; 1999.

24. Rimando A. Perkins-Veazie P. Determination of citrulline in watermelon rind. J Chromatogr A. 2005; 1078: 196-200.

25. Kudo,M, Yoshitomi H, Momoo M, Suguro S, Yamagishi Y, Gao M. Evaluation of the effects and mechanism of L-citrulline on anti-obesity by appetite suppression in obese/diabetic KK-Ay mice and high-fat diet fed SD rats. Biol Pharm Bull. 2017; 40: 524-530.

26. Ito $Y$, Banno R, Shibata M, Adachi K, Hagimoto S, Hagiwara D. GABA type B receptor signaling in proopiomelanocortin neurons protects against obesity, insulin resistance, and hypothalamic inflammation in male mice on a high-fat diet. J Neurosci. 2013; 33: 1716617173.

27. Kawai K, Sakairi T, Harada S, Shinozuka J, Ide M, Sato H, et al. Diet modification and its influence on metabolic and related pathological alterations in the SHR/NDcmcr-cp rat, an animal model of the metabolic syndrome. Exp Toxicol Pathol. 2012; 64: 333-338.

28. Nagase M, Yoshida S, Shibata S, Nagase T, Gotoda T, Ando K, et al. Enhanced aldosterone signaling in the early nephropathy of rats with metabolic syndrome: Possible contribution of fat-derived factors. J Am Soc Nephrol. 2006; 17: 3438-3446.

29. Li L, Yoshitomi H, Wei Y, Qin L, Zhou J, Xu T, et al. Tang-Nai-Kang alleviates pre-diabetes and metabolic disorders and induces a gene expression switch toward fatty acid oxidation in SHR. Cg-Leprcp/NDmcr Rats. PLoS One. 2015; 10: e0122024.

30. Smith DL, Johnson M, Nagy T. Precision and accuracy of bioimpedance spectroscopy for determination of in vivo body composition in rats. Int J Body Compos Res. 2009; 7: 21-26.

31. Liu Q, Li W, Nagata K, Fu H, Okada S, Tanabe I, et al. Isolation, structural elucidation, and liquid chromatography-massspectrometry analysis of steroidal glycosides from Polygonatum odoratum. J Agric Food Chem. 2018; 66: 521-531.

32. Morrison CD, Morton GJ, Niswender KD, Gelling RW, Schwartz MW. Leptin inhibits hypothalamic Npy and Agrp gene expression via a mechanism that requires phosphatidylinositol 3-OH-kinase signaling. Am J Physiol Endocrinol Metab. 2005; 289: 10511057.

33. Banks AS, Davis SM, Bates SH, Myers MG. Activation of downstream signals by the long form of the leptin receptor. J Biol Chem. 2000; 275: 14563-14572.

34. Tartaglia L. The leptin receptor. J Biol Chem. 1997; 272: 6093-6096. 
35. Tremblay F. Matette A. Amino acids and insulin signaling via the mTOR/p70S6 kinase pathway: A negative feedback mechanism leading to insulin resistance in skeletal muscle cells. J Biol Chem. 2001; 276: 38052-38060.

36. Shima $H$, Pende $M$, Chen $Y$, Fumagalli $S$, Thomas $G$, Kozma SC. Disruption of the p70(s6k)/p85(s6k) gene reveals a small mouse phenotype and a new functional S6 kinase. EMBO J. 1998; 17: 6649-6659.

37. Um SH, Frigerio $F$, Watanabe $M$, Picard $F$, Joaquin $M$, Sticker $M$, et al. Absence of S6K1 protects against age-and diet-induced obesity while enhancing insulin sensitivity. Nature. 2004; 431: 200-205.

38. Um SH, D'Alessio D, Thomas G. Nutrient overload, insulin resistance, and ribosomal protein S6 kinase 1, S6K1. Cell Metab. 2006; 3: 393-402.

39. Mirouse V, Billaud M. The LKB1/AMPK polarity pathway. FEBS Lett. 2011; 585: 981-985.

40. Chen $Q$, Liu M, Yu H, Li J, Wang S, Zhang Y, et al. Scutellaria baicalensis regulates FFA metabolism to ameliorate NAFLD through the AMPK-mediated SREBP signaling pathway. J Nat Med. 2018; 72: 655-666.

41. Medica CM. Jiangsu New Medical College. Shanghai: Shanghai Science and Technology Publishing House; 1977.

42. Fujikawa T, Hirata T, Wada A, Kawamura N, Yamaguchi Y, Fujimura K, et al. Chronic administration of Eucommia leaf stimulates metabolic function of rats across several organs. Br J Nutr. 2010; 104: 1868-1877.

43. Namba T. Studies on Tu-Chung leaves (I), Pharmacological effects of the water extract in vivo. J Trad Med. 1986; 3: 89-97.

44. Metori K, Ohashi S, Takahashi S, Tamura T. Effects of du-zhong leaf extract on serum and hepatic lipids in rats fed a high-fat diet. Biol Pharm Bull. 1994; 17: 917-920.

45. Hosoo S, Koyama M, Watanabe A, Ishida R, Hirata T, Yamaguchi Y, et al. Preventive effect of Eucommia leaf extract on aortic media hypertrophy in Wistar-Kyoto rats fed a high-fat diet. Hypertens Res. 40; 2017: 546-551.

46. Inada AC, Figueiredo PS, Santos-Eichler RAD, Freitas KDC, Hiane PA, Castro APD, et al. Morinda citrifolia Linn. (Noni) and its potential in obesity-related metabolic dysfunction. Nutrients. 2017; 9: 540. 


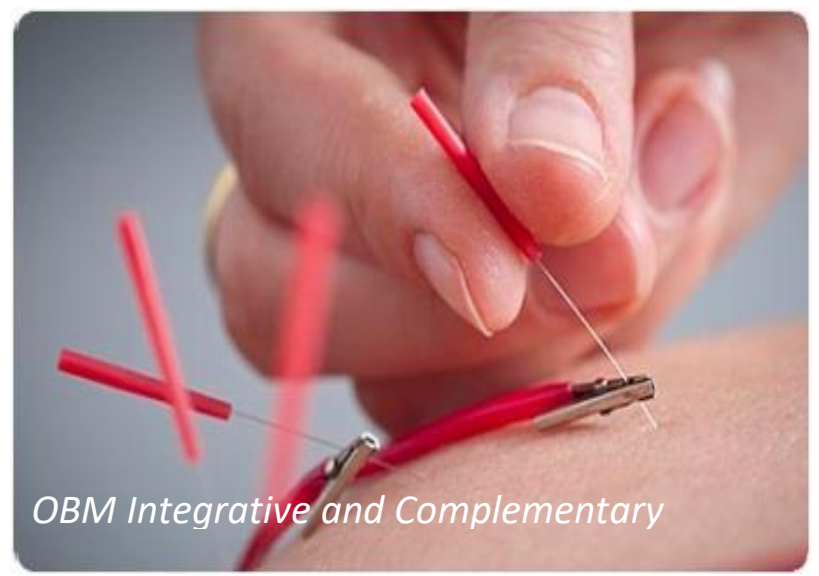

Enjoy OBM Integrative and Complementary Medicine by:

1. Submitting a manuscript

2. Joining in volunteer reviewer bank

3. Joining Editorial Board

4. Guest editing a special issue

For more details, please visit:

http://www.lidsen.com/journals/icm 
Communication

\title{
Child Life Specialists in Pediatric Hospital Care
}

Kokila Jeyamurugan MD *, Ratna B Basak MD, FRCPCH

Department of Pediatrics, Brookdale University Hospital Medical Centre, Brooklyn, NY, USA; EMails: kjeyamur@bhmcny.org; ratnabimalbasak@gmail.com

* Correspondence: Kokila Jeyamurugan; E-Mail: kjeyamur@bhmcny.org

Academic Editor: Leila Kozak

Special Issue: Integrative Therapies in Palliative Care

OBM Integrative and Complementary Medicine Received: May 12, 2020

2020, volume 5 , issue 3

Accepted: July 15, 2020

doi:10.21926/obm.icm.2003034

Published: July 17, 2020

\begin{abstract}
Child life specialists (CLS) are trained providers who form part of a pediatric multidisciplinary and pediatric palliative care team. Their role is invaluable to mitigate the stress and anxiety of children during hospitalization. They may use various strategies in children like play, art and music therapy and pet therapy, to help self-express and cope with painful procedures.

We present a brief narrative on CLS with a case of a 10- year- old Hispanic boy who had metastatic osteosarcoma.

The case illustration is from a prior institute that one of the coauthors was associated with.
\end{abstract}

\section{Keywords}

Pet therapy; child life specialist; pediatric palliative care

\section{Introduction}

In the United States, more than 500,000 children are coping with life-threatening conditions every year [1]. Many of them are admitted for acute conditions, and a few for end of life care.

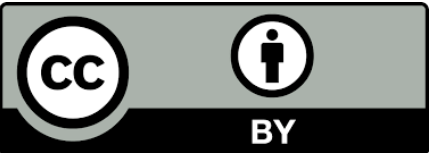

(C) 2020 by the author. This is an open access article distributed under the conditions of the Creative Commons by Attribution License, which permits unrestricted use, distribution, and reproduction in any medium or format, provided the original work is correctly cited. 
Hospitalization in children is a great source of stress; they are not only deprived of their familiar and comforting environment, but may have to undergo various painful procedures and treatments leading to significant physical and emotional distress [2]. Pediatric palliative care consults help in mitigating many such issues to provide good experiences during these times.

Pediatric Palliative care has an integrated interdisciplinary approach, with the goal of enhancing the quality of life, minimizing the suffering of children and their families facing serious illnesses by embracing the physical, emotional, psychosocial and spiritual elements [3]. Palliative care should be initiated when a serious illness is diagnosed and continued throughout the course, regardless of the outcome [3]. The members of the palliative team may vary in hospitals and usually include physicians, nurse practitioners, nurses, social workers, chaplains, bereavement coordinators and child life specialists (CLS) [4]. Most pediatric hospitals across United States have child life specialists with a commonly accepted standard ratio of 1 CLS to 15 patients. However, the staffing may be individualized based on the severity and acuity of illness of the patients served [5].

CLS are professionals who undergo training and develop expertise in helping children and their families cope with the stress and challenge during an illness needing hospitalization [6]. Armed with a background in child development, psychology, and counselling, CLS work closely with children and families in medical settings, help them navigate through the challenges of hospitalization, offer emotional support, educate and prepare children using age appropriate strategies to better understand a medical event or procedure. They collaborate with parents and the palliative care team to meet the distinct needs of the patient in a family centered model of care $[5,7]$. CLS engage themselves in a variety of hospital settings, such as inpatient units, ambulatory clinics, intensive care units, emergency departments and at times in homes of terminally sick children [5, 7]. Apart from providing developmentally appropriate therapeutic play strategies like music, art and reading activities to help reduce anxiety and improve coping skills, additional novel programs like animal assisted therapy and therapeutic clowning are now being employed for pediatric patients of all ages [5].

The story of CLS began early in the 1920s when early child life professionals were identified as "play ladies" as they considered play as a means to promote optimal development and minimize the adverse effects of hospitalization for children and their families [8]. Today the field has grown exponentially and has proven to be an excellent career choice [6]. The requirements of a certified child life specialist (CCLS), include a minimum of a bachelor's degree in child life, child development or a closely related field, with a successful completion of a 480 to 600 hours of child life internship under the direct supervision of a CCLS and passing the child life professional certification examination [5].

A recent research on parental perception of CLS revealed that most parents had no prior knowledge of the role of CLS but were highly satisfied with their experience with them [9]. Another scholarly article found that child-life interventions had a positive effect on family and staff satisfaction and enhanced the child's perception of pain and distress [10].

We present a case that emphasize the role of CLS in assisting the pediatric and palliative care team to manage a child with life limiting illness by employing animal assisted (pet) therapy. 


\section{Case Description}

We describe a case seen by one of the coauthors at an institution with past affiliation. A 10year old boy diagnosed with metastatic osteosarcoma which had spread to his lungs, bones and liver was admitted for yet another round of chemotherapy and pain management. The parents were from Dominican Republic and knew little English. The child was always quiet and avoided all interactions with the providers. It was difficult to understand how much the family knew about his prognosis. It was also impossible to gauge what the child knew about his illness and if the parents wanted him to know of his terminal condition.

The CLS used several strategies to bridge the gap. They deployed a CLS working in an outpatient setting who was fluent in Spanish to visit the family every day. The CLS was able to build a rapport and identify that the patient had a pet dog back home who he was very attached with. She contacted an organization which specializes in pet therapy. Soon a pet dog was brought to the hospital to visit our patient every day. The child's transition was dramatic - he became more interactive and social, appeared relaxed and even took part in the medical clown show. The pet visit helped reduce his anxiety and boosted his mood and appetite. He appeared to be more receptive to treatment and ready to take part in his care. It allowed the child and family to relax and bond with each other. The positive response in child's behavior gave a sense of relief and satisfaction to the parents. It was an opportunity to temporarily escape the medical decisions and procedures. Perhaps, 'Pet therapy [2]' allowed him to express his love for animals and this became a source of comfort for the patient and the family during his final days.

CLSs made every effort to build a good rapport and trust with the patient and the family. After assessing the patient and the family's needs and coping skills, CLSs worked with other team members to provide support for the plan of care. The factors that had an influence on optimizing the quality of life such as patient's temperament, coping and cognitive abilities, parental anxiety and involvement were considered. Interpreter services were used as appropriate to overcome language barrier and ensure effective communication with the family facilitating family-centered care model [5].

CLSs helped in normalizing the hospital environment for our patient, making it appear as friendly and comfortable as possible. The child's favorite articles from home were left in his room, especially his blanket, favorite toy and his own pajamas. His hospital room walls were decorated with posters and photographs of family members that made him feel happy and at home. In addition to working with our patient, CLSs encouraged support for the family. Through appropriate communication they made parents and siblings understand their responsibilities and roles. They engaged the parents in the care of the child and gave them guidance on helping the child during treatments and procedures. This helped our patient feel less anxious and he was able to cope more effectively. CLSs used play therapy because it allowed the child to express himself and use his imaginations, which provided opportunities to learn, explore and better understand the feelings and the environments around them [11]. They also helped our patient to maintain relationships and feel connected with his peers through regular video calls. These interventions indeed, helped the child to get well adapted to the hospital environment. Family activities like 'Friday movie nights' were encouraged to have sense of normal life in the hospital setting. CLSs encouraged sibling support, allowing them to visit when possible and spend some time creating art, reading books and having fun together. CLSs prepared the siblings to acknowledge the 
changes they can note in the appearance and behavior of the child which helped in decreasing anxiety by addressing their concerns and preparing them for the future including end-of-life situations $[11,12]$. Debriefing with the medical team was done routinely to keep all the members of the team informed about the goals of care and help the team cope with the impending loss.

Finally, CLSs spent time with the child making legacy craft items such as cast molds, scrapbooks, fingerprint charms and videos. These crafts were made by the child for their loved ones to make memories and have their legacy carried forward [8, 12].

CLSs created a supporting and trusting environment for the family. During the final days, they provided emotional support and bereavement care to overcome the painful experience. Siblings were given the opportunity to express their feelings. They attended the funeral and were assured that their feelings will change over time [6]. The parents appreciated the support and the compassionate and consistent care offered by the CLS to make the end of life experience a bearable one.

\section{Comment}

This case highlights the important role of CLS as an integral member of palliative care team. CLS recognize individuality in a child and provide developmentally appropriate activities based on one's self-directed interest, to help cope with medical experiences [5, 7].

The ways by which young children cope with stress vary with that of adults. Children between the ages 10-12 use regression, withdrawal, acting out or feeling guilty which were all found in our patient. Adolescents use defense mechanisms or uncooperative behavior to combat stressors [13]. This can have a negative impact on the parents and siblings affecting their physical and psychological wellbeing [14].

CLSs serve as advocates for addressing the special needs of children and families. They help to increase the child's cooperation and comfort by preparing and describing to them in a child friendly language before any procedure and treatment. The involvement and presence of family members around positively impacts the child's adjustment to the health care experience [11].

Play is an important aspect of child life program. It provides an opportunity for parental and sibling engagement. CLSs also offer sibling support, provide space for discussion of their feelings and allow them to spend quality time with the sick child whenever possible [5].

CLSs play a vital role in preparing family members for anticipated death of the child in end-of life circumstances. They help foster family-centered pediatric palliative care, from including the child and family in legacy making to providing grief counseling [5].

Pet therapy is one of the multiple coping techniques that CLSs use to help children deal with traumatic experiences.

Pet therapy serves to improve physical and mental wellbeing, increases social interaction and provides a sense of self-esteem and independence in children [15]. A pilot project on animal assisted therapy in pediatric oncology found that dog visits helped to reduce the stress and anxiety in hospitalized children and increased treatment receptivity [2]. While dogs and cats were the most common animals used in pet therapy, other animals including horses, guinea pigs, birds and fish are also used. The animal's type and natural behavior will determine where it will be helpful [16]. Dogs of any breed, size, or age may qualify to become a therapy animal provided they 
possess certain traits - calm temperament, non-aggressive, patient, friendly and receptive to training [17].

In the United States, pet therapy began in 1919 when dogs were used to treat psychiatric patients. Dr. Boris Levinson, an American child psychiatrist was the first to document the positive impact of using pets in child care practice. Since then, animal therapy has been extensively used as a therapeutic tool in many countries [18]. Pet therapy or Animal assisted therapy is a novel approach that has become available in many medical centers and provide hospitalized children, the opportunity to interact with visiting pets or animals that are raised in the medical setting [15].

Despite the benefits, some reasonable concerns of pet therapy include allergic reactions, chances of infection from animals, animal bites and other untoward pet behaviors. However, therapy animals should be clean, well trained and housebroken, screened medically and fully vaccinated [15].

Although the field of child life is rapidly developing in the United States, awareness about child life programs and the function and responsibilities of CLSs in children's hospitals is still very limited. While health care professionals may be aware of child life, they often lack a comprehensive understanding of the educational and training needs, the services they provide and their role in the interdisciplinary health care team [19]. While future research is required to illustrate the importance of the contributions of child-life specialists to the pediatric palliative care team, it remains essential that child-life programs continue to grow and adapt to the evolving health care environment and provide the best possible quality of care for children and their families $[5,20]$.

\section{Conclusion}

Our patient's end of life experience was powerfully impacted by enriching and improving the quality as a result of coordinated approach and involvement of the CLS. They should be considered as an essential member of pediatric and pediatric palliative care teams, and their work should be integrated into the plan of care to ensure the best outcome.

\section{Author Contributions}

Dr. Jeyamurugan has designed, analyzed, drafted the manuscript and approved the final version of the manuscript. Dr. Basak has conceptualized, designed, analyzed, drafted the manuscript and approved the final version of the manuscript.

\section{Competing Interests}

The authors have declared that no competing interests exist.

\section{References}

1. Huang IC, Wen PS, Revicki DA, Shenkman EA. Quality of life measurement for children with life-threatening conditions: Limitations and a new framework. Child Indic Res. 2011; 4: 145160.

2. Bouchard F, Landry M, Belles-Isles M, Gagnon J. A magical dream: A pilot project in animalassisted therapy in pediatric oncology. Can Oncol Nurs J. 2004; 14: 14-17.

3. Committee on Bioethics. Palliative care for children. Pediatrics. 2000, 106: 351-357 
4. Linebarger J, Moreno MA. Pediatric palliative care. JAMA Pediatr. 2019; 173: 1115.

5. Committee on Hospital Care and Child Life Council. Child life Services. Pediatrics. 2014, 133: e1471-e1478.

6. Home - Association of Child Life Professionals. Arlington: The Association of Child Life Professionals; 2020 [cited date 2020 April]. Available from: https://www.childlife.org/.

7. Child life specialist. Wikipedia, The Free Encyclopedia; 2020 [cited date 2020 April]. Available from: https://en.wikipedia.org/wiki/Child life specialist.

8. Beickert K, Mora K. Transforming the pediatric experience: The story of child life. Pediatr Ann. 2017; 46: e345-e351.

9. LeBlanc CK, Naugler K, Morrison K, Parker JA, Chambers CT. Parent perceptions and satisfaction with inpatient child life specialist interventions and the role of child temperament. Child Health Care. 2014; 43: 253-272.

10. Tyson ME, Bohl DD, Blickman JG. A randomized controlled trial: Child life services in pediatric imaging. Pediatr Radiol. 2014; 44: 1426-1432.

11. Goodhue K. Child life at end of life: Providing child life services in a pediatric home hospice setting. Child Life Council Bulletin Spring. 2016; 34: 6-26.

12. What is Pediatric Palliative care? New York: Center to Advance Palliative Care; 2017 [cited date 2020 April]. Available from: https://getpalliativecare.org/whatis/pediatric/.

13. Krupnick JL. CHAPTER 5, Bereavement During Childhood and Adolescence. Bereavement: Reactions, consequences, and care. Washington (DC): National Academies Press; 1984. Available from: https://www.ncbi.nlm.nih.gov/books/NBK217849/.

14. Wittenberg E, Saada A, Prosser LA. How illness affects family members: A qualitative interview survey. Patient. 2013; 6: 257-268.

15. Donowitz LG. Pet therapy. Pediatr Infect Dis J. 2002; 21: 64-66

16. Pet therapy. San Francisco: Healthline Media; 2020 [cited date 2020 May]. Available from: https://www.healthline.com/health/pet-therapy.

17. Therapy dogs and animal-assisted therapy. New York: The Spruce Pets; 2019 [cited date 2020 May]. Available from: https://www.thesprucepets.com/therapy-dogs-and-animal-assistedtherapy-1118680.

18. Hooker SD, Freeman LH, Stewart P. Pet therapy research: A historical review. Holist Nurs Pract. 2002; 16: 17-23.

19. Lookabaugh S, Ballard SM. The scope and future direction of child life. J Child Fam Stud. 2018; 27: 1721-1731. 


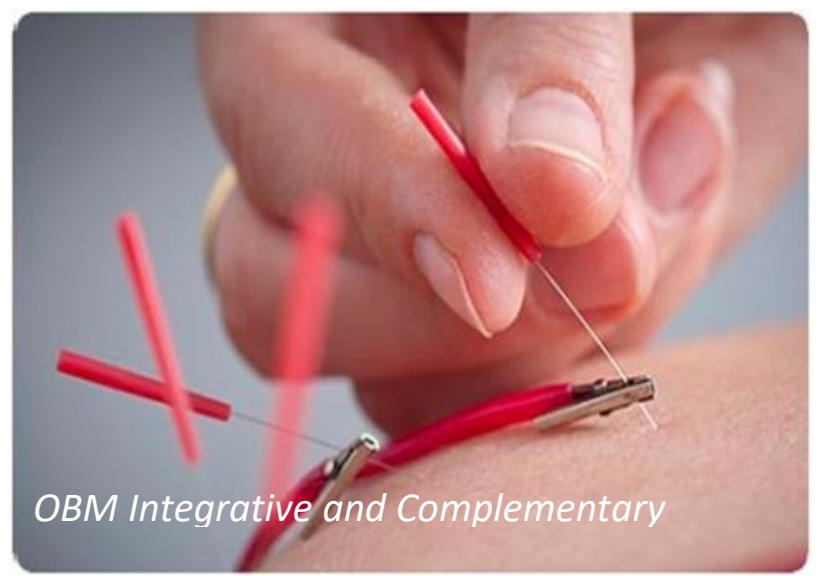

Enjoy OBM Integrative and Complementary Medicine by:

1. Submitting a manuscript

2. Joining in volunteer reviewer bank

3. Joining Editorial Board

4. Guest editing a special issue

For more details, please visit:

http://www.lidsen.com/journals/icm 
Original Research

\title{
Cognitive Impairment, Meditative Movement, and Gene Expression in Breast Cancer Survivors
}

Francisco V. Muñoz ${ }^{\ddagger}$, Linda Larkey *

Arizona State University, College of Nursing and Health Innovation, Pomona Valley Hospital Medical Center, Lewis Family Cancer Care Center, USA; E-Mails: fmunoz007@verizon.net; linda.larkey@asu.edu

¥ Current Affiliation: Casa Colina Centers for Health Care, Research Institute

* Correspondence: Linda Larkey; E-Mail: linda.larkey@asu.edu

Academic Editor: Leila Kozak

Special Issue: Integrative Therapies in Palliative Care

OBM Integrative and Complementary Medicine 2019, volume 5 , issue 3

doi:10.21926/obm.icm.2003035
Received: May 20, 2020

Accepted: July 20, 2020

Published: July 27, 2020

\begin{abstract}
Breast cancer survivors (BCSs) report decrements in cognitive functioning. A Meditative Movement (MM) program (Qigong/Tai Chi Easy) combines meditation and exercise, practices known to improve cognitive function. Method: Using a single group, pre- to postintervention assessment design, a pilot study was conducted in BCSs to test the effects of an 8-week MM intervention on cognitive functioning, sleep and mood and to explore changes on selected gene expression factors, BDNF, NF-kB1, and TP53, expected to improve with symptoms. BCSs $(n=14$; mean age $=61$ ) completed the MM intervention, provided blood samples and answered questionnaires assessing cognitive function using the Functional Assessment of Cancer Therapy-Cognitive Function (FACT-COG) and the Wechsler Adult Intelligence Scale (WAIS-III). Sleep and mood were assessed using the Pittsburgh Sleep Quality Index (PSQI) and Profile of Mood States (POMS) subscales for anxiety and depression. Results: Significant improvements were noted in the FACT-COG subscales: Perceived Cognitive Impairments $(p=.01)$, Perceived Cognitive Abilities $(p=.03)$, Perceived
\end{abstract} conditions of the Creative Commons by Attribution License, which permits unrestricted use, distribution, and reproduction in any medium or format, provided the original work is correctly cited. 
Impairments on Quality of Life $(p=.04)$, and Comments from Others $(p=.04)$. The WAIS-III results indicated a significant improvement in Letter-Number sequencing ( $p$-value $=.01$ ), but not for Digit Span Forward/Backwards ( $p$-value $=.60)$. The PSQI $(p=.03$ ) and the POMS/anxiety subscale $(p=.05)$ showed a significant decrease. Significant changes in POMS/depression, BDNF, NF-kB1, and TP53 were not found. The intervention was shown to improve cognitive functioning, sleep quality and anxiety suggesting that $\mathrm{MM}$ may contribute to the recovery of a subset of persistent symptoms among BCSs.

\section{Keywords}

Cognitive impairment; Breast cancer survivors; Gene expression; Tai Chi; Qigong

\section{Introduction}

Approximately $78 \%$ of breast cancer survivors suffer from adverse effects of cancer treatment [1]. Decrements in cognitive functioning among BCSs is one of these adverse effects that may be due to a combination of factors such as the stress of the cancer diagnosis, treatment effects, and increased sedentary behavior, and is often referred to as chemobrain, or cancer-related cognitive impairment [1].

In addition to cognitive impairment, behavioral comorbidities such as depression, anxiety, and poor sleep quality are also prevalent in cancer survivors, affecting their quality-of-life [2-6]. Inflammation is considered a leading mechanism causing changes in neurobiology that underlie these behavioral conditions [6].

There is growing evidence for mind-body practices such as meditation/mindfulness and meditative movement as well as physical activity to improve quality of life and cognitive function in cancer patients and survivors [7-15]. Meditative Movement (MM) has been defined as practices that integrate body movement or postures, a focus on the breath, and a meditative state to cultivate deep state of relaxation [16] and offers the potential of combining both benefits of meditation and exercise for breast cancer survivors. MM combines Tai Chi movements and Qigong into a practice that has been used in research with BCSs because it is very easy to learn and guides participants quickly into a moving meditative state.

Less understood are the molecular signatures that may explain the improvements in cognitive function, anxiety, depression, and sleep quality in breast cancer patients affected by Tai Chi and/or Qigong. Although many studies have examined the effects of mind-body interventions on inflammatory markers, Bowers and Irwin [17] reviewed this body of research and noted that results are mixed and highly dependent upon clinical factors of patients at baseline. In breast cancer survivors, specifically, Janelsins et al., [18] found that the mind-body practice of Tai Chi demonstrated down-regulating effects on pro-inflammatory biomarkers.

For the current study, the targeted gene expression factors in this study were brain derived neurotrophic factor (BDNF), Nuclear Factor kappa B (NF-kB1) and Tumor Protein 53 (TP53). The BDNF gene regulates synaptic plasticity associated with cognitive functioning [19]. Increased levels of BDNF gene expression are associated with improved cognitive functioning [20]. Decreased levels of NF-kB1 gene expression are associated with improvements in managing 
chronic stress $[6,17]$. Increased TP53 gene expression is associated with suppressing cancer growth [21]. There is a need for more research exploring the interactions between inflammation, cognitive functioning, and tumor suppression [6].

This pilot study examined the effects of $\mathrm{MM}$ on cognitive function and associated symptoms/conditions such as anxiety, depression, and sleep quality. Gene expression factors that may be associated with these changes and/or critical to recovery and future health of BCSs were explored.

Hypothesis 1: In a group of BCSs, 8 weeks of MM will significantly improve cognitive function.

Hypothesis 2: In a group of BCSs, 8 weeks of MM will significantly improve anxiety, depression, and sleep quality.

Hypothesis 3: In a group of BCSs, 8 weeks of MM will significantly affect gene expression associated with cognitive impairment, inflammation, and tumor growth.

\section{Method}

This was a single-group pilot study testing the effects of 8 weeks of MM practice on changes in cognitive function, anxiety, sleep quality, depression, and selected gene expression factors. The enrollment goal was to consent and assign forty BCSs to an eight-week MM program. Measures on cognitive functioning, associated symptoms/conditions, and gene expression data were collected before and after the 8-week MM program. This study utilized the Paired Sample t-test of SPSS [22] to report $p$-values from the analysis of pre- and post-MM intervention changes in the cognitive functioning, associated symptoms/conditions, and gene expression data. This study was approved by both the IRB committees at Pomona Valley Hospital Medical Center (PVHMC as the primary IRB) and at Arizona State University (ASU as the secondary IRB).

\subsection{Study Population}

\subsubsection{Eligibility Criteria}

Inclusion criteria: minimum 45 years of age; female patients diagnosed with breast cancer, stages 0-III; between six months and five years past primary treatment; ability to speak or understand English; and post-menopausal for at least one year. Exclusion criteria: Women who were unable to stand (e.g., wheelchair or walker bound); patients who were too weak or ill; patients on antibiotics; women working on night shift; and patients with anemia or uncontrolled diabetes. Pregnant women, mentally disabled persons, and prisoners were excluded.

\subsubsection{Participant Recruitment}

On a daily basis, the clinical trials research coordinator (CRC) at the Pomona Valley Hospital Medical Center (PVHMC) Cancer Care Center (CCC) in Pomona, CA, identified potential participants with the support of site oncologists, site oncology nurses, and the site cancer registry. Flyers were displayed at the Breast Cancer Care Center at the CCC and other affiliated breast cancer care centers in the region. The site cancer registry prepared a mailing list based on the eligibility criteria and invitations were mailed. The CRC generated a list of potential participants 
based on referrals from the CCC staff and from phone calls from potential participants responding to flyers and mailings.

\subsubsection{Screening and Consenting}

There were two options for screening and consenting potential participants. In the first option, the site PI or the CRC contacted potential participants referred by the oncology team to screen for study interest and eligibility. In the second option, potential participants responded to the mailed invitation sent by the CRC. Study eligibility and enrollment for participants recruited and screened through both options were confirmed upon review of their medical records after obtaining written consent from potential participants in accordance with Good Clinical Practice (GCP) and Health Insurance Portability and Accountability Act of 1996 (HIPAA). As CCC staff members, the CRC and site PI had access to medical records. After reception of signed Informed Consent form and medical chart review, study participants were scheduled to attend the MM classes.

\subsection{Study Intervention}

\subsubsection{The Intervention}

The MM (Qigong/Tai Chi Easy) intervention is a standardized, protocol [23] with a formal training program for practice leaders from the Institute of Integral Qigong and Tai Chi (IIQTC) and has been used in previous research with various populations [8, 24, 25]. This practice is similar to the short, simplified forms used in the majority of Tai Chi research protocols showing health benefits [26]. The protocol is taught as a series of repeated and simple-to-learn movements rather than long chains of choreographed moves that are more difficult to learn (typical of how traditional long-form Tai Chi is taught).

In this study, the MM intervention was implemented over 8 weeks with class sessions once a week at the Pomona Cancer Care Center. Each class session was approximately one hour. The participants learned gentle movements, ranging from mild to moderate levels of exertion. The participants were asked to practice the MM exercises at home, at their own pace, most days of the week, totaling at a minimum, $2 \frac{1}{2}$ to 3 hours per week and to log their MM practices in a logbook provided to them. A professionally produced DVD and manual demonstrating a core set of 10, and additional exercises for variety were given to participants to help guide their practice at home. The lead investigator, a certified Mind-Body Medicine Practitioner, and certified QG/TCE practice leader assisted the research participants with the MM sessions. The $\mathrm{PI}$ and $\mathrm{CRC}$ provided support and guidance to the participants during the MM program.

\subsection{Measures}

Basic demographic data (gender, ethnicity/race, and age) was collected at baseline. Self-report data on cognitive abilities (perceived and objective assessments), anxiety, depression, and sleep quality, and blood draws to examine gene expression, were collected pre- and post- 8-week MM program (within two weeks prior to and subsequent to the intervention). 


\subsubsection{Cognitive Function (CF) and Cognitive performance (CP) Tests}

Cognitive function was assessed using both a self-report and an objective performance test.

Self-reported CF was assessed using the Functional Assessment of Cancer Therapy-Cognitive Function (FACT-COG), 37 items, validated, including 4 subscales including perceived cognitive impairment $(\mathrm{PCl})$, perceptions of effects of cognitive function on quality of life (QOL), and perceived cognitive abilities (PCA) and comments from other (OTH [27-29]

CP Tests: Two brief measures of attention/working memory from the Wechsler Adult Intelligence Scale (WAIS-III) Third Edition [30, 31] were used to assess CP: Digit Span and LetterNumber Sequencing, with reliability ratings of .90 and .82 respectively.

\subsubsection{Profile of Mood States Short Form (POMS-SF)}

The POMs-SF consists of 37 items, adjectives scored on a 5-point Likert scale [32]. The POMS is one of the most frequently used and validated scales in studies of psychosocial interventions with BCSs, and has been validated with Hispanics [33] and multicultural populations [34]. POMS consists of the Total Mood Disturbance (TMD) dimensions (tension-anxiety; depression-dejection; anger-hostility; confusion-bewilderment; Cronbach's alpha $=.93)$. This pilot study reported results for the tension-anxiety and depression-dejection TMD dimensions (12 items).

\subsubsection{Sleep Quality}

The Pittsburgh Sleep Quality Index (PSQI): 19 items assess sleep, including subscales for subjective sleep quality, sleep latency, sleep duration, sleep disturbance, habitual sleep efficiency, daytime dysfunction and use of sleep medications [35]. A global PSQI score $>5$ distinguishes good from poor sleepers with $89.6 \%$ sensitivity and $89.5 \%$ specificity and demonstrates Cronbach's $\alpha=$ $0.83[36]$.

\subsubsection{Process Control, Manipulations and Fidelity}

Each participant received a phone call or email midweek between class attendance (whether they attended or not) to remind them to document practice time (session/minutes) and weekly record level of exertion. MM Practice Logs were provided for participants to document home practice. The midweek contact served both as process control evaluation and as a method for encouraging adherence. Whenever a participant missed a scheduled class, she received an additional call to encourage adherence.

\subsubsection{Gene Expression Data}

The PAXgene Blood RNA Tube (Catalog No. 762165) was at room temperature (18-25C) and properly labeled for patient identification. The CRC collected one $2.5 \mathrm{ml}$ of blood into one tube using the standard technique for BD Vacutainer ${ }^{\circledR}$ Evacuated Blood Collection Tubes. 


\subsubsection{After Blood Collection}

The CRC inverted the PAXgene Blood RNA Tube 8 to 10 times and stored the PAXgene Blood RNA Tube upright at room temperature $\left(18^{\circ} \mathrm{C}-25^{\circ} \mathrm{C}\right)$ for a minimum of 2 hours and a maximum of 72 hours before processing or transferring to refrigerator $\left(28^{\circ} \mathrm{C}\right)$ or freezer $\left(-20^{\circ} \mathrm{C}\right)$. After 48 hours in freezer $\left(-20^{\circ} \mathrm{C}\right)$ the blood samples were transferred and stored in a freezer $\left(-80^{\circ} \mathrm{C}\right)$ until they were prepared for RNA sequencing. Transport Collected Blood Samples: Blood samples were transported to SC2 Core lab for processing and library preparation for RNA sequencing.

\subsection{Retention Strategies}

The PI and CRC maintained contact with the study participants by telephone, in person, or email to encourage retention in the study. In addition, to providing log-book instructions and meeting time reminders during this contact, the CRC or PI encouraged questions and sharing on how they are experiencing the research study with goal of establishing a therapeutic alliance between the research staff and the study participants. The study participants were also encouraged to initiate contact with the PI or CRC with any questions or concerns by phone, email, or in person.

\subsubsection{Sample Size Justification}

The enrollment goal of 40 participants followed the guidelines of Browne [37] to formulate samples sizes for pilot studies. This was the target for recruitment with an expected attrition rate of $20 \%$. Although 27 participants were consented, only 14 completed the study. The 14 who completed the study met the standards established by Julious [38] for pilot study sample sizes. Browne and Julious $[37,38]$ provided sample size calculation guidelines for pilot studies designed to collect preliminary data for a clinical trial.

\subsubsection{Hypothesis Testing Data Analysis Plan}

This study utilized the Paired Sample t-test of the SPSS statistical program to analyze the primary outcome changes in cognitive function anxiety, depression, and sleep quality over an 8week period. Changes in BDNF, NF-kB1, and TP53 gene expression results were analyzed using the paired sample t-test in SPSS to determine if the means of the pre- and post-MM gene expression data were significantly different.

\subsubsection{Missing Data}

Participant responses were reviewed for missing data and participants were given an opportunity to complete overlooked questions or indicate a preference not to answer during the data collection session. All analyses were conducted on participants who completed the intervention. If post-intervention data was unavailable, missing data were not imputed. As a small pilot study to detect trends in change from pre- to post-intervention, we do not expect there to be a systematic bias introduced by the data loss of a small number of participants. One study participant did not complete her post-MM program WAIS-III measure and did not submit her MM logbook due to schedule conflicts. 


\subsubsection{Secondary Outcomes}

Peripheral blood samples were collected before and after the 8-week MM program. The gene expression data was processed and analyzed by the bioinformatics team at the Single-Cell, Sequencing, and CyTOF Core (SC2), Children's Hospital Los Angeles (CHLA), Los Angeles. These data were analyzed using the paired sample t-test in the IBM SPSS Statistics program.

RNA sequencing: Sequencing libraries were prepared from previously purified RNA using the Illumina TruSeq Stranded mRNA Library Prep kit following the manufacturer's instructions. Sequencing was performed on a NextSeq 500 platform using $2 \times 75 \mathrm{bp}$ chemistry [39].

Gene Expression data analysis: Quality control and adapter trimming was performed using trim galore (v0.4.2) with default parameters [40]. Reads were aligned to the GRCh38 reference genome and transcriptome using HISAT2, v2.1.0 [41], and transcript quantification was performed using featureCounts, v1.5.1 [42]. Differential expression analysis was performed using the 'DESeq2' R package, v1.16.1, [43] and a rank score calculated as - log10(q-val)*sign (log2 FoldChange) was used as input to the GSEA Preranked tool for pathway analysis [44].

The DESeq2 data were used to identify the gene expression changes over the 8-week MM program. DESeq2 (differential expression sequence) files are TMM (weighted trimmed mean of the log expression ratios - trimmed mean of $\mathrm{M}$ values) normalized count per million reads.

\section{Results}

Twenty-seven breast cancer survivors were consented and enrolled into the study. Fourteen completed the MM program in 8-week class cohorts ranging from 5 to 9 participants. All of the 14 study participants were female and ranged in age from 45 to 95 years old. Ten of the study participants were White, three were Latina, and one was Black.

The primary reason 13 of the 27 consented study participants dropped out of the study was schedule conflicts. Other reasons included changes in physical or emotional health related to preexisting conditions, lack of transportation, and perceived prolonged waiting time to begin MM groups after consenting. The research staff maintained contact with those who discontinued participation in case their circumstances changed until they requested no further contact with the study.

Twelve of the fourteen participants attended every weekly session at the Cancer Care Center. Two were absent more than two weekly sessions. Thirteen study participants submitted their logbooks documenting the number of minutes they practiced MM weekly. Their weekly log included their weekly 60-minute MM sessions at the Cancer Care Center. The MM logbook reported mean in minutes per week was $M=91.06, S D=46.12$.

\section{Hypothesis One (Table 1): Cognitive Functioning}

Significant improvements, as predicted, were noted in the FACT-COG subscales: Perceived Cognitive Impairments (CogPCI), $(\mathrm{t}(13)=3.4, \mathrm{p}=.01)$; Perceived Cognitive Abilities (CogPCA), ( $\mathrm{t}(13)$ $=-2.4, p=.03)$; Perceived Impairments on Quality of Life (CogQOL), $(t(13)=2.2, p=.04)$; and Comments from Others (CogOth), $(t(13)=2.3, p=.04)$.

The significant changes for Perceived Cognitive Impairments (CogPCI) from pre-MM program, mean $=25.4$ to post-MM program, mean $=17.3$ indicated the BCS perceived their cognitive impairment declined. The BCS also perceived a decline in Perceived Impairments on Quality of Life 
(CogQOL) indicated by the significant change in pre-MM program, mean $=3.7$ to post-MM program, mean $=1.8$.

The positive significant changes indicated in the Perceived Cognitive Abilities (CogPCA) subscale suggested the BCSs' subjective improvement in their cognitive abilities noted in the pre-MM, mean $=16.0$ significant change to post-MM, mean $=19.2$. Another significant decline reported by the BCS was on the subscale, Comments from Others (CogOth), evidenced by the pre-MM program, mean $=1.5$ to post-MM, mean $=0.2$. This subscale reflects the BCSs' experience of what others have said to them regarding perceived cognitive decline.

Significant improvements, as predicted, were noted in the the WAIS-III, Letter/Number sequencing results, $(t(12)=-3.2, p=.01)$. Significant improvements were not noted in the WAIS-III, Digit Span Forward and Backward measure, $(t(12)=-0.532, p=.60)$. One of the two objective WAIS-III assessments of cognitive performance, Letter/Number sequencing, showed significant improvement demonstrated by the pre-MM mean 10.7 increase to the post-MM mean 12.7. The WAIS-III digit span Forward/Backward assessment also demonstrated an increase in the pre-MM mean 19.2 to post-MM mean 19.7 but did not reach significance.

Table 1 Functional Assessment of Cancer Therapy-Cognitive Function (FACT-COG) Subscales.

\begin{tabular}{|l|l|l|l|l|}
\hline Measure & $\begin{array}{l}\text { Pre-MM } \\
\text { mean (sd) }\end{array}$ & $\begin{array}{l}\text { Post-MM } \\
\text { mean (sd) }\end{array}$ & $\begin{array}{l}\text { Pre/Post } \\
\text { MM } \\
\text { mean (sd) } \\
\text { difference }\end{array}$ & P-Value \\
\hline CogPCI & $25.4(14.2)$ & $17.3(10.5)$ & $*_{-} 8.1(3.7)$ & .01 \\
\hline CogPCA & $16.0(5.1)$ & $19.2(5.3)$ & $3.2(0.2)$ & .03 \\
\hline CogQOL & $3.7(3.8)$ & $1.8(2.2)$ & $*-1.9(1.6)$ & .04 \\
\hline CogOth & $1.5(2.1)$ & $0.2(0.4)$ & $*_{-1.3(1.7)}$ & .04 \\
\hline $\begin{array}{l}\text { WAIS-III } \\
\text { Letter/Number } \\
\text { sequence }\end{array}$ & $10.7(3.2)$ & $12.7(2.8)$ & $2.0(0.4)$ & .01 \\
\hline $\begin{array}{l}\text { WAIS-III Digit } \\
\text { Span Forward } \\
\text { and Backward }\end{array}$ & $19.2(4.8)$ & $19.7(4.4)$ & $0.5(0.4)$ & .60 \\
\hline \multicolumn{4}{|l|}{ * reduction in scores indicate improvement. } \\
\hline
\end{tabular}

\section{Hypothesis Two (Table 2): Sleep Quality, Anxiety, and Depression}

The Pittsburg Sleep Quality Index (PSQI) scores, evidenced significant improvement, $(t(13)=2.5$, $p=.03)$. The POMS/anxiety subscale showed a significant decrease $(t(13)=1.9, p=.05)$ and the POMS/depression reduction did not reach significance $(t(13)=1.9, p=.08)$. BCSs' poor sleep quality significantly decreased from pre-MM program, mean $=1.5$ to post-MM program mean = 0.9 . Their anxiety levels also significantly decreased from pre-MM program mean $=9.2$ to post$\mathrm{MM}$ program mean $=4.2$. Depression levels also decreased, pre-MM mean $=4.1$ to post-MM mean 2.0, but did not reach significance. 
Table 2 The Pittsburgh Sleep Quality Index (PSQI) and Profile of Mood States (POMS).

\begin{tabular}{|l|l|l|l|l|}
\hline Measure & $\begin{array}{l}\text { Pre-MM } \\
\text { mean (sd) }\end{array}$ & $\begin{array}{l}\text { Post-MM } \\
\text { mean (sd) }\end{array}$ & $\begin{array}{l}\text { Pre/Post MM } \\
\text { mean (sd) } \\
\text { difference }\end{array}$ & P-Value \\
\hline PSQI & $1.5(0.8)$ & $0.9(0.7)$ & $*_{-0.6(0.1)}$ & .03 \\
\hline POMS Anxiety & $9.2(7.7)$ & $4.2(3.7)$ & $*_{-5.0(4.0)}$ & .05 \\
\hline $\begin{array}{l}\text { POMS } \\
\text { Depression }\end{array}$ & $4.1(4.9)$ & $2.0(3.0)$ & $*_{-2.1(1.9)}$ & .08 \\
\hline
\end{tabular}

*reduction in scores indicate improvement.

\section{Hypothesis Three (Table 3): Gene Expression Factors}

Significant changes were not found for BDNF $(t(13)=-1.1, p=.30)$, NF-kB1 $(t(13)=-0.2, p=.80)$, and TP53 $(\mathrm{t}(13)=-0.52, \mathrm{p}=.61)$.

Table 3 Gene Expression Factors.

\begin{tabular}{|l|l|l|l|l|}
\hline Measure & $\begin{array}{l}\text { Pre-MM } \\
\text { mean (sd) }\end{array}$ & $\begin{array}{l}\text { Post-MM } \\
\text { mean (sd) }\end{array}$ & $\begin{array}{l}\text { Pre/Post MM } \\
\text { mean (sd) } \\
\text { difference }\end{array}$ & P-Value \\
\hline BDNF & $0.11(0.9)$ & $0.30(0.7)$ & $0.19(0.2)$ & .30 \\
\hline NF-kB1 & $171.7(25.4)$ & $173.7(21.6)$ & $2.0(3.8)$ & .80 \\
\hline TP53 & $12.3(2.7)$ & $13.1(5.5)$ & $0.8(2.8)$ & .61 \\
\hline
\end{tabular}

The mean (sd) differences (Table 3) in BDNF gene expression, $0.19(-0.2)$; NF-kB1 gene expression, 2.0 (-3.8); and TP53 gene expression, 0.8 (2.8); all indicated an increase in RNA between pre- and post-MM intervention. Although these differences are not statistically significant.

\section{Discussion}

The primary outcome expected to improve in response to the intervention as cognitive function, and the assessments showed promising results on this factor, measured both with self-report and one of the objective measures. The direction of change for the FACTCog subscales all indicated a perceived significant improvement in cognitive functioning. The WAIS-III Letter/Number assessment provided significant and objective evidence to support improvement in cognitive functioning. The direction of change for the WAIS-III Digit Span Forward/Backward assessment indicated an improvement in cognitive functioning but did not reach significance.

The PSQI and POMS/anxiety subscale also provided significant and positive subjective changes in sleep quality and anxiety levels. The POMS/depression subscale evidenced positive changes but these changes did not reach significance. This lack of significance may be due to the majority of the BCSs in this study not reporting any major issues with depression.

The research design for the GME study was based on the intent to perform a pilot study and examine a trend for effects of the intervention on gene expression and symptom changes. Regarding the enrolled participants failing to initiate, we have further explained that conducting 
this study in a small cancer center, recruitment was slow, thus often extending the time from consent to a new class group start date. This is now discussed in the limitation section.

Limitations. The MM suggested time goal for the study participants was between 2.5 and 3 hours per week. The MM logbooks showed a mean of $1.5 \mathrm{MM}$ hours per week for the study participants. Lower than projected time engagement in the intervention may have attenuated results across all of the assessments. Increasing the amount of engagement time between the research team and the study participants using phone calls, texts or other types of encouragement may increase the MM practice hours per week. The consented participants who did not begin the study may have perceived too long a wait time for the MM groups to begin. The wait time often resulted in loss of interest or change in other circumstances. For these consented participants, consistent communication from the research team may have maintained their engagement with the study until the MM groups were started.

Despite the small number of study participants, the results of this study parallel the results of larger studies conducted on the effects of meditation, exercise, and mind-body practices such as Yoga or Tai Chi/Qigong on the cognitive functioning, anxiety and quality of life factors for BCS [7$15,45]$. The absence of significant change in the means for pre- and post- intervention BDNF, TP53 and NF-kB1 gene expression may indicate that there is no effect of the intervention, that the intervention dose was insufficient, or that the sample size was too small. Another study that examined NF-kB gene expression in response to a 12-week MM intervention, Tai Chi Chih (TCC), but with higher dose (2 hours/week), reported less increase in NF-kB gene expression compared to control, but also not reaching significance [46]. Differences between the two studies may due to type of study participants (older adults vs. BCSs), and length and dose of intervention.

Given such a small sample size, we did not examine potential associations of the biomarkers assessed with the improvements in cognitive functioning and quality of life factors. In larger studies in the future, it would be important to examine these relationships as possible mediators of symptomatic change. Rather than a focus on the target genes themselves, an analysis of the biological pathways of cognitive functioning, tumor suppression, and pro-inflammation may yield more insight on potential effects of the MM program on the molecular signatures and gene expression within the study participants.

Further, while many studies of MM in cancer patients or survivors have examined (and found) reductions in inflammatory cytokines, very few have assessed the gene expression pathways to that inflammation, and none, to our knowledge, have explored BDNF specifically. Although significance changes were not found, these novel targets were worth exploring, and in fact, show promise for studies that are better powered for significance testing.

\section{Conclusion}

This pilot study tested the effects of the MM program on changes in cognitive functioning and associated symptoms/conditions such as anxiety, depression, and sleep quality. This study also utilized gene expression factors to improve understanding of the biological mechanisms potentially associated with these changes. The patient self-reported data indicated the MM program was perceived as improving cognitive functioning, in support of other study results. This perception was further supported by an objective cognitive performance measure showing significant improvements on one of the two assessments. The patient self-reported data also 
indicated the MM program was perceived as improving anxiety and sleep quality. The gene expression data did not evidence significant results to support association with positive changes in cognitive performance, anxiety, and sleep quality. The major limitation of this study is the underpowered sample size that does not allow for the definitive testing of the hypotheses. This study provided preliminary data for a future powered randomized control trial to study psychobehavioral outcomes and associated genomic expression factors.

\section{Acknowledgements}

This project was supported by a grant from the National Cancer Institute (1R01CA18290101A1).

\section{Author Contributions}

Dr. Munoz conducted the study, analyzed, and interpreted results while taking the lead in writing the manuscript. Dr. Larkey provided study oversight, expertise for MM intervention, and editorship for manuscript. Both authors provided critical analysis as they shaped the research and manuscript.

\section{Competing Interests}

The authors have declared that no competing interests exist.

\section{References}

1. Lambert, M, Ouimet LA, Wan C, Stewart A, Collins B, Vitoroulis I, et al. Cancer-related cognitive impairment in breast cancer survivors: An examination of conceptual and statistical cognitive domains using principal component analysis. Oncol Rev. 2018; 12: 371 . doi: 10.4081/oncol.2018.371. eCollection 2018 Jul 4.

2. Mosher CE, Duhamel KN. An examination of distress, sleep, and fatigue in metastatic breast cancer patients. Psychooncology. 2012; 21: 100-107. doi: 10.1002/pon.1873.Epub 2010 Nov 24.

3. Lockefeer JP, De Vries J. What is the relationship between trait anxiety and depressive symptoms, fatigue, and low sleep quality following breast cancer surgery. Psychooncology. 2013; 22: 1127-1133. doi: 10.1002/pon.3115. Epub 2012 Jun 13.

4. Fontes F, Severo M, Goncalves M, Pereira S, Lunet N. Trajectories of sleep quality during the first three years after breast cancer diagnosis. Sleep Med. 2017; 34: 193-199. doi: 10.1016/j.sleep.2017.03.022. Epub 2017 Apr 4.

5. McCall M. Yoga intervention may improve health-related quality of life (HRQL), fatigue, depression, anxiety and sleep in patients with breast cancer. Evid Based Nurs. 2018; 21: 9. doi: 10.1136/eb-2017-102673. Epub 2017 Nov 25.

6. Santos JC, Pyter LM. Neuroimmunology of behavioral comorbidities associated with cancer and cancer treatments. Front Immunol. 2018; 9: 1195. doi: 10.3389/fimmu.2018.01195.

7. Greenlee H, Balneaves LG, Carlson LE, et al. Clinical practice guidelines on the use of integrative therapies as supportive care in patients treated for breast cancer. J Natl Cancer Inst Monogr. 2014; 2014: 346-358. doi: 10.1093/jncimonographs/Igu041 
8. Larkey LK, Roe D, Smith LL, Millstine D. Exploratory outcome assessment of Qigong/Tai Chi Easy on breast cancer survivors. Complement Ther Med. 2016; 29: 196-203. doi: 10.1016/j.ctim.2016.10.006.

9. Greenlee H, Dupont-Reyes MJ, Balneaves LG, et al. Clinical guidelines on the evidence-based use of integrative therapies during and after breast cancer treatment. CA Cancer J Clin. 2017; 67: 194-232. doi: 10.3322/caac.21397.

10. Treanor CJ, McMenamin UC, O'Neill RF, et al. Non-pharmacological interventions for cognitive impairment due to systemic cancer treatment. Cochrane Database Syst Rev. 2016: CD011325. doi: 10.1002/14651858CD011325.pub2.

11. Carlson LE, Tamagawa R, Stephen J, Drysdale E, Zhong L, Speca M. Randomized-controlled trial of mindfulness-based cancer recovery versus supportive expressive group therapy among distressed breast cancer survivors (MINDSET): Long-term follow-up results. Psychooncology. 2016; 25: 705-709. doi: 10.1002/pon.4150.

12. Gentry AL, Erickson KI, Sereika SM, et al. Protocol for exercise program in cancer and cognition (EPICC): A randomized controlled trial of the effects of aerobic exercise on cognitive function in postmenopausal women with breast cancer receiving aromatase inhibitor therapy. Contemp Clin Trials. 2018; 67: 109-115. doi: 10.1016/j.cct.2018.02.012.

13. Hartman SJ, Nelson SH, Myers E, et al. Randomized controlled trial of increasing physical activity on objectively measured and self-reported cognitive functioning among breast cancer survivors: The memory \& motion study. Cancer. 2018; 124: 192-202. doi: 10.1002/cncr.30987.

14. Lyman GH, Greenlee H, Bohlke K, et al. Integrative therapies during and after breast cancer treatment: ASCO endorsement of the SIO clinical practice guideline. J Clin Oncol. 2018: JCO2018792721. doi: 10.1200/JCO.2018.79.2721.

15. Park HS, Kim CJ, Kwak HB, No MH, Heo JW, Kim TW. Physical exercise prevents cognitive impairment by enhancing hippocampal neuroplasticity and mitochondrial function in doxorubicin-induced chemobrain. Neuropharmacology. 2018; 133: 451-461. doi: 10.1016/j.neuropharm.2018.02.013.

16. Larkey LK, Jahnke R, Etnier J, Gonzalez J. Meditative movement as a category of exercise: Implications for research. J Phys Act Health. 2009; 6: 230-238.

17. Bower J, Irwin M. Mind-body therapies and control of inflammatory biology: A descriptive review. Brain Behav Immun. 2016; 51: 1-11. doi: 10.1016/j.bbi.2015.06.012.

18. Janelsins MC, Davis PG, Wideman L, et al. Effects of Tai Chi chuan on insulin and cytokine levels in a randomized controlled pilot study on breast cancer survivors. Clin Breast Cancer. 2011; 11: 161-170.

19. $\mathrm{Xu}$ B. BDNF (I)rising from exercise. Cell Metab. 2013; 18: 612-614. doi:10.1016/j.cmet.2013.10.008

20. Lange M, Joly F, Vardy J, et al. Cancer-related cognitive impairment: An update on state of the art, detection, and management strategies in cancer survivors. Ann Oncol. 2019; 30: 19251940. doi: 10.1093/annonc/mdz410.

21. Brenner DR, Brockton NT, Kotsoppoulos J, et al. Breast cancer survival among young women: A review of the role of modifiable lifestyle factors. Cancer Causes Control. 2016; 27: 459-472. doi: 10.1007/s10552-016-0726-5. 
22. IBM Corp. Released 2020. IBM SPSS Statistics for Windows, Version 26.0. Armonk, NY: IBM Corp.

23. Jahnke R, Larkey LK, Rogers CE. Dissemination and benefits of an accessible Tai-Chi-Qigong (TCQG) program for older adults. Geriatr Nurs. 2010; 31: 272-280. doi: 10.1016/j.gerinurse.2010.04.012

24. Smith LL, Larkey L, Blackstone R, Celaya M. Feasibility of a meditative movement intervention for bariatric patients. Appl Nurs Res. 2014; 27: 231-236. doi: 10.1016/j.apnr.2014.02.009.

25. Larkey LK, Roe D, Weihs K, Jahnke RA, Lopez AM, Guillen J, et al. Randomized controlled trial of Qigong/Tai Chi Easy on cancer-related fatigue in breast cancer survivors. Ann Behav Med. 2014; 49: 165-176. doi:10.1007/s12160-014-9645-4.

26. Jahnke R, Larkey LK, Rogers C, Etnier J, Lin F. A comprehensive review of health benefits of Qigong and Tai Chi. Am J Health Promot. 2010; 24: 1-25.

27. Jacobs SR, Jacobsen PB, Booth-Jones M, Wagner LI, Anasetti C. Evaluation of the functional assessment of cancer therapy cognitive scale with hematopoietic stem cell transplant patients. J Pain Symptom Manage. 2007; 33: 13-23.

28. Cheung YT, Lim SR, Shwe M, Tan YP, Chan A. Psychometric properties and measurement equivalence of the English and Chinese versions of the functional assessment of cancer therapy-cognitive in Asian patients with breast cancer. Value Health. 2013; 16: 1001-1013. doi: 10.1016/j.jval.2013.06.017.

29. Van Dyk K, Crespi CM, Petersen L, Ganz PA. Identifying cancer-related cognitive impairment using the fact-cog perceived cognitive impairment. JNCl Cancer Spectrum. 2020; 4: pkz099. doi:10.1093/jncics/pkz099.

30. Wechsler D. WAIS-III administration and scoring manual. 3rd ed. Psychological Corp; 1997. p. 217.

31. Lozano-Lozano M, Martin-Martin L, Galiano-Castillo N, et al. Integral strategy to supportive care in breast cancer survivors through occupational therapy and a $\mathrm{m}$-health system: Design of a randomized clinical trial. BMC Med Inform Decis Mak. 2016; 16: 150. doi: 10.1186/s12911-016-0394-0.

32. Curran SL, Andrykowski MA, Studts JL. Short form of the profile of mood states (POMS-SF): Psychometric information. Psychol Assess. 1995; 7: 80.

33. Perczek R, Carver CS, Price AA, Pozo-Kaderman C. Coping, mood, and aspects of personality in Spanish translation and evidence of convergence with English versions. J Pers Assess. 2000; 74: 63-87.

34. Annesi JJ. Behaviorally supported exercise predicts weight loss in obese adults through improvements in mood, self-efficacy, and self-regulation, rather than by caloric expenditure. Perm J. 2011; 15: 23.

35. Carpenter JS, Andrykowski MA. Psychometric evaluation of the Pittsburgh Sleep Quality Index. J Psychosom Res. 1998; 45: 5-13. Doi: 10.1016/s0022-3999(97)00298-5.

36. Buysse D, Reynolds CF, Monk TH, Berman SR, Kupfer DJ. The Pittsburgh Sleep Quality Index: A new instrument for psychiatric practice and research. Psychiatry Res. 1989; 28: 193-213.

37. Browne RH. On the use of a pilot sample for sample size determination. Stat Med. 1995; 14: 1933-1940

38. Julious SA. Sample size of 12 per group rule of thumb for a pilot study. Pharmaceut Stat. 2005; 4: 287-291. 
39. Illumina. Studying gene expression using RNA sequencing. 2018. Retrieved from: https://www.illumina.com/techniques/sequencing/rna-sequencing.html.

40. FelixKrueger/TrimGalore. Trim Galore is a wrapper around Cutadapt and FastQC to consistently apply adapter and quality trimming to FastQ files, with extra functionality for RRBS data. 2018. Retrieved from: https://github.com/FelixKrueger/TrimGalore.

41. Kim D, Langmead B, Salzberg S. HISAT: A fast spliced aligner with low memory requirements. Nat Methods. 2015; 12, 357-360. doi: 10.1038/nmeth.3317

42. Liao Y, Smyth GK, Shi W. FeatureCounts: An efficient general purpose program for assigning sequence reads to genomic features. Bioinformatics. 2014; 30: 923-930. doi: 10.1093/bioinformatics/btt656.

43. Love M, Huber W, Anders S. Moderated estimation of fold changes and dispersion for RNAseq data with DESeq. Genome Biol. 2014; 15: 550. doi: 10.1186/s13059-014-0550-8.

44. Subramanian A, Tamayo P, Mootha V, et al. Gene set enrichment analysis: A knowledge-based approach for interpreting genome-wide expression files. PNAS. 2005; 102: 15545-15550. doi: 10.1073/pnas.0506580102.

45. Wayne PM, Lee MS, Novakowski J, et al. Tai Chi and Qigong for cancer-related symptoms and quality of life: A systematic review and meta-analysis. J Cancer Surviv. 2018; 12: 256-267. doi: 10.1007/s11764-017-0665-5.

46. Black DS, Irwin MR, Olmstead R, Ji E, Crabb Breen E, Motivala SJ. Tai chi meditation effects on nuclear factor-KB signaling in lonely older adults: A randomized controlled trial. Psychother Psychosom. 2014 ;83: 315-317. doi.org/10.1159/000359956

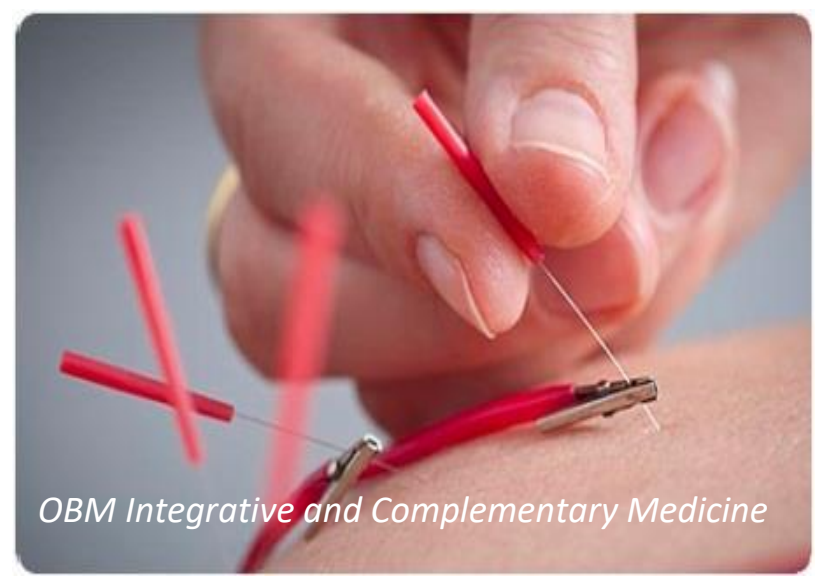

Enjoy OBM Integrative and Complementary Medicine by:

1. Submitting a manuscript

2. Joining in volunteer reviewer bank

3. Joining Editorial Board

4. Guest editing a special issue

For more details, please visit: http://www.lidsen.com/journals/icm 
Research Article

\title{
Preclinical Investigation of the Acute Effects of Trigonella foenum- graecum Seed Powder on Blood Glucose in Normal and Alloxan-Induced Diabetic Rabbits
}

Ramesh Alluri ${ }^{1,2}$, Hardik Ghelani ${ }^{3,4}$, Shayal Devi ${ }^{3}$, Vamsi Krishna Inampudi ${ }^{3}$, Srinivas Nammi ${ }^{2,3,4}$,

1. Vishnu Institute of Pharmaceutical Education and Research, Vishnupur, Narsapur, Medak 502313, Telangana, India; E-Mail: principal@viper.ac.in

2. Past Address: Department of Pharmacology, College of Pharmaceutical Sciences, Andhra University, Visakhapatnam 530003, Andhra Pradesh, India

3. Discipline of Medical Sciences, School of Science, Western Sydney University, NSW 2751, Australia; E-Mails: hardikghelani37@gmail.com; s.devi@westernsydney.edu.au; v.inampudi@westernsydney.edu.au; s.nammi@westernsydney.edu.au

4. NICM Health Research Institute, Western Sydney University, NSW 2751, Australia

* Correspondence: Srinivas Nammi; E-Mail: s.nammi@westernsydney.edu.au

Academic Editor: Gerhard Litscher

Special Issue: $\underline{\text { Herbal Medicines for the Treatment of Metabolic Syndrome }}$

OBM Integrative and Complementary Medicine

2020 , volume 5 , issue 3

doi:10.21926/obm.icm.2003036
Received: May 03, 2020

Accepted: August 3, 2020

Published: August 6, 2020

\begin{abstract}
To investigate the blood glucose lowering effect of the seed powder of $T$. foenum-graecum Linn (Papilionaceae) in normal and alloxan-induced diabetic rabbits. The blood glucose lowering effect of the seed powder was determined in normal and alloxan-induced (100 $\mathrm{mg} / \mathrm{kg}$, i.v.) diabetic rabbits, after oral administration of doses of 50,100 and $150 \mathrm{mg} / \mathrm{kg}$ body weight. Blood samples were collected from the marginal ear vein before and also at 4 , $6,8,10,12,16,18,20$ and $24 \mathrm{~h}$ after drug administration and blood glucose was analysed by Nelson-Somogyi's method using a visible spectrophotometer. The data was compared statistically by using Student's t-test. The seed powder of $T$. foenum-graecum produced a
\end{abstract}

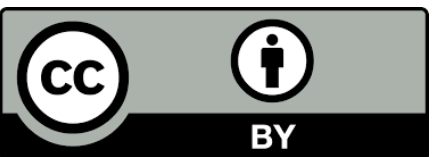

(C) 2020 by the author. This is an open access article distributed under the conditions of the Creative Commons by Attribution License, which permits unrestricted use, distribution, and reproduction in any medium or format, provided the original work is correctly cited. 
dose-dependent reduction in blood glucose of both normal and diabetic rabbits and comparable with that of standard drug, glibenclamide. The results indicate a prolonged action in reduction of blood glucose by $T$. foenum-graecum and the mode of action of the active compound (s) of $T$. foenum-graecum is probably mediated through enhanced secretion of insulin from the $\beta$-cells of Langerhans or through extrapancreatic mechanism. The present study clearly indicated a significant anti-diabetic activity with the seed powder of $T$. foenum-graecum and supported the traditional usage of the seed powder by Ayurvedic physicians for the control of diabetes.

\section{Keywords}

Diabetes; alloxan; beta-cells; rabbit; Trigonella foenum-graecum

\section{Introduction}

Diabetes mellitus is a metabolic disease that emerges as one of the leading diseases all over the World. Global statistics on diabetes indicate that approximately $50 \%$ of diabetic population live in Asia. Recent estimates indicate that approximately 366 million people are affected with diabetes, with $90 \%$ suffering from $T 2 D$ and by the year 2030, this number is expected to increase to 552 million [1]. Increased consumption of high-calorie fatty food associated with decreased physical activity also contributes to the pandemic of T2D [2]. The current therapeutic options such as diet modification, oral hypoglycaemic agents (OHA) and insulin treatment have their own limitations in treating T2D. Ayurveda, the indigenous Indian system of medicine, has offered many herbal medicines for the treatment of diabetes or 'madhumeha'. Although, some of these traditional herbal medicines have been experimentally evaluated, search for new anti-diabetic drugs continues. [3-9].

Trigonella foenum-graecum Linn (Papilionaceae) commonly referred as fenugreek is a herb that belongs to the family, Papilionaceae and indigenous to the Indian sub-continent and Eastern Mediterranean [10]. In Ayurveda, the seeds and leaves of $T$. foenum-graecum have been regarded as carminative, tonic, aphrodisiac and used to treat diabetes and cardiovascular disorders [11-13]. Its dried ripe seeds are known as Trigonella seeds or fenugreek seeds. The seeds possess pungent aromatic properties [14] and often used as a spice in food preparations to enhance its flavor [15], while the leaves are widely consumed as a leafy vegetable in India [16]. A converging point of evidence from earlier investigations on the seed extract and leaf extracts of $T$. foenum-graecum revealed significant anti-diabetic effects in both animals [17-22] and humans [16, 23-25]. The pharmacological effects of $T$. foenum-graecum are attributed to a range of bioactive compounds such as polyphenols, steroids, lipids, alkaloids, saponins, flavonoids, hydrocarbons, carbohydrates, galactomannan fiber, and amino acids. More recently, Sharma and colleagues have reported that the chronic administration of fenugreek seed extract showed protective effect against diabetes induced oxidative DNA damage in alloxan-induced diabetic rats [26]. Furthermore, it has also been demonstrated that fenugreek seed extract, protects brain tissue by mitigating oxidative stress induced by alloxan-exposed diabetic rats [27]. Diosgenin saponin is considered the most bioactive 
substance of $T$. foenum-graecum seeds and found to have anti-oxidative effects and plays a pivotal role in improving the diabetic condition in several in vivo and in vitro models [28].

However, some clinical trials did not show any benefit from fenugreek [29, 30]. The seeds of $T$. foenum-graecum are also known to possess antiulcer [31], hepatoprotective [32] and hypocholesterolaemic effects [33,34]. Nevertheless, the seed powder of $T$. foenum-graecum is being prescribed by Ayurvedic physicians for the treatment of diabetes [35]. However, there are only meager reports on the direct usage of the seed powder. Therefore, the present study was aimed to study the influence of the seed powder of $T$. foenum-graecum on the fasting blood glucose in normal and alloxan diabetic rabbits.

\section{Materials and Methods}

\subsection{Plant Material}

The seeds of $T$. foenum-graecum were bought at the local market, botanically authenticated and a voucher specimen was preserved for future reference. Seeds were cleaned, dried for 4 hours and then grounded to fine powder.

\subsection{Chemicals Used}

Glibenclamide was a generous gift sample by Hoechst Pharmaceuticals, Mumbai whereas alloxan was purchased from Sigma-Aldrich, St. Louis, MO, USA. All other reagents used were of analytical grade and purchased from Loba-Chemie, Mumbai, India.

\subsection{Animals}

A total of fifty (50) adult albino rabbits (B.N. Ghosh \& Co., Kolkata, India) weighing $1.5-2 \mathrm{~kg}$ of both sexes were chosen for investigation. The rabbits were maintained in a well-ventilated animal house with an ambient temperature $(24 \pm 2 \mathrm{o}$ ) and relative humidity (50-60\%) with 12-h light and dark cycle. The rabbits were acclimatized to the laboratory environment for 1 week before the start of the experiments and fed with standard diet and water ad libitum. They were fasted for overnight, allowing only access to water, and deprived of both food and water during the 24-hour monitoring cycle of the experiment after treatment with either the drug or distilled water (control) to reduce plasma volume changes. For each treatment the same procedure has been followed. The local Institutional Animal Ethics Committee has approved the use and handling of the animals in the experimental protocol (Regd. No. 516/01/A/CPCSEA) following the guidelines of the Committee for the Purpose of Control and Supervision of Experiments on Animals (CPCSEA), Government of India.

\subsection{Experimental Design and Treatments}

The rabbits were matched in weight and split into 10 groups, each consisting of five rabbits. Groups I, II and III were respectively given the seed powder of $T$. foenum-graecum (suspended in distilled water) by oral gavage at doses of 50,100 and $150 \mathrm{mg} / \mathrm{kg}$ body weight. Glibenclamide was given by oral gavage in Group IV (positive control) at a dose of $40 \mu \mathrm{g} / \mathrm{kg}$ body weight in a total volume of $3 \mathrm{~mL}$ for each rabbit. Group $V$ used as normal control and administered with $3 \mathrm{~mL}$ of 
distilled water. Diabetes was induced in Groups VI to X by injecting $100 \mathrm{mg} / \mathrm{kg}$ of alloxan into the marginal ear vein after determining the baseline blood glucose levels. Two weeks post-alloxan treatment when stable diabetes was achieved, rabbits with blood glucose levels above $300 \mathrm{mg} / \mathrm{dl}$ were selected for the experiments. Animals in groups VI, VII \& VIII, received by oral gavage, the seed powder of $T$. foenum-graecum at doses of 50, 100 and $150 \mathrm{mg} / \mathrm{kg}$ respectively. Group IX (positive control) received glibenclamide by oral gavage at a dose of $40 \mu \mathrm{g} / \mathrm{kg}$ while group X served as diabetic control.

\subsection{Blood Collection and Analytical Procedure}

Approximately $0.3 \mathrm{~mL}$ of blood samples were drawn from the marginal ear vein of rabbits before and also at 4, 6, 8, 10, 12, 16, 18, $20 \& 24 \mathrm{~h}$ after treatment. The samples were collected in glass vials that contained a small amount of an anti-coagulant mixture of potassium oxalate and sodium fluoride. Separation of plasma was done by centrifuging at $2000 \mathrm{rpm}$ and stored at $-20^{\circ} \mathrm{C}$ until analysis for glucose by Nelson-Somogyi's method [36, 37] using a visible spectrophotometer.

\subsection{Data and Statistical Analysis}

Data was presented as a means \pm SEM. To examine the quantitative differences among the experimental groups, the respective data were subjected to analysis of variance (ANOVA) using GraphPad Prism-7.03 (GraphPad Software Inc., California, CA) statistical programme. Post hoc comparisons were made using Student's unpaired $t$-test. In all tests, $\mathrm{p}<0.05$ value was used as the criterion for statistical significance.

\section{Results}

\subsection{T. foenum-graecum Lowered Blood Glucose in Normal Rabbits}

In normal rabbits the seed powder of $T$. foenum-graecum produced dose-dependent hypoglycemia. A maximum reduction in blood glucose of $9.4 \%$ (105.8 vs $95.4 ; 6 \mathrm{~h}$ ), $26.9 \%$ (106.4 vs $77.8 ; 8 \mathrm{~h}, \mathrm{p}<0.01$ ), and $39.2 \%$ (108.2 vs $65.8 ; 10 \mathrm{~h}, \mathrm{p}<0.001)$ with doses of 50,100 and $150 \mathrm{mg} / \mathrm{kg}$ body weight respectively (Table 1 ) and the glucose reduction tendency continued up to 24 hours with 100 and $150 \mathrm{mg} / \mathrm{kg}$ doses. Glibenclamide $(40 \mu \mathrm{g} / \mathrm{kg})$ produced a significant $(\mathrm{p}<0.01)$ reduction of blood glucose relative with control $(31.9 \%, 8 \mathrm{~h})$. 
Table 1 Effect of $T$. foenum-graecum seed powder on blood glucose levels after oral administration in normal rabbits.

\begin{tabular}{|c|c|c|c|c|c|c|c|c|c|c|}
\hline \multirow{2}{*}{$\begin{array}{l}\text { Group } \\
(n=5)\end{array}$} & \multirow{2}{*}{ Dose } & \multicolumn{9}{|c|}{ Blood glucose levels (mg/dL) } \\
\hline & & 4 & 6 & 8 & 10 & 12 & 16 & 18 & 20 & $24(h)$ \\
\hline Control & --- & $\begin{array}{c}107.2 \pm \\
5.3\end{array}$ & $\begin{array}{l}105.8 \\
\pm 6.5\end{array}$ & $\begin{array}{c}106.4 \pm \\
6.2\end{array}$ & $\begin{array}{c}108.2 \pm \\
5.1\end{array}$ & $\begin{array}{c}103.5 \pm \\
6.3\end{array}$ & $\begin{array}{c}106.1 \pm \\
4.3\end{array}$ & $\begin{array}{l}105.4 \\
\pm 9.9\end{array}$ & $\begin{array}{l}100.9 \\
\pm 5.5\end{array}$ & $\begin{array}{c}104.8 \pm \\
4.7\end{array}$ \\
\hline $\begin{array}{l}\text { T. foenum- } \\
\text { graecum }\end{array}$ & $\begin{array}{c}50 \\
\mathrm{mg} / \mathrm{kg}\end{array}$ & $\begin{array}{c}100.3 \pm \\
3.5\end{array}$ & $\begin{array}{c}95.4 \pm \\
4.5\end{array}$ & $\begin{array}{c}98.0 \pm \\
5.7\end{array}$ & $\begin{array}{c}101.6 \pm \\
4.8\end{array}$ & $\begin{array}{c}103.8 \pm \\
4.6\end{array}$ & $\begin{array}{c}105.1 \pm \\
3.3\end{array}$ & $\begin{array}{l}101.6 \\
\pm 4.4\end{array}$ & $\begin{array}{c}98.1 \pm \\
6.3\end{array}$ & $\begin{array}{l}101.0 \\
\pm 6.7\end{array}$ \\
\hline $\begin{array}{l}\text { T. foenum- } \\
\text { graecum }\end{array}$ & $\begin{array}{c}100 \\
\mathrm{mg} / \mathrm{kg}\end{array}$ & $\begin{array}{l}90.2 \pm \\
5.8^{* *}\end{array}$ & $\begin{array}{c}82.3 \pm \\
6.4^{* *}\end{array}$ & $\begin{array}{l}77.8 \pm \\
5.9^{* *}\end{array}$ & $\begin{array}{l}83.4 \pm \\
6.1^{* *}\end{array}$ & $\begin{array}{c}79.0 \pm \\
6.8^{* *}\end{array}$ & $\begin{array}{l}84.7 \pm \\
5.8 * * *\end{array}$ & $\begin{array}{r}84.8 \\
\pm 6.5\end{array}$ & $\begin{array}{c}82.2 \pm \\
7.6^{*}\end{array}$ & $\begin{array}{c}88.9 \pm \\
5.9 * *\end{array}$ \\
\hline $\begin{array}{l}\text { T. foenum- } \\
\text { graecum }\end{array}$ & $\begin{array}{c}150 \\
\mathrm{mg} / \mathrm{kg}\end{array}$ & $\begin{array}{l}76.5 \pm \\
6.9 * * *\end{array}$ & $\begin{array}{c}67.6 \pm \\
6.9 * * *\end{array}$ & $\begin{array}{l}67.5 \pm \\
6.5^{* * *}\end{array}$ & $\begin{array}{l}65.8 \pm \\
5.7^{* * *}\end{array}$ & $73.4 \pm 4.1^{* *}$ & $\begin{array}{c}75.2 \pm \\
6.1 * * *\end{array}$ & $88.2 \pm 6.4$ & $\begin{array}{c}87.2 \pm \\
8.7^{*}\end{array}$ & $\begin{array}{c}92.9 \pm \\
6.6^{*}\end{array}$ \\
\hline Glibenclamide & $\begin{array}{c}40 \\
\mu \mathrm{g} / \mathrm{kg}\end{array}$ & $\begin{array}{l}79.9 \pm \\
4.1^{* *}\end{array}$ & $\begin{array}{l}74.4 \pm \\
4.9 * *\end{array}$ & $72.5 \pm 4.8^{* *}$ & $\begin{array}{c}76.0 \pm \\
5.2^{* *}\end{array}$ & $74.2 \pm 4.7^{* *}$ & $81.6 \pm 3.6^{* *}$ & $82.3 \pm 3.6$ & $80.8 \pm 7.4$ & $86.8 \pm 4.7$ \\
\hline
\end{tabular}


OBM Integrative and Complementary Medicine 2020; 5(3), doi:10.21926/obm.icm.2003036

Table 2 Effect of $T$. foenum-graecum seed powder on blood glucose levels after oral administration in alloxan-induced diabetic rabbits.

\begin{tabular}{|c|c|c|c|c|c|c|c|c|c|c|}
\hline \multirow{2}{*}{$\begin{array}{l}\text { Group } \\
(n=5)\end{array}$} & \multirow{2}{*}{ Dose } & \multicolumn{9}{|c|}{ Blood glucose levels (mg/dL) } \\
\hline & & 4 & 6 & 8 & 10 & 12 & 16 & 18 & 20 & $24(h)$ \\
\hline Control & --- & $\begin{array}{c}324.7 \pm \\
9.3\end{array}$ & $\begin{array}{c}316.5 \pm \\
11.2\end{array}$ & $\begin{array}{c}312.8 \pm \\
10.4\end{array}$ & $\begin{array}{c}315.9 \pm \\
10.9\end{array}$ & $\begin{array}{r}310.1 \\
\pm 12.2\end{array}$ & $\begin{array}{c}310.6 \pm \\
10.5\end{array}$ & $\begin{array}{c}305.4 \pm \\
11.9\end{array}$ & $\begin{array}{c}307.5 \pm \\
10.1\end{array}$ & $\begin{array}{c}312.5 \\
\pm \\
10.3\end{array}$ \\
\hline $\begin{array}{l}\text { T. foenum- } \\
\text { graecum }\end{array}$ & $\begin{array}{c}50 \\
\mathrm{mg} / \mathrm{kg}\end{array}$ & $\begin{array}{l}293.8 \pm \\
8.3 * * *\end{array}$ & $\begin{array}{l}277.2 \pm \\
10.7^{* * *}\end{array}$ & $\begin{array}{l}277.9 \pm \\
12.7^{* * *}\end{array}$ & $\begin{array}{l}292.5 \pm \\
9.8^{* * *}\end{array}$ & $\begin{array}{c}291.3 \\
\pm \\
9.9 * * *\end{array}$ & $\begin{array}{c}297.6 \pm \\
10.3^{* *}\end{array}$ & $\begin{array}{l}273.5 \pm \\
11.4^{* *}\end{array}$ & $\begin{array}{c}300.1 \pm \\
10.7^{* *}\end{array}$ & $\begin{array}{c}308.0 \\
\pm \\
11.3\end{array}$ \\
\hline $\begin{array}{l}T . \text { foenum- } \\
\text { graecum }\end{array}$ & $\begin{array}{c}100 \\
\mathrm{mg} / \mathrm{kg}\end{array}$ & $\begin{array}{c}265.5 \pm \\
9.6 * *\end{array}$ & $\begin{array}{l}235.5 \pm \\
12.2 * * *\end{array}$ & $\begin{array}{l}211.0 \pm \\
11.8 * * *\end{array}$ & $\begin{array}{l}232.3 \pm \\
12.7^{* * *}\end{array}$ & $\begin{array}{c}247.5 \\
\pm \\
8.4^{* * *}\end{array}$ & $\begin{array}{l}262.8 \pm \\
12.8 * * *\end{array}$ & $\begin{array}{l}268.5 \pm \\
12.2^{* *}\end{array}$ & $\begin{array}{c}278.6 \pm \\
11.9 *\end{array}$ & $\begin{array}{c}295.5 \\
\pm \\
12.3\end{array}$ \\
\hline $\begin{array}{l}T . \text { foenum- } \\
\text { graecum }\end{array}$ & $\begin{array}{c}150 \\
\mathrm{mg} / \mathrm{kg}\end{array}$ & $\begin{array}{l}258.1 \pm \\
10.8 * *\end{array}$ & $\begin{array}{l}226.3 \pm \\
9.6 * * *\end{array}$ & $\begin{array}{l}173.5 \pm \\
12.2 * * *\end{array}$ & $\begin{array}{l}206.6 \pm \\
14.9 * * *\end{array}$ & $\begin{array}{l}223.0 \pm \\
13.2 * * *\end{array}$ & $\begin{array}{c}248.3 \pm \\
15.6^{* *}\end{array}$ & $\begin{array}{l}270.1 \pm \\
13.2 * *\end{array}$ & $\begin{array}{l}284.4 \pm \\
12.4^{* *}\end{array}$ & $\begin{array}{c}297.3 \pm \\
13.2\end{array}$ \\
\hline Glibenclamide & $\begin{array}{c}40 \\
\mu \mathrm{g} / \mathrm{kg}\end{array}$ & $\begin{array}{l}253.0 \pm \\
10.6 * * *\end{array}$ & $\begin{array}{l}226.5 \pm \\
10.5^{* * *}\end{array}$ & $\begin{array}{l}205.8 \pm \\
14.6 * * *\end{array}$ & $\begin{array}{c}225.2 \pm \\
16.5^{* *}\end{array}$ & $\begin{array}{c}233.3 \pm \\
15.7^{* *}\end{array}$ & $\begin{array}{l}234.5 \pm \\
14.1 * * *\end{array}$ & $\begin{array}{c}240.9 \pm \\
15.6 * *\end{array}$ & $\begin{array}{c}254.0 \pm \\
19.8^{*}\end{array}$ & $\begin{array}{c}266.9 \pm \\
15.9 *\end{array}$ \\
\hline
\end{tabular}

Values are the mean blood glucose ( \pm S.E.M.) of five animals.

Significant difference from control at corresponding intervals: ${ }^{*} p<0.05, * * p<0.01, * * * p<0.001$ 


\subsection{T. foenum-graecum Lowered Blood Glucose in Diabetic Rabbits}

The diabetic rabbits treated with $T$. foenum-graecum also displayed a dose-dependent decrease in blood glucose. However, a higher reduction of blood glucose was seen in the diabetic rabbits compared with the normal rabbits. A significant reduction $(p<0.001)$ of blood glucose of $12.4 \%$ (316.5 vs 277.2; 6 h), 32.5\% (312.8 vs 211.0; 8 h) and $44.6 \%$ (312.8 vs 173.5; 8 h) respectively was seen with $T$. foenum-graecum at doses of 50, 100 and $150 \mathrm{mg} / \mathrm{kg}$ body weight (Table 2). Although less significant, the glucose lowering tendency continued up to 20 hours with all the doses of $T$. foenum-graecum. Glibenclamide $(40 \mu \mathrm{g} / \mathrm{kg})$ resulted in a significant reduction $(p<0.001)$ in blood glucose at $8 \mathrm{~h}(34.1 \%)$ compared to diabetic control.

\section{Discussion}

Diabetes mellitus is probably the biggest rising metabolic condition in the world, and as understanding of this complex condition is advanced, there is an increasing need for more effective treatment $[9,36]$. Traditional plant medicinal products are used for a variety of diabetic complications around the world. Studying such medicines could give a natural key for opening the potential pharmacy of a diabetologist. The seeds of $T$. foenum-graecum are commonly used for managing diabetes in India. For this reason, the seed powder of $T$. foenum-graecum was tested, and the results verified the conventional indications as well. The findings of our experiments on rabbits are also substantiated by earlier investigations [20, 22, 37, 38]. In addition, our findings also suggest a prolonged period of antidiabetic activity that could be attributed to several sites of activity possessed by the active principles of $\mathrm{T}$. foenum-graecum.

Earlier, it was reported that the seed powder of $T$. foenum-graecum lowered blood glucose in normal and streptozotocin-induced diabetic rats [37]. Our present study in rabbit model also substantiates the previous results observed in rats. Herefele and colleagues isolated galactomannan and 4-hydroxy isoleusine, an insulin releasing substance from the seeds that appears to be responsible for the hypoglycaemic effect of $T$. foenum-graecum [39]. Additionally, another potential action mechanism of $T$. foenum-graecum is an effect on the digestion of intestinal carbohydrate, as shown by the strong inhibitory effect on the digestive enzymes [40, 41].

Alloxan, a beta-cytotoxin induces significant death of pancreatic $\beta$-cells leading to decreased synthesis and release of insulin [42-44]. Sulphonylureas are well known to cause hypoglycaemia by increasing insulin secretion from the pancreas $[45,46]$ and these compounds are active in mild diabetes induced by alloxan while they are inactive in intense alloxan diabetes (nearly all $\beta$-cells were destroyed). Since our findings have shown that glibenclamide has decreased blood glucose levels in hyperglycemic animals, diabetes status is not severe. Alloxan-treated animals receiving the seed powder of $T$. foenum-graecum showed rapid normalisation of blood glucose levels relative to control and this may be due to the fact that certain $\beta$-cells still survive to function on $T$. foenum-graecum to exert its insulin releasing effect. In addition, hypoglycaemia was produced in normal animals by oral administration of $T$. foenum-graecum in the same way as sulphonylureas. This indicates that the mode of action of the active ingredients of $T$. foenum-graecum is possibly mediated by an increased insulin secretion, like sulphonylureas. Nevertheless, the likelihood increased tissue glucose utilization by $T$. foenum-graecum cannot be ruled out. It is speculated that one or more of the previously isolated bioactive compounds of $T$. foenum-graecum could be 
responsible for the observed acute lowering of blood glucose. Further work on fractionation, purification, identification of active principle(s) and detailed mechanistic evaluation is obviously required on the seeds of $T$. foenum-graecum.

\section{Conclusion}

Our research clearly showed a major anti-diabetic activity with $T$. foenum-graecum seed powder, and supports the traditional use of seed powder for diabetes control. This can also help to avoid diabetic complications and act as a strong adjuvant in the new anti-diabetic medication armamentarium.

\section{Author Contributions}

SN, RA, HG and VI made substantial contributions to conception design and conduction of research. SN and RA designed the study and executed the project. Data collection, analysis, graphical representation and interpretation were done by HG and SN. Article was written by HG and VI. Critical revision of the article was done by SN and RA. Critical statistical analysis was done by HG and VI. All Authors read and approved the final manuscripts.

\section{Funding}

The financial assistance provided by University Grants Commission, New Delhi, India to SN is greatly acknowledged.

\section{Competing Interests}

The authors declare that they have no conflicts of interest concerning this article.

\section{References}

1. Wild S, Roglic G, Green A, Sicree R, King H. Global prevalence of diabetes: Estimates for the year 2000 and projections for 2030. Diabetes Care. 2004; 27: 1047-1053.

2. Aude YW, Mego P, Mehta JL. Metabolic syndrome: Dietary interventions. Curr Opin Cardiol. 2004; 19: 473-479.

3. Ivorra MD, Paya M, Villar A. A review of natural products and plants as potential antidiabetic drugs. J Ethnopharmacol. 1989; 27: 243-275.

4. Alarcon-Aguilara FJ, Roman-Ramos R, Perez-Gutierrez S, Aguilar-Contreras A, ContrerasWeber CC, Flores-Saenz JL. Study of the anti-hyperglycemic effect of plants used as antidiabetics. J Ethnopharmacol. 1998; 61: 101-110.

5. Kar A, Choudhary BK, Bandyopadhyay NG. Preliminary studies on the inorganic constituents of some indigenous hypoglycaemic herbs on oral glucose tolerance test. J Ethnopharmacol. 1999; 64: 179-184.

6. Grover JK, Yadav S, Vats V. Medicinal plants of India with anti-diabetic potential. J Ethnopharmacol. 2002; 81: 81-100. 
7. Rao N, Nammi S. Antidiabetic and renoprotective effects of the chloroform extract of Terminalia chebula Retz. seeds in streptozotocin-induced diabetic rats. BMC Complement Altern Med. 2006; 6: 17.

8. Patel DK, Prasad SK, Kumar R, Hemalatha S. An overview on antidiabetic medicinal plants having insulin mimetic property. Asian Pac J Trop Biomed. 2012; 2: 320-330.

9. Nammi S, Boini M, Lodagala S, Behara RB. The juice of fresh leaves of Catharanthus roseus Linn. reduces blood glucose in normal and alloxan diabetic rabbits. BMC Complement Altern Med. 2003; 3: 4.

10. Morton JF. Mucilaginous plants and their uses in medicine. J Ethnopharmacol. 1990; 29: 245266.

11. Kirtikar KR. BB. Indian Medicinal Plant. 3rd ed. Allahabad: Lalit Mohan Prakashan; 2000.

12. Fazli FRY Hardman R. The spice, fenugrek (Trigonella foenum-graecum): Its commercial varieties of seed as a source of diosgenin. Trop Sci. 1986; 10: 66-78.

13. Chopra RN Cl, Honda KL, Kapur LD. Chopra's Indigenous Drugs of India. Calcutta,: Academic Publishers; 1982.

14. Girardon P, Bessiere JM, Baccou JC, Sauvaire Y. Volatile constituents of fenugreek seeds. Planta Medica. 1985; 51: 533-534.

15. Max B. This and that: The essential pharmacology of herbs and spices. Trends Pharmacol Sci. 1992; 13: 15-20.

16. Sharma RD. Effect of fenugreek seeds and leaves on blood glucose and serum insulin responses in human subjects. Nutr Res. 1986; 6: 1353-1364.

17. Hannan JM, Ali L, Rokeya B, Khaleque J, Akhter M, Flatt PR, et al. Soluble dietary fibre fraction of Trigonella foenum-graecum (fenugreek) seed improves glucose homeostasis in animal models of type 1 and type 2 diabetes by delaying carbohydrate digestion and absorption, and enhancing insulin action. Br J Nutr. 2007; 97: 514-521.

18. Vijayakumar MV, Singh S, Chhipa RR, Bhat MK. The hypoglycaemic activity of fenugreek seed extract is mediated through the stimulation of an insulin signalling pathway. Br J Nutr. 2005; 146: 41-48.

19. Broca C, Manteghetti M, Gross R, Baissac $Y$, Jacob M, Petit P, et al. 4-Hydroxyisoleucine: Effects of synthetic and natural analogues on insulin secretion. Eur J Pharmacol. 2000; 390: 339-345.

20. Abdel-Barry JA, Abdel-Hassan IA, Al-Hakiem MH. Hypoglycaemic and antihyperglycaemic effects of Trigonella foenum-graecum leaf in normal and alloxan induced diabetic rats. J Ethnopharmacol. 1997; 58: 149-155.

21. Ribes G, Sauvaire Y, Baccou JC, Valette G, Chenon D, Trimble ER, et al. Effects of fenugreek seeds on endocrine pancreatic secretions in dogs. Ann Nutr Metab. 1984; 28: 37-43.

22. Vats V, Grover JK, Rathi SS. Evaluation of anti-hyperglycemic and hypoglycemic effect of Trigonella foenum-graecum Linn, Ocimum sanctum Linn and Pterocarpus marsupium Linn in normal and alloxanized diabetic rats. J Ethnopharmacol. 2002; 79: 95-100.

23. Kassaian N, Azadbakht L, Forghani B, Amini M. Effect of fenugreek seeds on blood glucose and lipid profiles in type 2 diabetic patients. Int J Vitam Nutr Res. 2009; 79: 34-39.

24. Alamdari KA CS, Jadidi JP. Antidiabetic effects of exercise and fenugreek supplementation in males with NIDDM. Med Sport. 2009; 62: 315-324. 
25. Gopalpura PB JC, Dubey S Effect of Trigonella foenum-graecum seeds on the glycemic index of food: A clinical evaluation. Int J Diab Dev Ctries. 2007; 27: 41-45.

26. Sharma S, Mishra V, Srivastava N. Protective effect of Trigonella foenum-graecum and Cinnamomum zeylanicum against diabetes induced oxidative DNA damage in rats. Indian J Biochem Biophys. 2020; 57: 15-26

27. Pradeepkiran JA, Venkata SN, Matcha B. Trigonella foenum-graecum seeds extract plays a beneficial role on brain antioxidant and oxidative status in alloxan-induced Wistar rats. Food Qual Safe. 2020; 4: 83-89.

28. Ota A, Ulrih NP: An overview of herbal products and secondary metabolites used for management of type two diabetes. Front Pharmacol. 2017; 8: 436.

29. Chevassus H, Molinier N, Costa F, Galtier F, Renard E, Petit P. A fenugreek seed extract selectively reduces spontaneous fat consumption in healthy volunteers. Eur J Clin Pharmacol. 2009; 65: 1175-1178.

30. Mathern JR, Raatz SK, Thomas W, Slavin JL. Effect of fenugreek fiber on satiety, blood glucose and insulin response and energy intake in obese subjects. Phytothe Res. 2009; 23: 1543-1548.

31. Al Meshal IA PN, Tariq M, Aqeel AM. Gastric antiulcer activity in rats of Trigonella foenumgraecum (Hu-Lupa). Fitoterarapia. 1985; 56: 232-235.

32. Zargar S. Protective effect of Trigonella foenum-graecum on thioacetamide induced hepatotoxicity in rats. Saudi J Biol Sci. 2014; 21: 139-145.

33. Singhal P, Gupta, RK, Joshi, LD. Hypochlesterolaemic effect of Trigonella foenum-graecum (Methi). Curr Sci. 1982.; 51: 136-137.

34. Valette G SY, Beccou JC, Ribes G. Hypocholesterolemic effect of fenugreek seeds in dogs. Athersclerosis. 1984: 105-111.

35. Neelakantan N, Narayanan M, de Souza R, van Dam R. Effect of fenugreek (Trigonella foenumgraecum L.) intake on glycemia: A meta-analysis of clinical trials. Nutr J. 2014; $13: 7$.

36. Patel $D$, Prasad $S$, Kumar R, Hemalatha $S$. An overview on antidiabetic medicinal plants having insulin mimetic property. Asian Pac J Trop Biomed. 2012; 2: 320-330.

37. Ali L, Azad Khan AK, Hassan Z, Mosihuzzaman M, Nahar N, Nasreen T, et al. Characterization of the hypoglycemic effects of Trigonella foenum graecum seed. Planta Med. 1995; 61: 358360.

38. Khosla P, Gupta DD, Nagpal RK. Effect of Trigonella foenum graecum (Fenugreek) on blood glucose in normal and diabetic rats. Indian J Physiol Pharmacol. 1995; 39: 173-174.

39. Haefele C, Bonfils C, Sauvaire Y. Characterization of a dioxygenase from Trigonella foenumgraecum involved in 4-hydroxyisoleucine biosynthesis. Phytochemistry. 1997; 44: 563-566.

40. Wong S, Traianedes K, O'Dea K. Factors affecting the rate of hydrolysis of starch in legumes. Am J Clin Nutr. 1985; 42: 38-43.

41. Edwards CA, Johnson IT, Read NW. Do viscous polysaccharides slow absorption by inhibiting diffusion or convection? Eur J Clin Nutr. 1988; 42: 307-312.

42. Lenzen S. The mechanisms of alloxan- and streptozotocin-induced diabetes. Diabetologia. 2008; 51: 216-226.

43. Szkudelski T. The mechanism of alloxan and streptozotocin action in B cells of the rat pancreas. Physiolo Res. 2001; 50: 537-546.

44. Rohilla A, Ali S. Alloxan induced diabetes: Mechanisms and effects. Int J Res Pharm Biomed Sci. 2012; 3: 819-823. 
45. Grodsky GM EG, Fanska R, Karam JH. Pancreatic action of sulphonylurea. Fed Proc. 1971; 36: 2719-2728.

46. Yalow RS, Black H, Villazon M, Berson SA. Comparison of plasma insulin levels following administration of tolbutamide and glucose. Diabetes. 1960; 9: 356-362.

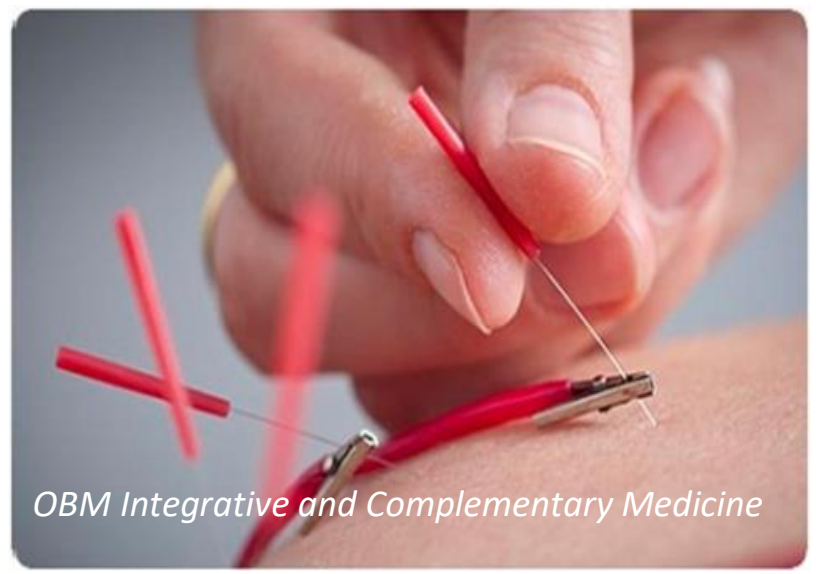

Enjoy OBM Integrative and Complementary Medicine by:

1. Submitting a manuscript

2. Joining in volunteer reviewer bank

3. Joining Editorial Board

4. Guest editing a special issue

For more details, please visit: http://www.lidsen.com/journals/icm 
Review

\section{Serious Illness Management: A Fuller Approach to Integrative Palliative Care}

Melissa Gaule*, Erin Allen, Kathleen Benton

Hospice Savannah, Inc., 1352 Eisenhower Drive, Savannah, GA, USA; E-Mails: mgaule@hospicesavannah.org; eallen@hospicesavannah.org; kbenton@hospicesavannah.org

* Correspondence: Melissa Gaule; E-Mail: mgaule@HospiceSavannah.org

Academic Editor: Leila Kozak

Special Issue: Integrative Therapies in Palliative Care

OBM Integrative and Complementary Medicine Received: March 29, 2020

2020 , volume 5 , issue 3

Accepted: August 21, 2020

doi:10.21926/obm.icm.2003037

Published: August 26, 2020

Across the nation, hospitals have established comprehensive palliative care programs to help patients navigate the complexities of serious illness by utilizing interdisciplinary teams of specialized physicians, nurses, social workers and chaplains within the acute setting. The annual report card from the Center to Advance Palliative Care [1] shows an uptick in hospitals that have these programs, but there are clear disparities in access to care and new opportunity for palliative care to continue evolving to include integrative therapies and better serve its mission to help people live longer with the best possible quality of life.

The question programs like the Steward Center for Palliative Care in Savannah, Georgia must answer is: how best do we meet the needs of our seriously ill neighbors outside the inpatient setting and provide a truly integrative palliative service? The Steward Center established an outpatient clinic four years ago to offer support to patients after they leave the hospital and while this has been a successful addition, there have been key learnings that have inspired a new approach to the care we provide. Firstly, we serve a patient population that is amongst the most underserved in the country. Georgia reports that at least $16 \%$ of its population, or approximately 
1.38 million people, lack insurance coverage, increasing incidence of chronic illness, and low socioeconomic status just to name a few risk factors [2]. It's rural populations tend to have greater overall health disparities when compared to urban populations leading to higher rates of COPD, cardiovascular disease and cancer among residents [3]. This makes attending a clinic appointment very difficult for people, especially for those who are experiencing symptom exacerbation. Secondly, we know that many physicians and patients still do not understand the difference between palliative care and hospice, leading to stigma that often prohibits early access to palliative treatment [4]. Above all else, we know that true integrative palliative care is more than a one-shot conversation in the hospital or clinic and it includes more than medical management. Thus, in order to truly understand how our team can add value and honestly establish trust with our patients, our care must follow them home and integrate their environment and unique needs into the care plan. However, with the burden of low reimbursement rates for palliative services coupled with state regulations that prohibit cost-effective means of staffing home-based programs, this is not an easy task.

Over the last nine months, the Steward Center has implemented a model of care that utilizes palliative social workers and nurse practitioners called Serious Illness Management (SIM). The SIM model expands on current approaches by bringing palliative care to the emergency room, nursing homes, assisted living facilities and into the homes of especially complex patients as a means of early and continuous intervention. The social work component functions on trigger criteria rather than physician referral, effectively eliminating the connection to palliative care being dependent on the training of hospital physicians. If a patient meets criterion, the "Serious IIIness Specialist" (SIS) connects with the patient in the emergency room to provide a social assessment focused on palliative needs, goals of care and barriers to effective symptom management, advocates for a consult to palliative care when appropriate, and facilitates earlier intervention for other supportive services. This not only provides focus to the patients care plan by helping physicians and nursing staff identify goals of care and limitations to traditional symptom management before an admission, it aims to provide cost savings to the hospital and health plan by avoiding expenditure that is not in line with a patient's wishes. The program identified 1491 patients that screened positive for intervention from a SIS and successfully navigated 552 of those patients in the first six months, focusing limited human resource on patients who had repeat visits to the emergency department and a diagnosis of congestive heart failure (CHF) or chronic obstructive pulmonary disease (COPD). Utilizing a workflow that touches on as many variables of the patient's lived experience as possible, the SIM team realized great success at discovering where exactly things were going wrong in the care plan and helped the patient find a way to overcome barriers to success.

For patients discharging to nursing homes and assisted living facilities served by the Steward Center, our nurse practitioners and social workers go to them. This has been the most eyeopening aspect of our program. Of the patients we are able to follow to their home setting, 79\% have not had a readmission or repeat emergency room visit. There have been clear improvements to crisis management, ongoing advance care planning and earlier transition into hospice. Patients and families have direct access to palliative care all the time to ensure that they have the opportunity to stay ahead of a crisis through after hours' tele-services, on-call providers and holistic resources for managing symptom burden without medication. 


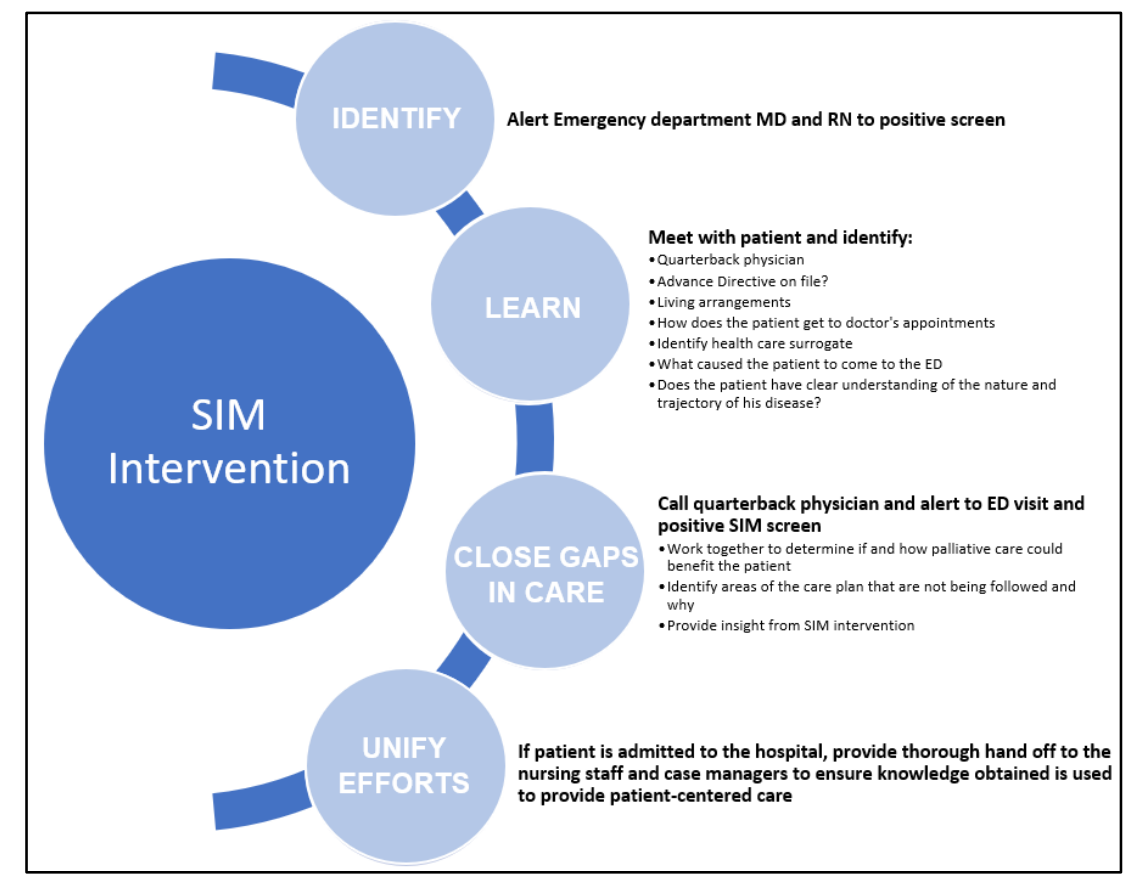

Figure 1 The Serious Illness Management Intervention figure above shows the process utilized to identify patient care plan issues and intervention strategy aimed at closing any gaps in care and removing barriers to accessing palliative care

Although palliative care focuses on improving quality of life for seriously ill patients, many programs often have an emphasis on traditional medical intervention, giving less weight to the potential impact of integrative therapies. For many of the patients identified through the SIM model, restrictions on controlled substances, unique physical traits of the patient, past traumas or a desire to avoid opioids posed a barrier to providing lasting pain relief. By introducing integrative therapies like massage, music therapy and our most popular, virtual reality, the SIM models offers a fuller approach to palliative care that can be tailored to a patient's lived experience.

Mr. Hall, an 87-year-old man suffering with worsening COPD with a history of frequenting the emergency room for symptom relief is a valuable case study for the success of the SIM model.

Mr. Hall arrived at the emergency room on a Sunday evening for the seventh time in the last six months. The doctors and nurses knew his face well and were sad to see him there again struggling to breathe, overwhelmed with anxiety. He had previously experienced a respiratory event resulting in a month long hospital stay where he required ventilator support. The fear of experiencing that again was palpable. Given his progressive illness and frequent visits to the emergency room, the Serious IIIness Specialist (SIS) was alerted and quickly went to the patient to learn more about his and his family's concerns and determine what services and resources could help. "I get so nervous when I get short of breath. I just panic! And every time, I end up back here." the patient shared.

During their interaction, the SIS was able to learn that the patient relied on the help of his older wife, a very tired caregiver who was running out of ideas on how to help her husband. The patient shared that he was living at a nursing home and that all of the staff were not equally prepared to help him with breathing treatments when he went into distress. As more light was shed on the dynamics of his care and his hopes for the future it also became clear that Mr. Hall had not had the opportunity to fill out an Advance Directive or POLST form to make clear what his wishes were. 
From there, the SIS called Mr. Hall's pulmonologist, the quarterback of his care team, to let him know his patient was in the emergency room again and initiate a discussion about palliative care. Within an hour, the physician placed an order for Mr. Hall to be seen by the Palliative Care team and the SIS had arranged for his wife to be present for the consultation while he was in the observation unit. By the next morning, a plan was in place for the patient to return to a different nursing home that offered the additional palliative support. The SIS mediated a thorough discussion about advanced care planning and the patient was able to convey his treatment preferences to his wife and make sure his children were also informed about his goals for future intervention. Once Mr. Hall was discharged and set up in his new facility, virtual reality was introduced as a way for him to cope with the anxiety that comes with managing difficulty breathing. It has now been five months since Mr. Hall was last seen in the emergency department, but he does report that he takes occasional virtual trips to the mountains to help calm his nerves and avoid the panic he had previously been accustomed to when he experiences periods of exacerbated symptoms. This, for us, illustrates that the trajectory of a patient's care can be transformed when we prioritize the need to meet patients where they are and incorporate strategies for coping that address their unique experience alongside the disease process.

Although our results are limited given the SIM program is in its infancy, they draw attention to the change that is needed to have lasting impact. We have to take charge of the full continuum of care to fully support patients, families and other specialty providers. When our teams become an integral part of the entire disease management process, patients live longer with better quality of life outside of the hospital. There is much for legislators, health systems and payors to change in order for this type of care to be provided efficiently and effectively for the broader population. Georgia has some of the most restrictive laws that govern the practice of nurse practitioners making it very costly to provide home-based care. Given our area's rural geography, the organizational cost of physicians making house calls is a sizeable burden. In states like Washington and Oregon where mid-level providers can be utilized to the full extent of their ability, models similar to Serious Illness Management are flourishing [5]. This suggests a need for further research and outcomes reporting to show the impact of integrative palliative care beyond its traditional, acute care functions.

\section{Author Contributions}

K.B. conceived the idea for the Serious IIIness Management program and supervised the project. M.G. developed the programming and performed the data collection. E.A. verified the research methods. All authors discussed the results and contributed to the final manuscript. M.G. carried out the qualitative work that informed the findings of this article. M.G. wrote this article with support from E.A. and K.B.

\section{Competing Interests}

The authors have declared that no competing interests exist. 


\section{References}

1. Morrison RS, Augustin R, Souvanna P, Meier DE. America's care of serious illness: A state-bystate report card on access to palliative care in our nation's hospitals. J Palliat Med. 2011; 14: 1094-1096.

2. University of Wisconsin Population Health Institute. County Health Rankings State Report 2020.

3. Eberhardt MS, Pamuk ER. The importance of place of residence: Examining health in rural and nonrural areas. Am J Public Health. 2004; 94: 1682-1686.

4. Kavalieratos D, Mitchell EM, Carey TS, Dev S, Biddle AK, Reeve BB, et al. "Not the 'grim reaper service'": An assessment of provider knowledge, attitudes, and perceptions regarding palliative care referral barriers in heart failure. J Am Heart Assoc. 2014; 3: e000544.

5. State Nurse State Practice Acts and Administration Rules, 2017 CAmerican Association of Nurse Practitioners, 2017.

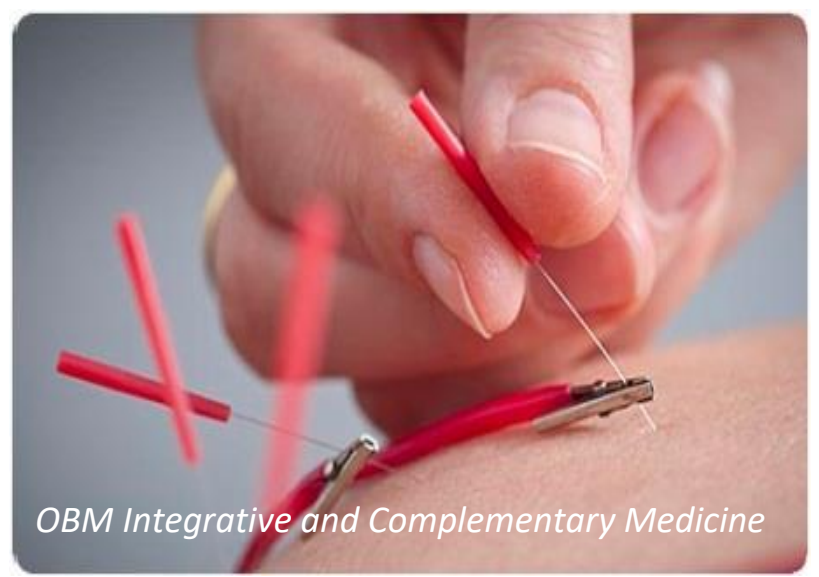

Enjoy OBM Integrative and Complementary Medicine by:

1. Submitting a manuscript

2. Joining in volunteer reviewer bank

3. Joining Editorial Board

4. Guest editing a special issue

For more details, please visit:

http://www.lidsen.com/journals/icm 
Review

\title{
Health Benefits of Green Tea in Obesity
}

\author{
Mario F. Tecce ${ }^{1}$, Walter Milano ${ }^{2}$, Anna Capasso ${ }^{1,}{ }^{*}$
}

1. Department of Pharmacy, University of Salerno, Fisciano (Salerno), Italy; E-Mails: tecce@unisa.it; annacap@unisa.it; pharmacologyunisa@gmail.com

2. U.O.S.D. Eating Disorder Unit - Mental Health Department ASL Napoli 2 Nord, Napoli, Italy; EMail: wamilano@tin.it

* Correspondence: Anna Capasso; E-Mails: annacap@unisa.it; pharmacologyunisa@gmail.com

Academic Editor: Rafat A. Siddiqui

Special Issue: Managing Obesity through Nutraceuticals

OBM Integrative and Complementary Medicine

2020, volume 5 , issue 3

doi:10.21926/obm.icm.2003038
Received: June 26, 2020

Accepted: August 17, 2020

Published: August 30, 2020

\begin{abstract}
Adipocytes play a central role in maintaining lipid homeostasis and energy balance by storing triacylglycerols (TAGs) or releasing free fatty acids in response to changes in energy requirements. Obesity is a major risk factor for many diseases, including diabetes, hypertension, and cardiovascular disease. Besides, morbidity and mortality associated with being overweight and obese are on the rise. The development of obesity is characterized by an increase in lipid cells due to mitogenesis and differentiation, which are regulated by genetic, endocrine, metabolic, neurological, pharmacological, environmental, and nutritional factors. Therefore, understanding the mechanism by which a given nutrient affects the mitogenesis of preadipocytes and their differentiation into adipocytes could help prevent the onset and progression of obesity, along with all its consequences in humans. It has been shown that nutraceuticals such as tea catechins and BCAAs (leucine, isoleucine, and valine) could be effective in preventing obesity. Green tea catechins (CTGs) are polyphenolic flavonoids, which were previously called vitamin P. CTGs, especially EGCGs, have been shown to reduce body weight and body fat. In support of its anti-obesity effect, some in vivo data have shown that EGCG or green tea extract containing EGCG reduces the absorption of
\end{abstract}

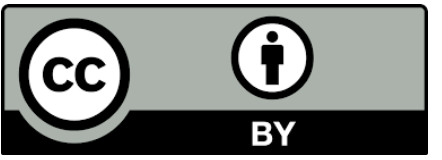

(C) 2020 by the author. This is an open access article distributed under the conditions of the Creative Commons by Attribution License, which permits unrestricted use, distribution, and reproduction in any medium or format, provided the original work is correctly cited. 
food, lipids, TAGs, cholesterol, and leptins. Furthermore, it stimulates energy expenditure and fat oxidation, and ultimately increases the level of high-density lipoproteins and fecal excretion of lipids. EGCG regulates various enzymes linked to anabolism and lipid catabolism, such as acetyl-CoA carboxylase (ACC), fatty acid synthase, pancreatic lipase, gastric lipase, and lipoxygenase; it also reduces the increase in insulin (INS) and TAG during the differentiation period of nine days. Taken together, these observations, in vivo and in vitro, suggest that the EGCG contained in green tea can modulate the mitogenic, endocrine, and metabolic functions of fat cells. In this study, we report the biochemical and biological evidence indicating the benefits of green tea in obesity.

\section{Keywords}

Diet; green tea; nutraceuticals; obesity; overweight

\section{Introduction}

From an etiological point of view, obesity has a multifactorial origin and is connected to modifiable risk factors (behaviors, lifestyle, and living conditions) and non-modifiable risk factors (genetic determinants) [1-5].

When the calorie intake exceeds calorie expenditure, a state of positive energy balance occurs, which increases body mass. A person can, therefore, become obese if, despite having normal energy expenditure, the calorie intake is excessive or if, despite feeding properly, he has a deficit in energy metabolism [6]. The complexity of the problem is determined by multilevel, interpersonal (family, social networks), community (school, workplaces, institutions), governmental influences (local, regional, national context, and policies). Even behavioral risk factors, including incorrect eating habits and sedentary lifestyle, which are often considered the main determinants of overweight and obesity, are strongly affected by complex collective dynamics involving large sectors of society: from families to schools, from health institutions to social organizations and mass media [7].

In parallel with the increase in the incidence of obesity and the progression of obese individuals toward higher BMI values, there is an increased risk of comorbidity. In Europe, overweight and obesity are responsible for about:

- $80 \%$ of cases of type 2 diabetes

- $55 \%$ of cases of high blood pressure

- $35 \%$ of cases of ischemic heart disease

All this translates into 1 million deaths and 12 million patients a year worldwide [8].

All the main obesity guidelines indicate that the first step of therapy is lifestyle modification through nutritional intervention, an increase in structured physical activity, and behavioral changes. However, long-term treatment is problematic and requires an integrated approach, which uses the tools available in a complementary way, making use of different professional skills, which share the same therapeutic objective [8]. It has now been established that to conquer the obesity epidemic; it is necessary to resort to various therapies (nutritional, cognitive-behavioral, pharmacological, and surgical) according to the individual patient [8]. The clinical goal must be to 
significantly decrease the bodyweight to significantly improve the risks associated with obesity, especially cardiovascular ones. However, if this strategy seems insufficient or ineffective, obese individuals can resort to drug therapy, taking into account that chronic diseases such as obesity must be managed, and treatment must be adapted to the individual patient [8].

Along with diet, physical activity (appropriate to the type of patient) and possibly also behavioral therapy must be combined. According to the American guidelines, the duration of drug therapy ranges from six months to one year for more complex cases. The use of surgical interventions is recommended only for extreme cases, for patients presenting acute obesity (with $\mathrm{BMI}>35-40$ ) and other comorbidities, who are at high risk of mortality, or who do not respond to other treatments. Besides, in recent years, there has been increasing use of natural remedies as adjuvants in the treatment of obesity, and green tea seems to be an effective remedy in the prevention of obesity [9].

\section{Green Tea: Biochemical and Biological Basis for Health Benefits in Obesity}

Many bioactive nutrients of vegetable origin present in the diet intervene in multiple cell signaling pathways. Some of these nutrients are currently investigated, while others have already been approved for their beneficial effects. They are named nutraceutical, a term formed by the combination of words "nutrition" and "pharmaceutical", which was coined by Stephen De Felice in 1989 [10] to simply designate any substance considered a food (or part of a food) and can provide health benefits. These nutrients are chemically different molecules, which can act as molecular targets in specific tumorigenesis processes-proliferation, invasion, angiogenesis, and metastasis [10].

Modern medical research has confirmed that drinking tea regularly brings numerous health benefits. This is due to the presence of polyphenols, in particular (-) - epigallocatechin-3-gallate [11]. In China, tea is generally believed to prolong and improve people's lives. Among the types of tea, green tea, white tea, yellow tea, and Oolong are considered the healthiest as the type of processing to obtain these teas allows them to retain healthy substances [11].

Adipocytes play a central role in maintaining lipid homeostasis and energy balance, accumulating triacylglycerols (TAGs), or releasing free fatty acids, in response to changes in energy needs. Obesity is an important risk factor for a range of ailments, including diabetes, hypertension, and cardiovascular disease. The prevalence of morbidity and mortality associated with obesity has been increasing. The development of obesity is characterized by an increase in lipid cells due to mitogenesis and differentiation, which are regulated by genetic, endocrine, metabolic, neurological, pharmacological, environmental, and nutritional factors. As a result, understanding the mechanism by which a given nutrient affects preadipocyte mitogenesis and their differentiation into adipocytes could help prevent the onset and progression of obesity along with its consequences [12].

Also, based on the data from experimental animal models, the World Cancer Research Fund and American Institute for Cancer Research published a report in 2007 on the causal relationship between high body fat and an increased risk of CRC (colorectal cancer). Meta-analysis studies also revealed that the level of $C R C$ risk was greater among obese men compared to non-obese men [13]. Studies have shown that nutraceuticals such as tea catechins and BCAAs (leucine, isoleucine, 
and valine) could be effective in preventing both colorectal and liver-related carcinogenesis and obesity [14].

\section{EGCG Reduces Body Fat}

Green tea catechins (CTG) are polyphenolic flavonoids, which were previously called vitamin P. CTGs, especially EGCGs, in addition to reducing the incidence of tumors, collagenopathies, neurodegenerative diseases induced by oxidative stress and streptozotocin-induced diabetes, are shown to reduce body weight and body fat [15]. In support of this anti-obesity effect, some in vivo data have shown that EGCG or EGCG-containing green tea extract reduces the absorption of food, lipids, TAGs, cholesterol, and leptins. Also, it stimulates energy expenditure and oxidation of fats and finally increases the level of high-density lipoproteins and fecal excretion of lipids [15]. EGCG regulates various enzymes linked to lipid anabolism and catabolism, such as acetyl-CoA carboxylase (ACC), fatty acid synthase, pancreatic lipase, gastric lipase, and lipoxygenase; it also reduces the increase in insulin (INS) and TAG in a 9-day differentiation period. Taken together, these in vivo and in vitro observations suggest that EGCG contained in green tea is capable of modulating the mitogenic, endocrine, and metabolic functions of fat cells [16].

\section{Effects of EGCG on Cell Viability in 3T3-L1 Cultures}

A study was conducted to evaluate the anti-adipogenic action of EGCG and to understand how this molecule acts to reduce the expression of adipocyte protein markers and their target genes during the differentiation of 3T3-L1 cells. 3T3-L1 is a cell line derived from mouse 3T3 cells that are used in biological research on adipose tissue because they differentiate into cells with a phenotype similar to adipocytes. The specific objective of this study was to establish the molecular mechanisms underlying the mitigating effect of EGCG on cell viability, adipocyte differentiation, and lipid accumulation [16].

It is well known that obesity results in increased size (hypertrophy) and number (hyperplasia) of adipocytes [17]. CTG treatment can decrease both the cell number and cell viability [18]. A significant reduction in cell viability was immediately observed after treatment, at different concentrations and time, with three specific catechins, in particular-EC, EGC, and EGCG. The results showed that with the increase in time and concentration, EGCG was the most effective of the three. In the study, the variation in cell viability was measured using a representative concentration of EGCG $(100 \mu \mathrm{M})$, with particular attention to the duration of treatment and differentiation of adipocytes: the differentiation was induced by exposing the cells to a culture medium consisting of $10 \%$ fetal bovine serum, $10 \mu \mathrm{g} / \mathrm{mL}$ of INS (insulin), $1 \mu \mathrm{M}$ of dexamethasone, and $0.5 \mu \mathrm{M}$ of 3-isobutyl-1-methylxanthines for $72 \mathrm{~h}$. It has been shown that short-term treatment ( 3 and five days) did not affect the viability of 3T3-L1 cells, while long-term treatment (6, 7, and 12 days) decreased cell viability. These results suggest that treatment with EGCG during differentiation of adipocytes is necessary and sufficient to prevent the accumulation of mature adipocytes [16]. 


\section{Effects of EGCG on Adipocyte Differentiation}

Also, during exercise, there is increased activity of AMPK (AMP-activate protein kinase) in the muscle. AMPK is a protein kinase that modulates cellular metabolism by phosphorylation of different enzymes. It checks the energy status and signals when the level is low. Its activation takes place when there is a cellular energy deficit, just like during physical exercise, where the activated AMPK blocks the production of adipocytes, promoting the increase in energy consumption and weight loss.

Activated AMPK promotes a series of a metabolic cascade of events such as:

- increase in fat burning processes;

- increase in the number of mitochondria, so that more energy (ATP) can be obtained from fat;

- inhibition of gluconeogenetic processes, to encourage the use of fat as energy;

- reduction in insulin release, which would otherwise promote the accumulation of additional fat.

Activation of AMPK by EGCG appears to be involved in the inhibition of differentiation of 3T3L1 cells, grown in normal medium, and then exposed to EGCG in the differentiation medium. The percentage of activation of AMPK and the phosphorylation of its acetyl-CoA carboxylase (P-ACC) substrate was subsequently measured using western blot. As a result, the phosphorylation of both AMPK (P-AMPK) and ACC (P-ACC) has significantly increased in a time-dependent manner [16]. Therefore, in this study, we demonstrated how the inhibitory effect of EGCG on the differentiation of adipocytes is dependent on the activation of AMPK.

\section{Effect of EGCG on the Accumulation of Lipids during the Differentiation of Adipocytes}

The anti-adipogenic effect of EGCG on 3T3-L1 cells was assessed based on the duration of treatment in hormone-induced adipogenesis (insulin increases the differentiation of adipocytes and the accumulation of lipids) [19]. In this study, a high percentage of 3T3-L1 cells, treated with adipogenic cocktails of INS, dexamethasone, and 3-isobutyl-1-methylxanthine, acquired the typical morphology of differentiated fat cells. At this point, the lipid accumulations were detected by staining with ORO (Oil Red O) of the differentiated 3T3-L1 cells (with untreated induction) compared to the control (without untreated induction). However, ORO staining and TAG content were attenuated by longer duration of EGCG treatment, while no reduction in lipid and TAG accumulation was observed after short-term treatment ( 3 days). Interestingly, the TAG content was not affected by EGCG treatment even on day 5, suggesting that longer treatment (6.7, and 12 days) is important for the anti-adipogenic effect of EGCG. These results confirm the antiadipogenic effect of EGCG on 3T3-L1 cells, also the inhibitory effect on hormone-induced adipogenesis [16].

\section{Green Tea Extract Contributes to the Prevention of NAFLD}

It is well known that a diet rich in saturated fat (HFD) and low in dietary fiber, can lead to obesity. Obesity, just like any other systemic and multifactorial disease, causes more damage than simple adipocyte hypertrophy [20]. By nonalcoholic hepatic steatosis (NAFLD), we mean nothing more than the hepatic manifestation of obesity which, will be the main cause of liver cirrhosis reducible by transplant in the next 20 years [21]. 
The liver is a vital organ for maintaining body homeostasis and to prevent and combat the onset of NAFLD. With the increase in visceral adiposity, there is an increase in the supply of nonesterified fatty acids (NEFA) to the liver. Studies have shown that the fraction of NEFA delivered to the liver by visceral fat is proportionally related to the area of visceral fat, and it is about $5-10 \%$ in normal-weight subjects and $20-30 \%$ in obese subjects. In the liver, NEFA is both oxidized and esterified to form triglycerides (TAG): the latter is thus stored in the cytosol before being incorporated into VLDL and then secreted. Now, when TAG production exceeds NEFA oxidation and VLDL secretion, TAGs accumulate in the liver, resulting in the development of NAFLD [22]. In another study, the level of NEFA was increased in the experimental groups, and, as we will see, the subsequent treatment through supplementation of green tea extract was able to reduce it, contributing to the prevention of the development of NAFLD [23].

\section{Experimental Study on Mice Fed with HFD}

The decaffeinated green tea extract can restore a normal hepatic metabolic profile and mitigate the effects induced by a high-fat diet (HFD), thereby preventing nonalcoholic fatty liver disease in mice. In a study by Santamarina et al. [23], the mice were maintained on a control (CD) or HFD diet for 16 weeks by supplementing this diet with water or green tea extract $(50 \mathrm{mg} / \mathrm{kg} / \mathrm{die}$ ) rich in EGCG. During the treatment, the increase in body mass, the level of adiponectin in the serum, and the lipid profile were measured; also, the expression of the pathway of the AMPK protein in the liver was measured. These experiments showed that mice fed a supplement of decaffeinated green tea extract benefited best from the antiadipogenic effect. The animals were divided into four experimental groups according to the type of diet (CD or HFD) and the type of supplement (decaffeinated green tea extract or water):

- $\mathrm{CD}+$ water $=\mathrm{CW}$ group

- $\mathrm{CD}+$ decaffeinated green tea extract $=\mathrm{CE}$ group

- $\mathrm{HFD}+$ water $=$ HFW group

- HFD + decaffeinated green tea extract = HFE group

From week 4, weight gain in the CE group was less than that in the CW group; from the 8th week, the weight acquired in the HFW group was higher than that of the CW group. Furthermore, the weight gain in the HFE group was lower than in the HFW group. The lipid content in the HFW group was higher than the other groups [23]. The serum analysis showed a decrease in the level of non-esterified fatty acids and an increase in the level of adiponectin in the CE and HFE groups compared to their corresponding placebo group. An increase in the secretion of VLDL-TG was observed in the HFW group compared to the CW and HFE groups while in the HFE group there was an increase in the expression of proteins, AdipoR2, SIRT1, pLKB1, and PAMPK, which explains the reduced expression of ACC, FAS, SREBP-1, and ChREBP in this group. These results indicate that the effects of decaffeinated green tea extract may be related to the activation of AMPK via LKB1 (liver serine/threonine kinase and main activator of AMPK) in the liver of HFD-fed mice [23].

\section{Green Tea Extract in the Regulation of Lipogenesis}

LKB1 phosphorylation appears to be necessary for AMPK activation; the role of adiponectin in the activation of LKB1 is controversial where one study demonstrated its stimulation [24], while the other one did not [25]. The complex formed by LKB1 and AMPK has a key role in regulating the 
metabolism of liver fatty acids: this complex is activated by phosphorylation. Several molecules activate LKB1 in the liver: one of them is SIRT1. Activated AMPK (phosphorylated) can modulate lipogenesis, and also its phosphorylation leads to the phosphorylation and inactivation of acetylCoA carboxylase (ACC), which is an important regulatory enzyme in the synthesis of fatty acids [26]. ACC catalyzes the conversion of acetyl-CoA to malonyl-CoA, which becomes a substrate for fatty acid synthase (FAS), an enzyme involved in the synthesis of fatty acids. The inhibition of ACC by AMPK, therefore, reduces the substrate flow for FAS, leading to a decrease in its activity. Moreover, AMPK is a negative regulator of SREBP-1c (sterol element-binding protein) and ChREBP (carbohydrate response element-binding protein), important transcription factors that activate lipogenic genes: this means that the increase in AMPK phosphorylation also determines a decrease in the level of nuclear SREBP $1-c$ and ChREBP $[27,28]$.

Studies have shown that a single dose of green tea extract can increase the level of liver AMPK and the phosphorylation of LKB1, manifesting the powerful effects of green tea on these molecules. The extract could reduce the risk of obesity and have concrete protective effects against liver damage [29]. Stimulation of AMPK phosphorylation, which in turn inhibits ACC and FAS activity, could reduce the accumulation of liver triglycerides. Considering the lack of studies on the effect of decaffeinated green tea extract on the activation of AMPK via LKB1, we aimed to study the effects of green tea supplements on the activation of enzymes and factors related to liver lipogenesis, in conjunction with the secretion of VLDL-TG in HFD-fed mice [23].

\section{EGCG increases AMPK level}

In recent years, several authors have described that green tea polyphenols and isolated EGCG are effective in increasing the level of adiponectin in serum and the expression of its receptor proteins (AdipoR1 and AdipoR2) in humans and mice fed with HFD [30]. The expression of the adiponectin gene is mainly regulated by the nuclear receptor PPAR-y (peroxisome proliferatoractivated receptor): this recognizes and activates specific transcription factors that regulate gene expression. PPARs bind to specific regions of DNA called peroxisome proliferator response elements (PPRE), located in the promoter of genes subject to regulation. PPAR-y receptors are mainly expressed in adipose tissue, but also in the skeletal muscle, liver, heart, and kidney and regulate adipogenesis and lipid metabolism. They also regulate the expression of hormones or cytokines secreted by the adipocyte, such as leptin, adiponectin, and TNF-alpha. Thus, researchers have shown that green tea polyphenols can increase the expression of PPAR-y by reducing its phosphorylation [31]. Based on these results, it was found that green tea extract is also responsible for the increase in the level of adiponectin and AdipoR2, which in turn mediate the activation of SIRT1 protein [23].

Based on this hypothesis that adiponectin, through its receptor more abundant in the liver (AdipoR2), can stimulate the activation of SIRT1 in the HFE group, where SIRT1 itself, seems to have activated AMPK through an LKB1-dependent pathway. When activated, LKB1 migrates from the nucleus to the cytoplasm of the hepatocytes, where it induces phosphorylation of the $\alpha A M P K$ subunit, the main culprit of AMPK activity in the liver of rodents [32]. Therefore, activated AMPK can keep the forms SREBP1C and ChREBP phosphorylated in the cytoplasm and prevent them from reaching the nucleus. ChREBP and SREBP 1-c are transcription factors that regulate the expression of liver enzymes involved in lipogenesis, and they can bind to the transcription promoter genes of 
lipogenic proteins such as ACC and FAS. Both, ChREBP and SREBP 1-c remain in an inactive form in the cytoplasm, connected to a phosphate group: their dephosphorylated (active) form has, however, demonstrated the ability to move to the nucleus and stimulate the synthesis of lipogenic enzymes. Consequently, the AMPK activating cascade resulted in the reduction of the expression of these enzymes in the liver of the subjects of the HFE group compared to the HFW group [23].

Activated AMPK also allowed the simultaneous reduction of ACC and FAS: when phosphorylated, ACC is in its inactive form, and we have observed that supplementation with green tea extract has increased the PACC level as well as reduced the level of FAS, indicating a further element that allowed the reduction of the synthesis of fatty acids from the path of lipogenesis [23].

Overall, these results indicate that green tea extract supplementation has been able to improve liver metabolism and reduce the absorption of NEFA in the liver; this led to a decrease in the hepatic secretion of VLDL-TG, decreased lipid synthesis, and increased adiponectin in HFD-fed mice. It has been observed that the integration of green tea extract has also been shown to stimulate the activation of AMPK via LKB1 through adiponectin, in HFD-fed mice, and to regulate essential enzymes involved in the path of lipogenesis in the liver. In all these respects, it can certainly contribute to the prevention and treatment of NAFLD.

\section{Green Tea Protects Blood Vessels}

Green tea can intervene in the protection of blood vessels. In the late 1960s, scientists from the University of California compared the level of arteriosclerosis in the arteries of the brain and coronary arteries of about 300 western coffee drinkers and 100 Chinese tea drinkers based on values measured following autopsies performed during a decade. Compared to coffee drinkers, only two-thirds of tea drinkers had coronary artery damage, and only a third of brain artery damage. To study this phenomenon more closely, animal guinea pigs were fed with high-fat foods for three months so that they develop arteriosclerosis, and some of them were also given green tea along with drinking water. After three months, the blood vessels of these animals were less compromised than those of the animals who had only water. The scientists discovered that arteriosclerosis is combated with tea if it is taken at the same time or immediately after a high-fat meal. The Japanese and Chinese habit of drinking green tea during meals is therefore completely justified. In the meantime, it has been established that epigallocatechin gallate contained in the tea is the only compound responsible for reducing the cholesterol level. In the early 1980s, a study was conducted in Japan to verify whether green tea exerted a preventive effect on cardiovascular and liver diseases: in this regard, more than 1300 men were interviewed and examined; blood tests performed during this study indicated that those who drank lots of green tea had a much lower total cholesterol rate, resulting in a lower risk of arteriosclerosis. However, the most sensational discovery was that green tea could "distinguish" useful (HDL) and harmful (LDL) cholesterol: the rate of "good" cholesterol in the blood was increased in those who consumed the green tea regularly [33]

\section{Green Tea Modulates the Gut Microbiota}

Nowadays, a new thought is emerging due to the recent scientific discoveries that intestinal microbiota is directly responsible for the management of body weight. Many studies have shown 
that microbiota balance is a decisive element in ensuring the correct intestinal absorption of macronutrients. Metagenomic studies in obese patients have highlighted how obesity is associated with an imbalance in bacterial flora, with the proliferation of potentially pathogenic bacteria [34]. The alteration of the microbiota can affect the metabolism and energy homeostasis and is involved in the control of body weight through the extraction of an additional amount of calories from ingested food [35]. The mechanism is linked to the extraction of energy from food components such as polysaccharides (cellulose, hemicellulose, non-digestible starch, pectins, gums) which are processed by bacterial enzymes with the production of monosaccharides (subsequently absorbed) and short-chain fatty acids (SCFA, mainly acetate, butyrate, and propionate) that participate in the breakdown of fats in the liver, through the expression of some key enzymes such as acetyl-CoA carboxylase (ACC) and fatty acid synthase (FAS). The conversion of fermentable dietary fibers into SCFAs provides additional energy for the host, suggesting the possibility to promote obesity in this way [36]. In the context of digestive processes, we can make a rough distinction between fermentative flora that can digest starch and other polysaccharides, and putrefactive flora involved in putrefaction, anaerobic metabolization of peptides and proteins (elastin and collagen from food sources, pancreatic enzymes, exfoliated epithelial cells, and lysed bacteria), which determines the production of SCFA and potentially toxic substances, including ammonia, amines, phenols, thiols, and indoles [35]. The intestinal epithelium is covered by a double layer of mucus, internal and external, secreted by the goblet cells, and filled with mucins. These are glycosylated proteins that allow the intestinal mucus to perform a lubricating, trophic, and protective action against the mucosal epithelial cells. Its concentration strictly depends on a dynamic and delicate balance between synthesis, secretion, and degradation of the mucins that constitute it.

A recent study demonstrated the efficacy of a diet based on $2 \%$ green tea extract on mice [37]. Specifically, green tea suppressed inflammation and improved the health of the intestinal bacterial flora, which are the two key factors in preventing obesity. To demonstrate this, the researchers selected two groups of male mice; the first group was fed on a normal diet, the second group a high-fat one. To half of the members of each group, green tea extract was supplemented in the food. During the 8-week experimental period, the body weight and body mass index, insulin resistance, and other indicators of intestinal health, such as permeability, the composition of the bacterial population, and level of inflammation, were measured. It was found that half of the mice fed on a fat diet along with green tea gained less than $20 \%$ of weight than those fed on a fat diet without tea. In parallel, inflammation and insulin resistance dropped. Therefore, it is interesting to see how the mice treated with tea had a more impermeable and healthier intestine. On the contrary, the permeable intestine, also called "leaky gut," allows bacterial fragments and digestive residues to pass into the blood more easily, inducing generalized inflammation throughout the body. Finally, the healthiest species of the gut bacteria population were found in green tea fed mice. These results were also found in mice fed with tea and normal diet, in more modest percentages, than those fed on a fat diet. This confirms that lifestyle changes are especially useful for those who are ill [37]. Mice fed on a high-fat diet, and green tea gained about 20 percent less weight and had lower insulin resistance than mice fed on an identical diet without tea. The amount of green tea in the experiment would be equivalent to about 10 cups of green tea per person. A daily consumption value would not be far from the usual consumption in some areas of 
the world. This study provides evidence that green tea encourages the growth of good gut bacteria, and leads to several benefits that significantly reduce the risk of obesity [37].

\section{Conclusions}

In conclusion, the habitual consumption of green tea could prove to be an effective method to prevent obesity over time. Besides, green tea extracts can improve the physiological profile of the organism at certain doses. However, it is still too early to affirm the therapeutic activity of green tea extracts in the treatment of obesity, but some in vitro studies have shown that EGCG, the main polyphenolic component of green tea, is an efficient molecule for several molecular targets. Therefore, the discovery of EGCG as an inhibitor of multiple signaling pathways which, unlike specific inhibitors of single targets could reduce drug resistance by hindering the activation of alternative signaling pathways, constituting a step forward toward the introduction of a new drug, capable of acting against many important diseases such as obesity.

Concrete results have also been identified in the treatment of diseases associated with obesity: by reducing the number and activity of lipid cells. EGCG can reduce the obesity "factor" and all the pathologies, including diabetes, hypertension, and nonalcoholic hepatic steatosis (NAFLD), also demonstrating excellent prospects on its ability to reduce the absorption of lipids and stimulate energy expenditure. Several in vitro studies have shown that EGCG reduces cell viability, lipid differentiation, and accumulation through the activation of AMPK kinase and the consequent phosphorylation and inactivation of acetyl-CoA carboxylase, an important regulator of synthesis of fatty acids. The only limitation is that a dose of $100 \mu \mathrm{M}$ of EGCG did not give any result on shortterm lipid reduction, but a prolonged treatment for 12 days reduced cell viability and accumulation of lipids, in particular, triglycerides and cholesterol in adipocytic cells.

However, decaffeinated green tea extract that is essentially rich in EGCG restored a normal hepatic metabolic profile in mice fed with a high-fat diet (HFD), preventing the development of nonalcoholic liver steatosis, which is identified as a hepatic manifestation of obesity. Furthermore, serum analysis showed a reduction in the levels of non-esterified fatty acids and an increase in adiponectin, which is responsible for the activation of AMPK via LKB1 in the liver. Therefore, this signaling process, as in obesity, reduces the activation of acetyl-CoA carboxylase. Also, in this case, the duration of treatment influenced the study result, ensuring a reduction in body weight and body fat accumulation in mice after 16 weeks of treatment with $50 \mathrm{mg} / \mathrm{kg} / \mathrm{day}$.

Overall, green tea extract has proven to be an excellent compound for the evaluation of new drug formulations and supplements, which are already sold in the market. However, tea contains two molecules-caffeine and theine. Although present in small quantities and its effect is reduced in association with polyphenols present in tea, it is mainly responsible for side effects and drug interactions. Finally, we can conclude by saying that how much enjoying a good cup of tea can only help your health.

\section{Author Contributions}

Study concept and design: Mario F. Tecce and Anna Capasso.

Acquisition, analysis, or interpretation of data: All authors.

Drafting of the manuscript: All authors.

Critical revision of the manuscript for important intellectual content: All authors. 
Study supervision: Mario F. Tecce and Anna Capasso.

\section{Competing Interests}

The authors have declared that no competing interests exist.

\section{References}

1. OECD. The heavy burden of obesity: The economics of prevention. Paris: OECD Publishing; 2019.

2. GBD 2017 Diet Collaborators. Health effects of dietary risks in 195 countries, 1990-2017: A systematic analysis for the Global Burden of Disease Study 2017. Lancet. 2019; 393: 19581972. doi: 10.1016/S0140-6736(19)30041-8.

3. Pednekar MS, Jóźwiak J, Kolsteren P, Giwercman A, Van-Herck K, Bettiol H, et al. Worldwide trends in body-mass index, underweight, overweight, and obesity from 1975 to 2016: A pooled analysis of 2416 population-based measurement studies in 128.9 million children, adolescents, and adults. Lancet. 2017; 390: 2627-2642. doi: 10.1016/S0140-6736(17)32129-3.

4. Yang W, Kelly T, He J. Genetic epidemiology of obesity. Epidemiol Rev. 2007; 29: 49-61.

5. Swinburn BA, Sacks G, Hall KD, McPherson K, Finegood DT, Moodie ML, et al. The global obesity pandemic: Shaped by global drivers and local environments. Lancet. 2011; 378: 804814.

6. Magni P. Obesity: Pathophysiology and new diagnostic perspectives, page 5. Kaleidoscope Italia.

7. Lang T, Rayner G. Overcoming policy cacophony on obesity: An ecological public health framework for policymakers. Obes Rev. 2007; 8: 165-181.

8. Italian Standards for the Treatment of Obesity 2016-2017 Italian Obesity Society (SIO) and Italian Association of Dietetics and Clinical Nutrition (ADI).

9. Prasanth MI, Sivamaruthi BS, Chaiyasut C, Tencomnao T. A review of the role of green tea (camellia sinensis) in antiphotoaging, stress resistance, neuroprotection, and autophagy. Nutrients. 2019; 11: 474.

10. DeFelice SL. The NutraCeutical revolution: Fueling a powerful, new international market. 1989.

11. Ferruzzi MG. The influence of beverage composition on delivery of phenolic compounds from coffee and tea. Physiol Behav. 2010; 100: 33-41.

12. Unger RH, Zhou YT. Lipotoxicity of beta-cells in obesity and in other causes of fatty acid spillover. Diabetes. 2001; 50: S118.

13. Renehan AG, Tyson $M$, Egger $M$, Heller RF, Zwahlen $M$. Body mass index and incidence of cancer: A systematic review and meta-analysis of prospective observational studies. Lancet. 2008; 371: 569-578.

14. Shimizu M, Kubota M, Tanaka T, Moriwaki H. Nutraceutical approach for preventing obesityrelated colorectal and liver carcinogenesis. Int J Mol Sci. 2012; 13: 579-595.

15. Liao S, Kao YH, Hiipakka RA. Green tea: Biochemical and biological basis for health benefits. Vitam Horm. 2011; 62: 1-94.

16. Moon HS, Chung CS, Lee HG, Kim TG, Choi YJ, Cho CS. Inhibitory effect of epigallocatechin-3gallate on lipid accumulation of 3T3-L1 cells. Obesity. 2007; 15: 2571-2582. 
17. Wolfram S, Wang Y, Thielecke F. Anti-obesity effects of green tea: From bedside to bench. Mol Nutr Food Res. 2006; 50: 176-187.

18. Hung PF, Wu BT, Chen $\mathrm{HC}$, Chen $\mathrm{YH}$. Antimitogenic effect of green tea epigallocatechin gallate on 3T3-L1 preadipocytes depends on the ERK and Cdk2 pathways. Am J Physiol Cell Physiol. 2005; 288: C1094-C1108.

19. Scavo LM, Karas $M$, Murray $M$, Leroith $D$. Insulin-like growth factor stimulates both cell growth and lipogenesis during differentiation of human mesenchymal stem cells into adipocytes. J Clin Endocrinol Metab. 2004; 89: 3543-3553.

20. Gregor MF, Hotamisligil GS. Inflammatory mechanisms in obesity. Annu Rev Immunol. 2011; 29: 415-445.

21. Charlton MR, Burns JM, Pedersen R, Watt KD, Heimbach JK, Dierkhising R. Frequency and outcomes of liver transplantation for nonalcoholic steatohepatitis in the United States. Gastroenterology. 2011; 141: 1249-1253.

22. Stanhope KL, Havel PJ. Fructose consumption: Potential mechanisms for its effects to increase visceral adiposity and induce dyslipidemia and insulin resistance. Curr Opin Lipidol. 2008; 19: 16-24.

23. Santamarina AB, Oliveira JL, Silva FP, Carnier J, Mennitti LV, Santana AA, et al. Green tea extract rich in epigallocatechin-3-gallate prevents fatty liver by AMPK activation via LKB1 in mice fed a high-fat. PloS ONE. 2015; 10: e0141227.

24. Blagih J, Krawczyk CM, Jones RG. LKB1 and AMPK: Central regulators of lymphocyte metabolism and function. Immunol Rev. 2012; 249: 59-71.

25. Shearn CT, Smathers RL, Jiang H, Orlicky DJ, Maclean KN, Petersen DR. Increased dietary fat contributes to dysregulation of the LKB1/AMPK pathway and increased damage in a mouse model of early stage ethanol mediated steatosis. J Nutr Biochem. 2013; 1: 1436-1445.

26. Hasenour CM, Berglund ED, Wasserman DH. Emerging role of AMP-activated protein kinase in endocrine control of metabolism in the liver. Mol Cell Endocrinol. 2013; 366: 152-162.

27. Seo HY, Kim MK, Jung YA, Jang BK, Yoo EK, Park KG, et al. Clusterin decreases hepatic SREBP1c expression and lipid accumulation. Endocrinology. 2013; 154: 1722-1730.

28. lizuka K. Recent progress on the role of ChREBP in glucose and lipid metabolism. Endocrinology. 2013; 60: 543-555.

29. Banerjee S, Ghoshal S, Porter TD. Phosphorylation of hepatic AMP activated protein kinase and liver kinase B1 is increased after a single oral dose of green tea extract to mice. Nutr Res. 2012; 32: 985-990.

30. Wang S, Moustaid-Moussa N, Chen L, Mo H, Shastri A, Su R, et al. Novel insights of dietary polyphenols and obesity. J Nutr Biochem. 2014; 25: 1-18.

31. Tian C, Ye X, Zhang R, Long J, Ren W, Ding S, et al. Green tea polyphenols reduced fat deposits in high fat-fed rats via erk1/2-PPARY-adiponectin pathway. PLoS ONE. 2013; 8: e53796.

32. Cantó C, Auwerx J. PGC-1alpha, SIRT1 and AMPK, an energy sensing network that controls energy expenditure. Curr Opin Lipidol. 2009; 20: 98-105.

33. Hu HF, Zerbst M. Il tè verde. Milano: Tecniche Nuove; 1999.

34. Dao MC, Clement K. Gut microbiota and obesity: Concepts relevant to clinical care. Eur J Int Med. 2018; 48: 18-24.

35. Angelakis $E$, Armougom F, Million M, Raoult D. The relationship between gut microbiota and weight gain in humans. Future Microbiol. 2012; 7: 91-109. 
36. Krajmalnik-Brown R, Ilhan ZE, Kang DW, DiBaise JK. Effects of gut microbes on nutrient absorption and energy regulation. Nutr Clin Pract. 2012; 27: 201-214.

37. Chung E, Campise SN, Joiner HE, Tomison MD, Kaur G, Dufour JM, et al. Effect of annattoextracted tocotrienols and green tea polyphenols on glucose homeostasis and skeletal muscle metabolism in obese male mice. J Nutr Biochem. 2019; 67: 36-43.

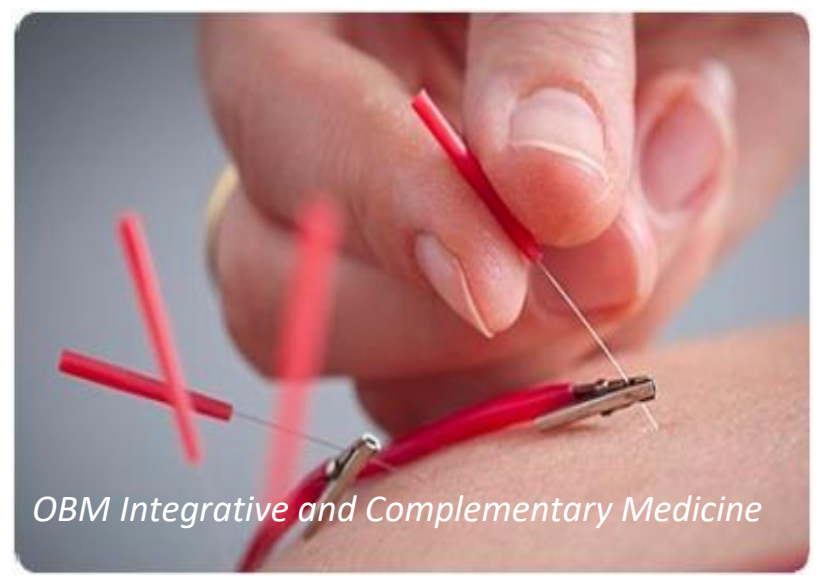

Enjoy OBM Integrative and Complementary Medicine by:

1. Submitting a manuscript

2. Joining in volunteer reviewer bank

3. Joining Editorial Board

4. Guest editing a special issue

For more details, please visit:

http://www.lidsen.com/journals/icm 
Editorial

\title{
Hypnosis: From Neural Mechanisms to Clinical Practice
}

\author{
Giuseppe De Benedittis *
}

Department of Neurosurgery, University of Milan, Italy; E-Mail: giuseppe.debenedittis@unimi.it

* Correspondence: Giuseppe De Benedittis; E-Mail: giuseppe.debenedittis@unimi.it

Academic Editor: Giuseppe De Benedittis

Special Issue: $\underline{\text { Hypnosis: From Neural Mechanisms to Clinical Practice }}$

OBM Integrative and Complementary Medicine 2020, volume 5 , issue 3

doi:10.21926/obm.icm.2003039
Received: August 25, 2020

Accepted: August 28, 2020

Published: August 31, 2020

Hypnosis is the oldest psychotherapy and is one of the oldest and most popularly-practiced methods for control of pain and other stress-related chronic disorders. The chequered history shows unsurpassed adaptive power of hypnosis, enabling it to survive till date [1].

Though having witnessed variations over centuries, the current interest in hypnosis has become stronger; hypnosis has emerged both as a useful topic for scientific research and an effective technique in clinical applications and therapeutic interventions.

Hypnosis has remained poorly understood for long primarily due to lack of knowledge about objective neurobiological markers of trance state, but continuous advances in neuroscience in past several decades, largely due to the introduction and refinement of sophisticated electrophysiological and neuroimaging techniques, have opened up a "bridge of knowledge" between the classic neurophysiological studies and psychophysiological studies of cognitive, emotional, and sensory systems [1]. Still many of the basic questions regarding hypnosis remain unanswered.

The Society of Psychological Hypnosis, Division 30 of the American Psychological Association, has defined hypnosis as "a state of consciousness involving focused attention and reduced peripheral awareness characterized by an enhanced capacity for response to suggestion" [2]. 
Of late, hypnosis has gained huge popularity in the health care and education sectors [3]. However, the exact role of hypnosis remains incompletely explored, and the mechanisms of its precise neural, biophysical, biochemical, and neurochemical actions remain inadequately understood. This Special Issue addresses some of the crucial questions relating to the neural mechanisms of hypnosis and improves understanding of hypnotic practices.

Thirteen acclaimed researchers and clinicians from all over the world were invited to present their perspectives, research findings, and recommendations for future work. The articles in this issue offer critical analysis, cutting edge research, clinical perspectives, and directions for future research and clinical practice. Through focusing on experimental research, this issue will prove extremely insightful for the clinicians, researchers, academicians, and medical scientists, thereby filling the gap between basic research and clinical practice, offering amply-useful therapeutic interventions.

In taking stock, Green et al. [4] (this issue) critically discuss the historical link between hypnotic responsiveness and dissociation. The Authors utilize scales of non-pathological dissociation and of pathological dissociation, failing to find any significant correlation with hypnotic responsiveness. In contrast, expectancies were the most influential in terms of variance accounted for in predicting hypnotizability.

Low-to-moderate statistically significant correlations were found between behavioral measures of hypnotizability with absorption and fantasy-proneness, with moderate-to-high correlations of measures of dissociation with measures of fantasy-proneness, suggesting that these constructs map on to a common domain of immersion in imaginative experiences.

It is of paramount importance to fill the gap between basic research and clinical practice. Vanhaudenhuyse et al. [5] (this issue) investigates how neuroimaging studies help clinicians to better understand the mechanisms of hypnosis in terms of brain modulation, especially of pain. Hypnotic suggestions dramatically influence not only the primary consciousness and selfconsciousness networks but also the attentional and somatosensorial networks. Resultantly, the subjects feel disengaged from their external stimuli combined with the modification of sensations related to their body, their affective resonance, and cognitive appraisal.

Schmidt et al. [6] (this issue) propose an innovative application of hypnotic procedural techniques in clinical practice. An important stressor and source of chronic suffering in the intensive care unit is non-invasive ventilation. Positive therapeutic suggestions under hypnosis can help patients in intensive care units to enhance their well-being by helping them deal with specific stressors like being ventilated. The authors set up a clinical design to assess the effects and safety of standardized therapeutic suggestions under hypnosis in patients on non-invasive ventilation during intensive care.

Relieving pain is one of the oldest and most important applications of hypnosis [7], however, mechanism of relieving pain remains largely unexplored. In the neurophysiological context, De Benedittis [8] (this issue) reviewed recent evidence supporting the notion how hypnotic suggestions of analgesia can modulate pain processing at multiple hierarchical levels and sites within the central nervous system (CNS). Hypnotic suggestions of analgesia could directly modulate both sensory and affective dimensions of pain perception, with the affective dimension registering more significant reduction compared to the sensory one. Moreover, highly hypnotizable subjects possessed stronger attentional filtering abilities and greater cognitive 
flexibility in comparison to the low hypnotizable subjects, thus allowing diversion of attention from the nociceptive stimulus as well as better ignoring the irrelevant stimuli in the environments.

Flynn [9] (this issue) provides a review of theories and biomedical paradigms of pain, including the biopsychosocial model that takes into account biological, psychological, and social factors that modulate the pain experience. He argued that it might be useful for clinicians who practice hypnotherapy to understand pain paradigms. As key brain areas involved in the processing of pain have been shown to be influenced by hypnosis and hypnotic analgesia, an experienced therapist who wishes to obtain optimal results with their pain patients/clients should include these targets in their treatment approach [10]. Biopsychosocial models emphasize the key role of psychological processes in the physical experience of pain, such as Fear-Avoidance and Fear-of-Pain [11]. A moderate- to- large positive association between pain-related fear and disability was observed, suggesting that pain-related fear may be considered an important risk factor for pain-related disability with implications in the treatment of pain [12]. Understanding and targeting these psychological variables may empower clinicians practicing hypnotherapy in tailoring suggestions specific to their pain patients to derive optimal results.

There is increasing evidence demonstrating that hypnosis can be effective in down-modulation of pain sensation in both acute and chronic pain states [13]. A summary of the recent systematic reviews would help better understand the quality of evidence regarding the efficacy of hypnosis, and provide the right direction for future research. Pathak et al. [14] (this issue) conducted a scoping review of systematic reviews and meta-analyses on the efficacy of hypnosis for the management of clinical pain conditions and concluded that there was low-quality evidence for beneficial effects of hypnosis in the management of procedural pain, headache, and pain associated with breast cancer care. Hypnosis may be an effective treatment for a variety of clinical pain conditions; its efficacy for clinical pain treatment is yet to be ascertained in large trials. Improvement of clinical designs and recommended guidelines are needed to avoid the methodological shortcomings of previously published trials.

Modern research does not offer due weight to the topic of the subjective experience in hypnosis. Hypnotizability scales focus mostly on behavioral responses, not on the subjective experience of the trance state. However, the brain/mind interface can better be explored by taking into account the first-person self-report and trying to link together behavioral, neurophysiological, and subjective experiences. Pekala \& Creegan [15] (this issue) introduce noetic qEEG analysis as a neurophenomenological method to quantify the mind during hypnosis in a reliable and valid manner. The differences in qEEG results may relate to differences in noetic experience under hypnosis and possibly altered states of consciousness.

Hypnosis offers effective treatment in disorders involving the autonomic nervous system (ANS). However, studies investigating the nature of its effect on the ANS have reported contradictory results. Kasos et al. [16] (this issue) investigate the effects of hypnosis on electrodermal activity (EDA) to objectively assess the activity of the sympathetic branch of the ANS. Their findings show that sympathetic arousal is bilaterally reduced during hypnosis induction, which is persistent across different levels of hypnotizability. At the same time, lateral differences define unique EDA patterns in the induction phase, characterizing high, medium, and low hypnotizability. These findings confirm with those in previous studies that highlighted the reduction in the sympathetic tone under hypnosis by means of heart-rate variability power spectrum analysis (HRV) [17]. 
Although significant research has been done to evaluate the neurobiological aspects underlying the phenomenon of consciousness, there is a lack of information regarding the effect of clinical and sociodemographic variables relating to altered states of consciousness and hypnosis. Ciaramella [18] (this issue) investigates clinical and sociodemographic factors on three hundred and forty-nine subjects from the general population in a single session. The age of the subjects was observed to be a negative predictor of hypnoidal state, intended to be a general measure of trance. Age also contributes to changing the phenomenology of consciousness, predicting greater vividness of imagery, reduction in time sense, fear, arousal, anger, negative affect, and perception. Female subjects were found to be more hypnotizable than the male subjects as they experienced a reduced memory of suggestions and an increase in the depth of trance. Subjects with a history of psychological trauma were found more prone to have reduced memory of suggestions than the normal ones. The subjective experience of a trance state results from a combination of several individual predisposing traits and variables that are contextual to a specific situation and influence the quality of sensation, emotion, volition, and thought, which are fundamental for an appropriate response to suggestions.

According to Casula [19] (this issue), 'therapist's focused attention, open awareness, and kind intention are basic ingredients for creating a relationship of trust with the subject from the very first session. When the attention of a non-judgmental therapist is centered on how the subjects express themselves and what contents they propose, the subjects rely more on the competent care of the therapist. The author emphasized that to empower patients, it is essential to accept their vulnerabilities, awaken hidden resources, and pursue realistic therapeutic goals. In this manner, each session focuses on the perceptual, cognitive, emotional, and behavioral changes that the subject can make during the session and implement after the session by themselves. Some clinical cases have outlined the significance of this empathic and interactional approach.

Resilience-the capacity of a system to adapt to the changes caused by external agents/factors-may be regarded as the key player in psychotherapy as well as the remedy for all sources of distress in both medicine and psychological disorders. Facco [20] (this issue) explores the potential of hypnotherapy to promote and enhance resilience by empowering patients to better cope with adverse events and with precipitating sources of suffering and pain and emphasizes the role of both Eastern and pre-Socratic philosophy in exploring the inner-outer world relationship, thereby allowing a deep resilience. The counterpart of resilience in modern Western culture is still to be explored.

Moss [21] (this issue) focuses on integrative medicine that attends the psychosocial dimensions of chronic lifestyle-based disorders comprehensively and seems to offer better promise for the patients, clinicians, and researchers. Despite being evidence-based, person-centered, and attuned to subjective and comprehensive dimensions of a human being, hypnosis currently receives relatively less attention in integrative medicine, and it remains untapped despite the availability of many effective clinical protocols for a wide range of medical conditions. The author introduces and discusses emerging paradigms in integrative healthcare in order to improve educational preparation for hypnosis practitioners to comply with these paradigms.

Hypnotizability is a psychophysiological trait associated with several patterns, including the level of functional, neuroanatomical equivalence between imagery and perception. This pattern is stronger in easily hypnotizable subjects (highs) than in low hypnotizable subjects (lows). 
Ruggirello et al. [22], (this issue) explored the correlation between electroencephalogram (EEG) of imagined arm/hand movements (MI) and actual movements performed in the absence of suggestions (M) and in the presence of suggestions of arm/hand anesthesia (MA) in easily and low hypnotizable subjects. Highs reported better imagery during $\mathrm{MI}$, greater perceived influence of the suggestion of anesthesia during MA, and lower cognitive efforts than the lows for both the tasks. As revealed in previous studies, the spectral analysis did not reveal significant restructuring of the cortical activity during tasks in highs, whereas lows showed cortical changes during $\mathrm{Ml}$ and MA indicating that they were able to mentally simulate movements and accept suggestions for anesthesia during voluntary movement, despite having low hypnotizability scores.

Nowadays, hypnosis is increasingly being recognized by the international scientific community not only as an effective clinical intervention to control several psychosomatic disorders but also as a valid and flexible physiological tool to explore the central and peripheral nervous system. This appears to be a real Copernican revolution in the field $[1,13]$.

This special issue compiles landmark studies and traces the evolution of hypnosis and charts its future therapeutic potential as well. It is hoped that the compendium of articles in this issue may raise more questions than answers, stimulating critical thinking, research at the leading edge of the fascinating and intriguing domain of hypnosis.

The Editor expresses his deepest gratitude to all the authors for contributing so generously to this special issue and the excellent reviewers for their feedback and great help that made this special issue possible.

The future of hypnosis depends greatly on the capacity of hypnosis researchers and clinicians to integrate hypnosis research and practice in broader areas of medicine, psychology and psychotherapy by building bridges of understanding.

\section{Author Contributions}

GDB wrote the manuscript and reviewed the final manuscript.

\section{Competing Interests}

The author has declared that no competing interests exist.

\section{References}

1. De Benedittis G. The hypnotic brain: Linking neuroscience to psychotherapy. Contemp Hypn Integr Ther. 2012; 29: 103-115.

2. Elkins G, Barabasz A, Council J, Speigel D. Advancing research and practice: The revised APA Division 30 definition of hypnosis. Int J Clin Exp Hypn. 2015; 63: 1-9. doi:10.1080/00207144.2014.96187013.

3. Häuser W, Hagl M, Schmierer A, Hansen E. The efficacy, safety and applications of medical hypnosis. A systematic review of meta-analyses. Dtsch Arztebl Int. 2016; 113: 289296. doi: 10.3238/arztebl.2016.0289

4. Green JP, Lynn SJ, Green OJ, Bradford VR, Rasekhy R. Hypnotic responsiveness and dissociation: A multi-variable analysis. OBM Integr Complement Med. 2020; 5: 21. doi:10.21926/obm.icm.2002029 
5. Vanhaudenhuyse A, Nyssen AS, Faymonville ME. Recent insight on how the neuroscientific approach helps clinicians. OBM Integr Complement Med. 2020; 5: 20. doi:10.21926/obm.icm.2002028

6. Schmidt B, Deffner T, Rosendahl J. Feeling safe during intensive care: Protocol of a pilot study on therapeutic suggestions of safety under hypnosis in patients with non-invasive ventilation. OBM Integr Complement Med. 2020; 5: 8. doi:10.21926/obm.icm.2002025

7. Thompson T, Terhune DB, Orama C, Sharangparnia J, Roufa R, Solmic M, Veronese N, Stubbse B. The effectiveness of hypnosis for pain relief: A systematic review and meta-analysis of 85 controlled experimental trials. Neurosci Biobehav Rev. 2019; 99: 298-310. DOI: 10.1016/j.neubiorev.2019.02.013

8. De Benedittis G. Neural mechanisms of hypnotic analgesia. OBM Integr Complement Med. 2020; 5: 14. doi:10.21926/obm.icm.2002023

9. Flynn N. Clinical, theoretical and conceptual issues in chronic pain and their application in a hypnosis practice. OBM Integr Complement Med. 2019; 4: 6. doi:10.21926/obm.icm.1903057

10. Elkins G, Jensen MP, Patterson DR. Hypnotherapy for the management of chronic pain. Int J Clin Exp Hypn. 2007; 55: 3, 275-287. DOI: 10.1080/00207140701338621

11. Turk DC, Wilson HD. Fear of pain as a prognostic factor in chronic pain: conceptual models, assessment and treatment implications. Curr Pain Headache Rep. 2010; 14: 88-95.

12. Zale EL, Lange KL, Fields SA, Ditre JW. The relations between pain-related fear and disability: A meta-analysis. J Pain. 2013; 14: 19-30.

13. De Benedittis G. Neural mechanisms of hypnosis and meditation. J Physiology. 2015; 109: 152164 . doi: http://dx.doi.org/10.1016/j.jphysparis.2015.11.001, 2015.

14. Pathak A, Sharma S, Jensen MP. Hypnosis for clinical pain management: A scoping review of systematic reviews. OBM Integr Complement Med. 2020; 5: 27. doi:10.21926/obm.icm.2001005

15. Pekala RJ, Creegan K. States of consciousness, the qEEG, and noetic snapshots of the brain/mind interface: A case study of hypnosis and sidhi meditation. OBM Integr Complement Med. 2020; 5: 35. doi:10.21926/obm.icm.2002019

16. Kasos K, Csirmaz L, Vikor F, Zimonyi S, Varga K, Szekely A. Electrodermal correlates of hypnosis: Current developments. OBM Integr Complement Med. 2020; 5: 20: doi:10.21926/obm.icm.2002017

17. De Benedittis G, Cigada M, Bianchi A, Signorini MG, Cerutti S. Autonomic changes during hypnosis: A heart rate variability power spectrum analysis as a marker of sympatho-vagal balance. Int J Clin Exp Hypn. 1994; 42: 141-153.

18. Ciaramella A. Sociodemographic Variables and History of Trauma and Disease Influence Consciousness after Hypnotic Induction. OBM Integr Complement Med. 2020; 5: 17. doi:10.21926/obm.icm.2001014

19. Casula CC. The importance of rapport in hypnotic clinical practice. OBM Integr Complement Med. 2020; 5: 13. doi:10.21926/obm.icm.2001010

20. Facco E. Hypnosis for resilience. OBM Integr Complement Med. 2020; 5: 20. doi: 10.21926/obm.icm. 2003032

21. Moss D. Paradigms in integrative medicine and the place of clinical hypnosis. OBM Integr Complement Med. 2020; 5: 17. doi:10.21926/obm.icm.2001007 
22. Ruggirello S, Santarcangelo EL, Sebastiani L. Imagined and actual movements with and without suggestions for anesthesia in subjects with different hypnotizability. OBM Integr Complement Med. 2019; 4: 14. doi:10.21926/obm.icm.1904066

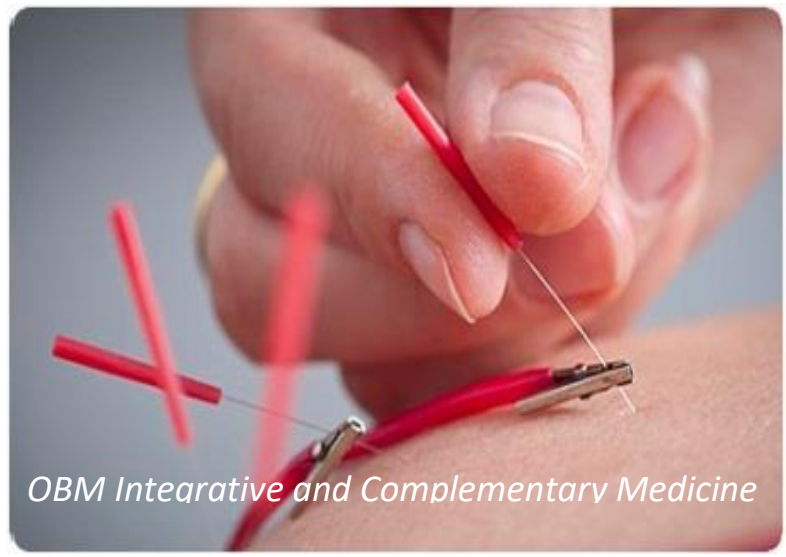

Enjoy OBM Integrative and Complementary Medicine by:

1. Submitting a manuscript

2. Joining in volunteer reviewer bank

3. Joining Editorial Board

4. Guest editing a special issue

For more details, please visit:

http://www.lidsen.com/journals/icm 


\author{
LIDSEN Publishing Inc. \\ 2000 Auburn Drive, One Chagrin \\ Highlands, Suite 200, Beachwood, OH 44122 \\ USA \\ Tel.: +1-216-370-7293 \\ Fax: +1-216-378-7505 \\ http://www.lidsen.com/
}

OBM Integrative and Complementary Medicine Editorial Office,

E-mail: icm@lidsen.com

http://www.lidsen.com/journals/icm 
LIDSEN Publishing Inc.

2000 Auburn Drive, One Chagrin

Highlands, Suite 200, Beachwood

OH 44122

USA

Tel.: +1-216-370-7293

Fax: +1-216-378-7505

http://www.lidsen.com/

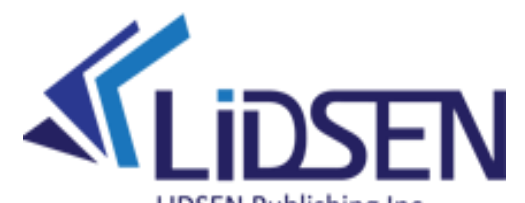

LIDSEN Publishing Inc.

ISSN 2573-4393 